\title{
RELAP5-3D Pre-test Prediction for High Temperature Test Facility Test PG-26
}

Paul D. Bayless

The INL is a

U.S. Department of Energy

National Laboratory

operated by

Battelle Energy Alliance

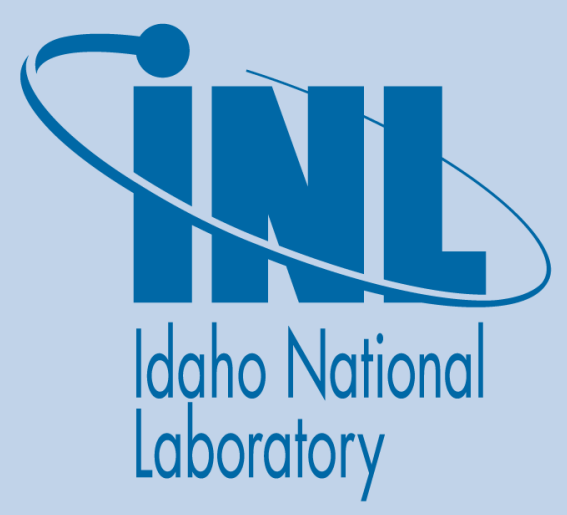

June 2018

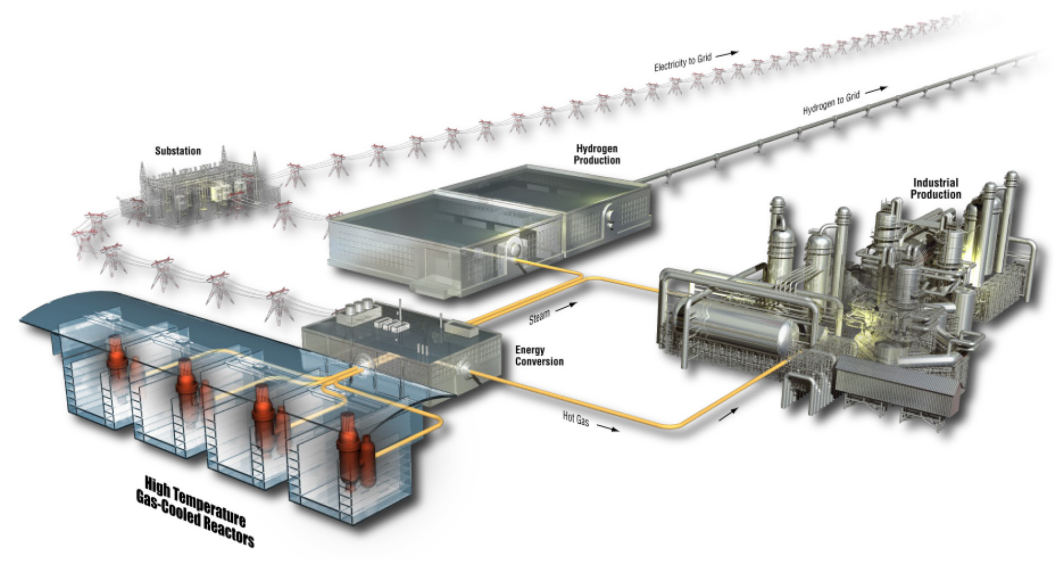




\section{DISCLAIMER}

This information was prepared as an account of work sponsored by an agency of the U.S. Government. Neither the U.S. Government nor any agency thereof, nor any of their employees, makes any warranty, expressed or implied, or assumes any legal liability or responsibility for the accuracy, completeness, or usefulness, of any information, apparatus, product, or process disclosed, or represents that its use would not infringe privately owned rights. References herein to any specific commercial product, process, or service by trade name, trade mark, manufacturer, or otherwise, does not necessarily constitute or imply its endorsement, recommendation, or favoring by the U.S. Government or any agency thereof. The views and opinions of authors expressed herein do not necessarily state or reflect those of the U.S. Government or any agency thereof. 


\title{
RELAP5-3D Pre-test Prediction for High Temperature Test Facility Test PG-26
}

\author{
Paul D. Bayless
}

June 2018

\begin{abstract}
Idaho National Laboratory INL ART Program Idaho Falls, Idaho 83415
\end{abstract}

http://www.inl.gov

Prepared for the

U.S. Department of Energy

Office of Nuclear Energy

Under DOE Idaho Operations Office

Contract DE-AC07-05ID14517 

INL ART Program

\title{
RELAP5-3D Pre-test Prediction for High Temperature Test Facility Test PG-26
}

\author{
INL/EXT-18-45717
}

June 2018

Author:

Pauld.Bagless

INL ART Nuclear Engineer

Technical Reviewer:
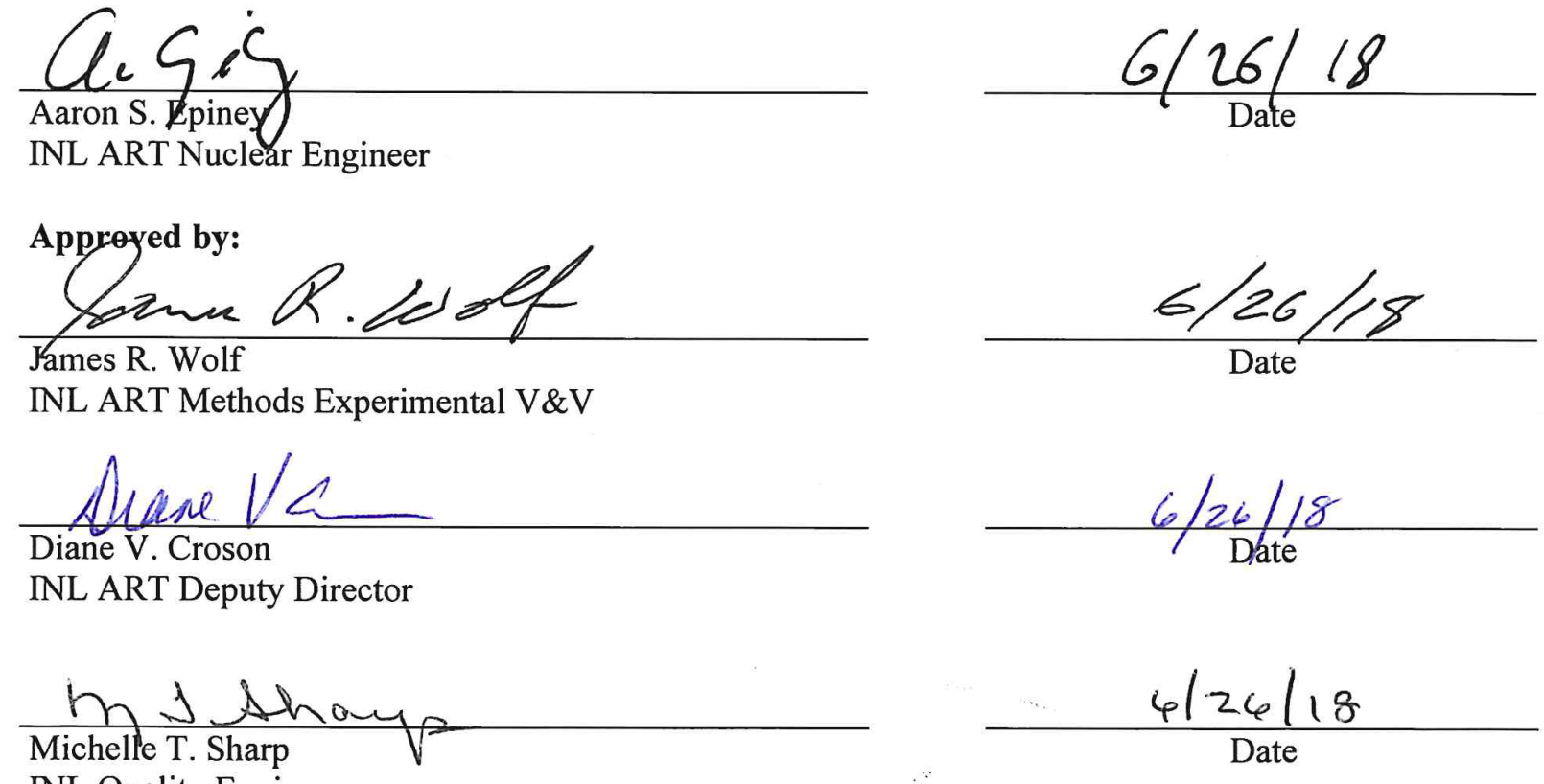

INL Quality Engineer 



\begin{abstract}
The RELAP5-3D computer code has been used to perform a pre-test prediction for Test PG-26 in the High Temperature Test Facility at Oregon State University. Test PG-26 will simulate a pressurized conduction cooldown transient following a trip of the primary coolant system gas circulator. The facility is initialized with a steady-state power of $700 \mathrm{~kW}$ and prototypic pressure vessel inlet and outlet helium coolant temperatures of 259 and $687^{\circ} \mathrm{C}$, respectively. Sensitivity calculations addressed the flow coastdown time, reactor cavity cooling system flow rate and temperature, and decay power.
\end{abstract}




\section{CONTENTS}

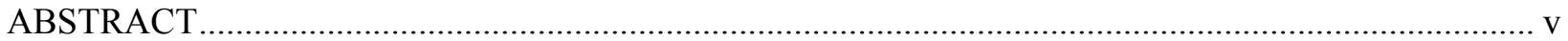

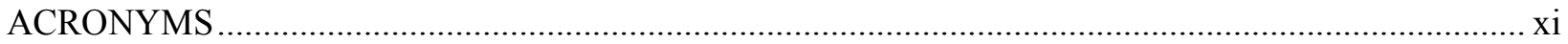

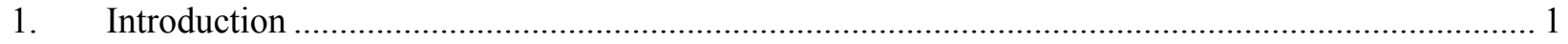

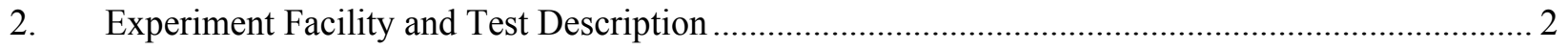

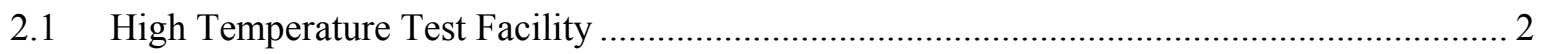

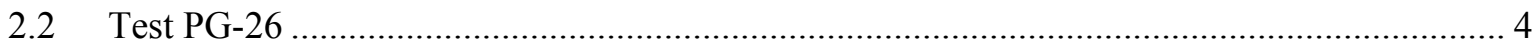

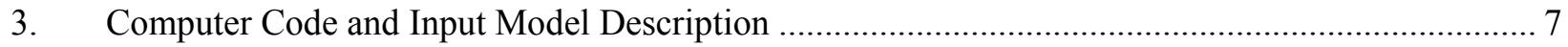

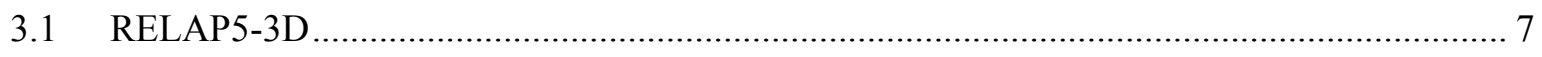

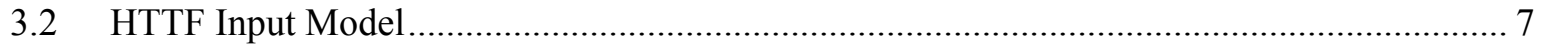

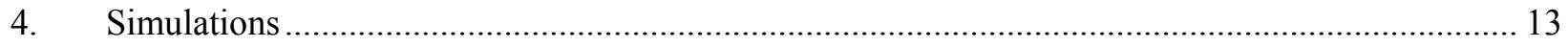

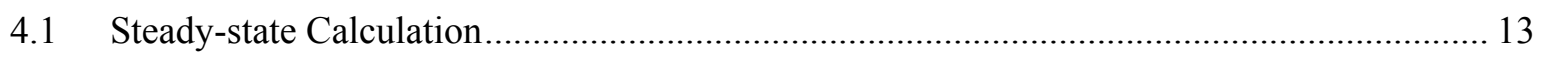

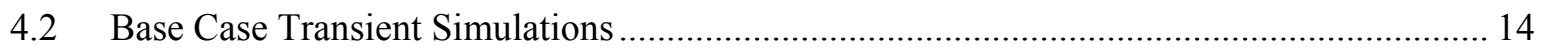

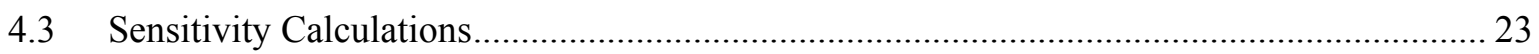

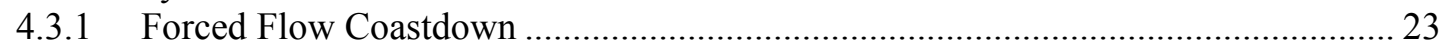

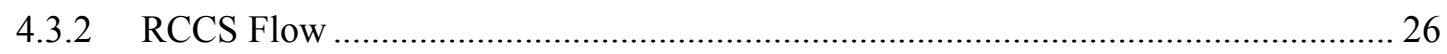

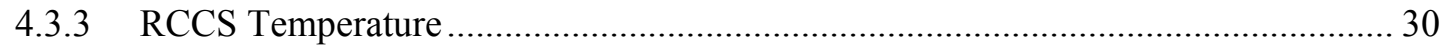

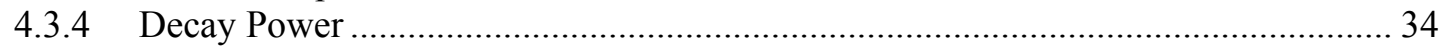

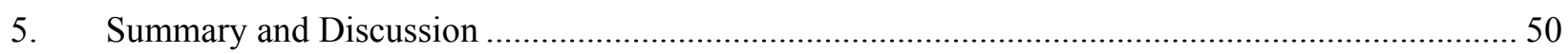

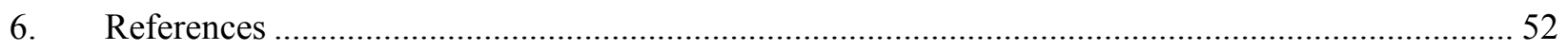

\section{FIGURES}

Figure 1. Diagram of the HTTF primary pressure vessel (right), RCST, and hot and cold ducts. .............. 3

Figure 2. Primary pressure vessel instrumentation sectors. .............................................................. 4

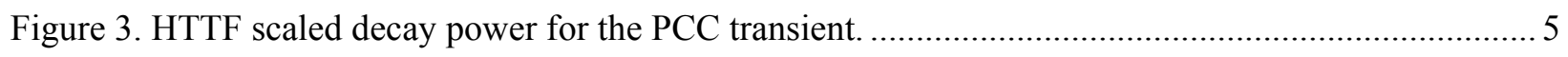

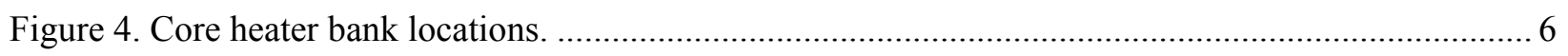

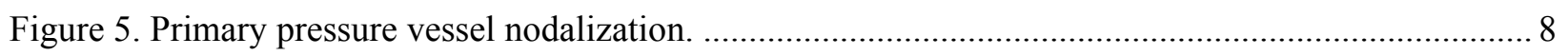

Figure 6. Primary pressure vessel radial nodalization. ...................................................................... 9

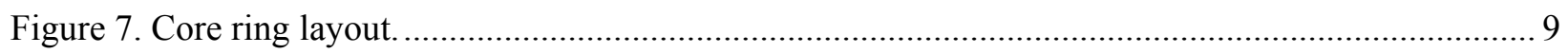

Figure 8. Nodalization of components outside the primary pressure vessel........................................... 11

Figure 9. Coolant velocities at the top of the upper reflector for the Test PG-26 pre-test

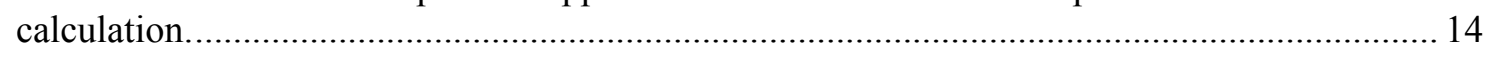

Figure 10. Peak temperatures in the three core rings for the Test PG-26 pre-test calculation................... 15

Figure 11. Peak temperatures in the central and side reflectors for the Test PG-26 pre-test calculation. 
Figure 12. Peak temperatures in the PSR, core barrel, and pressure vessel wall for the Test PG-26 pre-test calculation.

Figure 13. Core ceramic temperature distribution for the Test PG-26 pre-test calculation....................... 17

Figure 14. Core ceramic radial temperature distribution for the Test PG-26 pre-test calculation. .....

Figure 15. Axial average temperatures for some ex-core components for the Test PG-26 pre-test calculation.

Figure 16. Coolant temperatures at the top and bottom of the core for the three core rings for the Test PG-26 pre-test calculation.

Figure 17. Coolant temperatures at the top and bottom of the reflectors for the Test PG-26 pre-test calculation.

Figure 18. Coolant temperatures in the pressure vessel upper and outlet plenums for the Test PG26 pre-test calculation.

Figure 19. RCCS panel coolant inlet and outlet temperatures for the Test PG-26 pre-test calculation.

Figure 20. Core decay power and RCCS heat removal for the Test PG-26 pre-test calculation. 22

Figure 21. Primary pressure vessel inlet pressure for the Test PG-26 pre-test calculation. 22

Figure 22. Peak heater rod temperatures for the Test PG-26 pre-test calculation base and 10-s flow coastdown cases.

Figure 23. Peak inner core ring ceramic temperatures for the Test PG-26 pre-test calculation base and 10 -s flow coastdown cases.

Figure 24. Peak middle core ring ceramic temperatures for the Test PG-26 pre-test calculation base and 10-s flow coastdown cases.

Figure 25. Peak outer core ring ceramic temperatures for the Test PG-26 pre-test calculation base and 10-s flow coastdown cases.

Figure 26. Pressure vessel peak wall temperatures for the Test PG-26 pre-test calculation base and 10-s flow coastdown cases.

Figure 27. Core power and RCCS heat removal for the Test PG-26 pre-test calculation base and 10-s flow coastdown cases.

Figure 28. Core power and RCCS heat removal for the Test PG-26 pre-test calculation base and reduced RCCS flow cases.

Figure 29. RCCS panel coolant inlet and outlet temperatures for the Test PG-26 pre-test calculation base and reduced RCCS flow cases.

Figure 30. Peak heater rod temperatures for the Test PG-26 pre-test calculation base and reduced RCCS flow cases.

Figure 31. Peak inner core ring ceramic temperatures for the Test PG-26 pre-test calculation base and reduced RCCS flow cases.

Figure 32. Peak middle core ring ceramic temperatures for the Test PG-26 pre-test calculation base and reduced RCCS flow cases.

Figure 33. Peak outer core ring ceramic temperatures for the Test PG-26 pre-test calculation base and reduced RCCS flow cases. 
Figure 34. Peak pressure vessel wall temperatures for the Test PG-26 pre-test calculation base and reduced RCCS flow cases.

Figure 35. RCCS panel inlet and outlet coolant temperatures for the Test PG-26 pre-test calculation base and increased RCCS temperature cases.

Figure 36. Core power and RCCS heat removal for the Test PG-26 pre-test calculation base and increased RCCS temperature cases.

Figure 37. Peak heater rods temperatures for the Test PG-26 pre-test calculation base and increased RCCS temperature cases.

Figure 38. Peak inner core ring ceramic temperature for the Test PG-26 pre-test calculation base and increased RCCS temperature cases.

Figure 39. Peak middle core ring ceramic temperatures for the Test PG-26 pre-test calculation base and increased RCCS temperature cases.

Figure 40. Peak outer core ring ceramic temperatures for the Test PG-26 pre-test calculation base and increased RCCS temperature cases.

Figure 41. Peak pressure vessel wall temperature for the Test PG-26 pre-test calculation base and increased RCCS temperature cases.

Figure 42. Core power for the Test PG-26 pre-test calculation base and decay power cases

Figure 43. Coolant velocities at the top of the upper reflector for the Test PG-26 pre-test calculation $80-\mathrm{kW}$ power case.

Figure 44. Peak heater rod temperatures for the Test PG-26 pre-test calculation base and $80-\mathrm{kW}$ power cases.

Figure 45. Peak inner core ring ceramic temperatures for the Test PG-26 pre-test calculation base and $80-\mathrm{kW}$ cases.

Figure 46. Peak middle core ring ceramic temperatures for the Test PG-26 pre-test calculation base and $80-\mathrm{kW}$ cases.

Figure 47. Peak outer core ring ceramic temperatures for the Test PG-26 pre-test calculation base and $80-\mathrm{kW}$ cases.

Figure 48. Peak ceramic temperatures in the central and side reflectors for the Test PG-26 pre-test calculation $80-\mathrm{kW}$ case.

Figure 49. Peak primary pressure vessel wall temperatures for the Test PG-26 pre-test calculation base and $80-\mathrm{kW}$ cases.

Figure 50. Core power and RCCS heat removal for the Test PG-26 pre-test calculation base and $80-\mathrm{kW}$ cases.

Figure 51. Peak heater rod temperatures for the Test PG-26 pre-test calculation base case and 40-kW Cases A and B.

Figure 52. Peak inner core ring ceramic temperatures for the Test PG-26 pre-test calculation base case and $40-\mathrm{kW}$ Cases A and B.

Figure 53. Peak middle core ring ceramic temperatures for the Test PG-26 pre-test calculation base case and 40-kW Cases A and B.

Figure 54. Peak outer core ring ceramic temperatures for the Test PG-26 pre-test calculation base case and $40-\mathrm{kW}$ Cases A and B. 
Figure 55. Peak primary pressure vessel wall temperatures for the Test PG-26 pre-test calculation base case and 40-kW Cases A and B.

Figure 56. Core power and RCCS heat removal for the Test PG-26 pre-test calculation base case and $40-\mathrm{kW}$ Cases A and B.

Figure 57. Coolant velocities at the top of the upper reflector for the Test PG-26 pre-test calculation base case and 40-kW Case A.

Figure 58. Coolant velocities at the top of the upper reflector for the Test PG-26 pre-test calculation base case and $40-\mathrm{kW}$ Case B.

Figure 59. Peak heater rod temperatures for the Test PG-26 pre-test calculation base case and 40-kW Cases C and D.

Figure 60. Peak inner core ring ceramic temperatures for the Test PG-26 pre-test calculation base case and $40-\mathrm{kW}$ Cases $\mathrm{C}$ and D.

Figure 61. Peak middle core ring ceramic temperatures for the Test PG-26 pre-test calculation base case and 40-kW Cases C and D.

Figure 62. Peak outer core ring ceramic temperatures for the Test PG-26 pre-test calculation base case and 40-kW Cases C and D.

Figure 63. Peak primary pressure vessel wall temperatures for the Test PG-26 pre-test calculation base case and 40-kW Cases C and D.

Figure 64. Core power and RCCS heat removal for the Test PG-26 pre-test calculation base case and $40-\mathrm{kW}$ Cases $\mathrm{C}$ and D.

Figure 65. Coolant velocities at the top of the reflector for the Test PG-26 pre-test calculation 40-kW Case C.

Figure 66. Coolant velocities at the top of the reflector for the Test PG-26 pre-test calculation 40-kW Case D.

\section{TABLES}

Table 1. Initial conditions for Test PG-26. 


\section{ACRONYMS}

$\begin{array}{ll}\text { HTTF } & \text { High Temperature Test Facility } \\ \text { INL } & \text { Idaho National Laboratory } \\ \text { PCC } & \text { pressurized conduction cooldown } \\ \text { PCS } & \text { primary coolant system } \\ \text { PSR } & \text { permanent side reflector } \\ \text { RCCS } & \text { reactor cavity cooling system } \\ \text { RCST } & \text { reactor cavity simulation tank } \\ \text { SCS } & \text { secondary coolant system }\end{array}$




\section{RELAP5-3D Pre-test Prediction for High Temperature Test Facility Test PG-26}

\section{Introduction}

Version 4.4.2ie of the RELAP5-3D computer code (INL 2018) has been used to perform pre-test predictions for Test PG-26, 700kW Peak Core Power Pressurized Conduction Cooldown Test, in the High Temperature Test Facility (HTTF) at Oregon State University. This test is expected to be performed in the summer of 2018.

The HTTF is a scaled integral effects experiment facility designed to investigate transient behavior in high-temperature gas-cooled nuclear reactors with prismatic fuel and reflector blocks. Its electricallyheated ceramic core is cooled by helium. Test PG-26 simulates a loss of forced convection cooling accident, the trip of the circulator in the primary coolant system (PCS) of the reference plant.

Section 2 provides a description of the HTTF and Test PG-26. A brief description of the RELAP5-3D code and a more detailed description of the HTTF input model are provided in Section 3. Code predictions of significant parameters in the system are presented in Section 4, and Section 5 summarizes the results of the code calculations. References are listed in Section 6. 


\section{Experiment Facility and Test Description}

An overview of the HTTF is provided in the next section, followed by a description of Test PG-26.

\subsection{High Temperature Test Facility}

The HTTF is a helium-cooled, electrically-heated integral experiment facility. The reference design for the facility is General Atomics' modular high-temperature gas-cooled reactor (DOE 1986), which uses prismatic graphite blocks in the core and reflectors. The HTTF primary pressure vessel and core are onefourth scale in length and diameter. Most of the coolant channels in the core are full scale, with smaller diameter channels around the core periphery. The facility operates at low pressure, compared to the prototype reactor, and is designed primarily to investigate depressurized conduction cooldown transients.

The facility, described in detail in Woods 2017, includes a number of systems. The PCS has a pressure vessel, a concentric hot and cold duct, a steam generator, a gas circulator, and connecting pipes. Break valves in both the hot and cold legs connect to a large reactor cavity simulation tank (RCST), whose gas composition can be initialized to a range of values to simulate the different conditions that may exist outside the reactor vessel following a loss-of-coolant accident. Figure 1 presents a rendering of the primary pressure vessel, RCST, and hot and cold ducts (Gutowska 2018).

Alumina ceramic blocks are used to simulate the core and top and bottom reflectors. Each block encompasses the radial region occupied by the central reflector, fuel, and side reflector in the reference reactor. Holes in the blocks provide channels for the heater rods, which consist of stacks of graphite rodlets. The rods are grouped into 10 heater banks, each of which contains 21 heater rods. Smaller coolant holes are arranged in a hexagonal pattern around the heater rods. Larger holes cast in the central and side reflector regions represent the core bypass flow in these regions. Permanent or outer reflector blocks, made of a different ceramic material, are located between the core blocks and the core barrel. A graphite plate in the upper plenum covers the gaps on either side of the permanent reflector blocks, so that the only flow through the core is in the holes cast in the core blocks.

The steam generator has 188 U-tubes. Feedwater is pumped from a supply tank into the downcomer on the secondary side, and any steam generated is vented to the atmosphere.

The principal feature of the reactor cavity cooling system (RCCS) is the cooling panels that surround the pressure vessel. Water flowing through the panels provides the heat sink for the PCS during most transients. Water is pumped from the same tank as the steam generator feedwater, but is recirculated back to the tank after exiting the top of the cooling panels. The inlet flow can be controlled to provide a desired panel outlet temperature, and isolation valves on the panels can be closed to simulate a degraded heat sink. There is a cover above the space between the pressure vessel and the RCCS panels, so that there is no direct natural circulation path between the building and the pressure vessel to provide unwanted cooling.

Two additional break lines are available; one from the top of the primary pressure vessel to the top of the RCST, and a second from the bottom of the pressure vessel to the bottom of the RCST.

The facility has over 500 instruments, which are described in Woods 2018a. Most of these are thermocouples in the core region to provide a temperature profile of the ceramic. There are also vertical thermocouple rakes in the upper and lower plenums, and in the hot and cold ducts, to try to capture temperature variations associated with recirculating or unmixed flow streams. The core and reflector instrumentation is generally arranged in one-sixth azimuthal sectors. As illustrated in Figure 2, the primary measurement sector is opposite the outlet plenum connection to the hot duct (on the east side of the plenum), the secondary sector is adjacent to the hot duct (west side), and the tertiary sector is next to (south of) the secondary sector. 


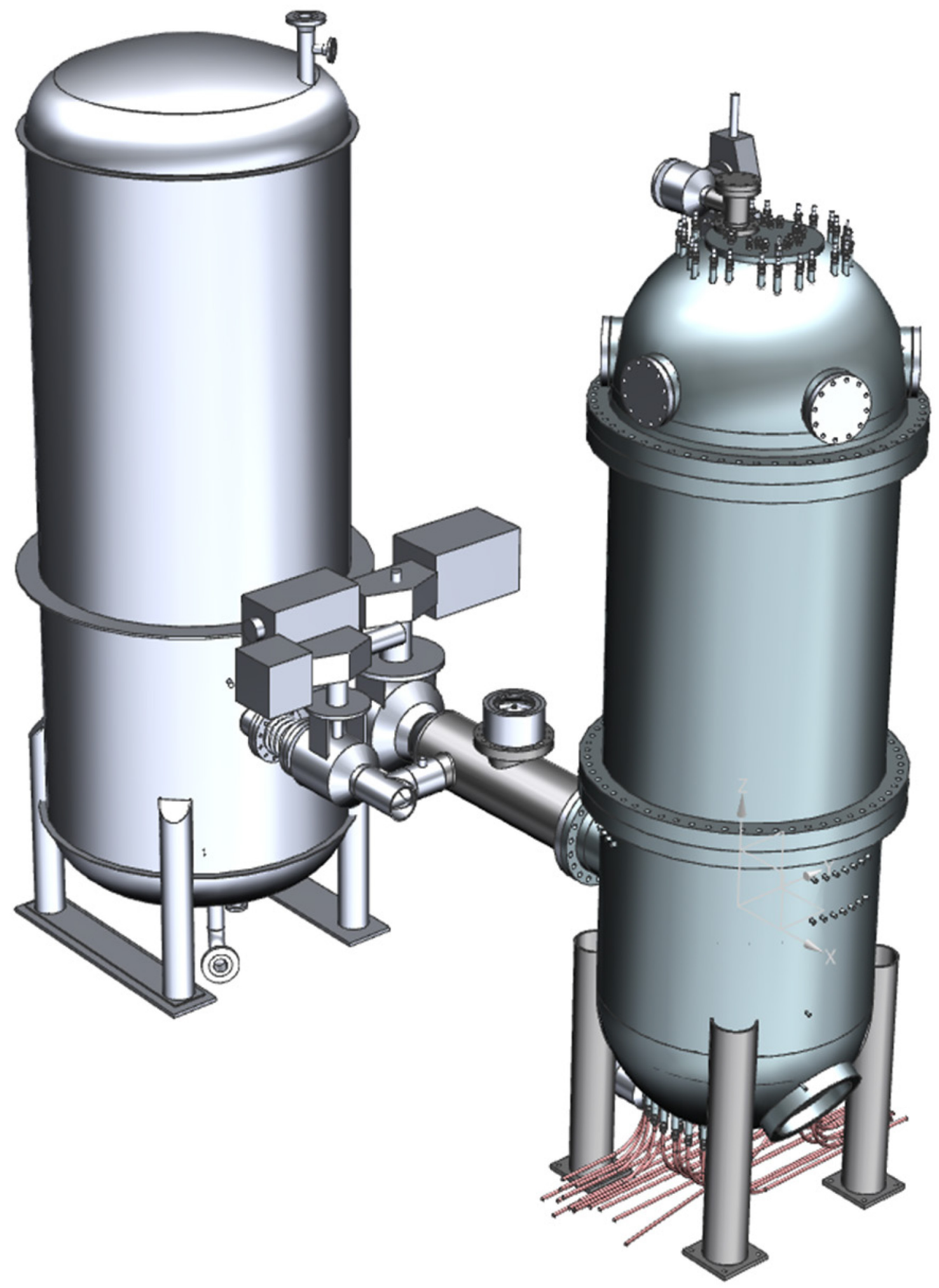

Figure 1. Diagram of the HTTF primary pressure vessel (right), RCST, and hot and cold ducts. 


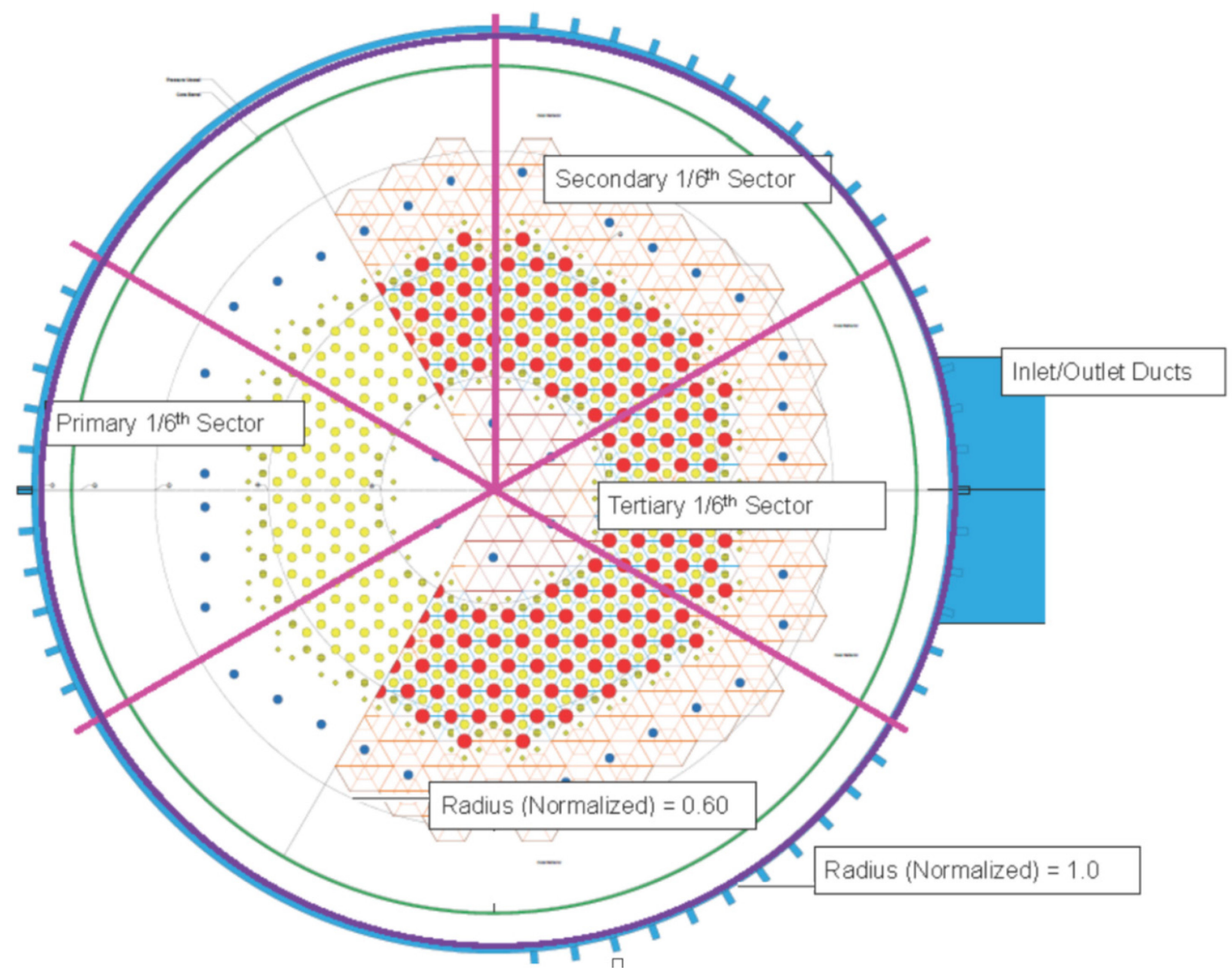

Figure 2. Primary pressure vessel instrumentation sectors.

\subsection{Test PG-26}

Test PG-26 is a pressurized conduction cooldown (PCC) transient planned to be conducted in the summer of 2018. It will have an initial core power of $700 \mathrm{~kW}$, and nominal primary coolant temperatures of $258.6^{\circ} \mathrm{C}$ at the pressure vessel inlet and $687.0^{\circ} \mathrm{C}$ in the core outlet plenum. The initial pressure is assumed to be $700 \mathrm{kPa}$.

After steady-state conditions are established, the gas circulator will be tripped off. Feedwater flow to the steam generator will be terminated after the PCS flow coastdown. The RCCS panel inlet temperature and flow rate will be adjusted manually during the test to prevent the water in the day tank from reaching saturation. The experiment operators will manually adjust the core heaters to follow the decay power curve shown in Figure 3 (Woods 2018b). This curve reflects the 1:55 power scaling between the facility and the reference plant for the PCC transient. The stair-step nature of the curve is designed to preserve the integral decay power while alleviating the need for the operators to be continually adjusting the power to the heaters. 


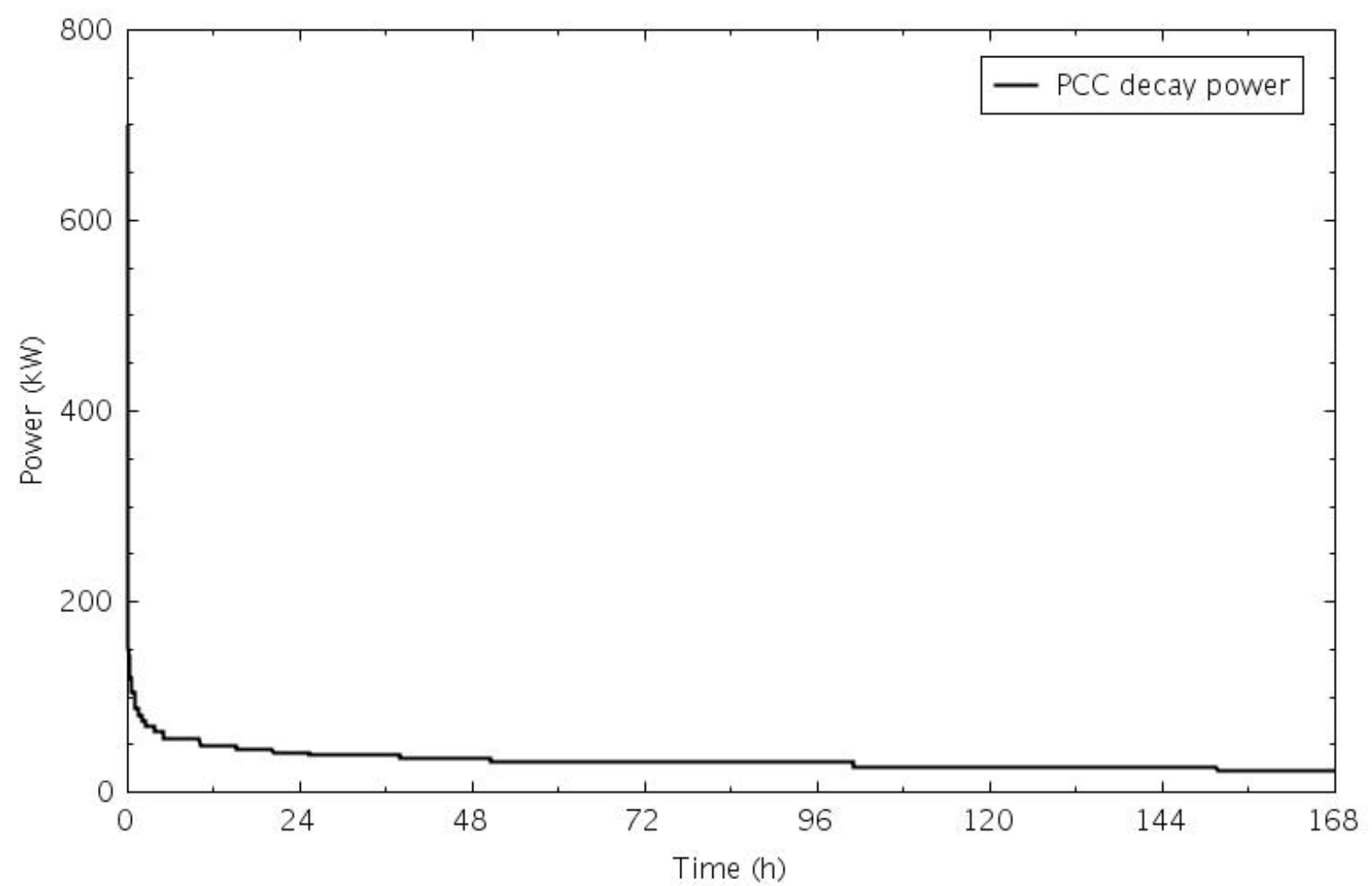

Figure 3. HTTF scaled decay power for the PCC transient.

Only four of the 10 heater banks will be used for this test: 107, 108, 109, and 110. The locations of these heaters in the core blocks are shown in Figure 4, and generally represent the second and fourth (of five) rings of heaters. Subsequent to preparation of this report, the heaters are expected to be renumbered so that each pair of consecutive numbers are symmetrically located in the two halves of the core. For example, heater banks 101 and 102 would generally be the innermost ring of heaters. The heaters used in this analysis are expected to be numbered 103, 104, 107, and 108 in the future.

With only the RCCS to remove the core heat, a slow heatup of the pressure vessel internals will occur, peaking after a day or two. The objective of the test is to measure the thermal response during the PCC transient. 


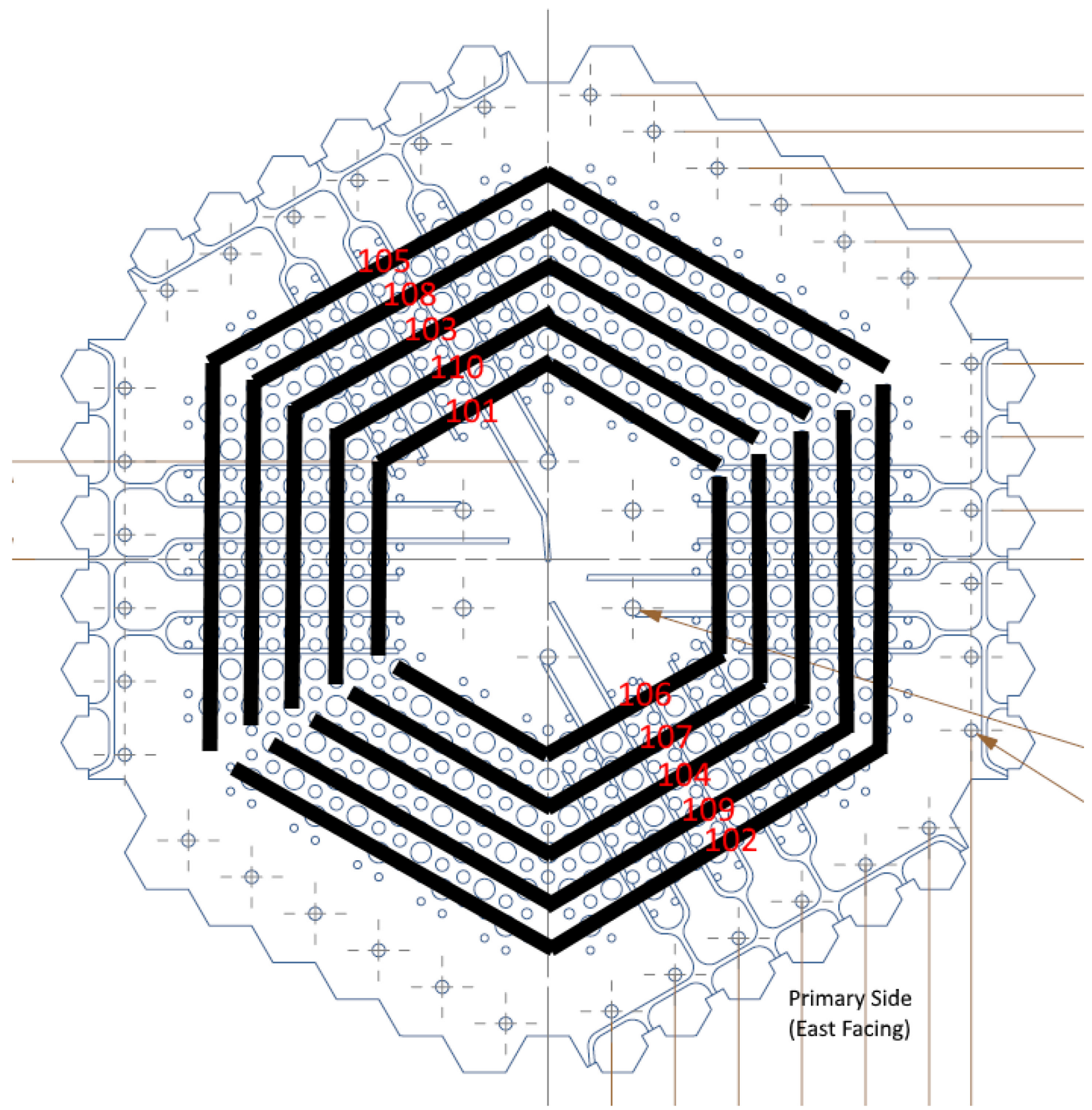

Figure 4. Core heater bank locations. 


\section{Computer Code and Input Model Description}

The general characteristics of the RELAP5-3D computer code are provided in the next section, followed by a description of the HTTF input model.

\subsection{RELAP5-3D}

The RELAP5 series of codes has been developed at Idaho National Laboratory (INL); RELAP5-3D is the latest code version in the series. While RELAP5 was originally developed to model accidents and operational transients in light-water reactor systems, the general nature of the code allows it to be used to simulate a wide variety of hydraulic and thermal transients in both nuclear and non-nuclear systems that can be stationary or moving. More than 25 working fluids are available in the code, including water, gases, liquid metals, refrigerants, and molten salts; 11 noncondensable gases are also available.

RELAP5-3D uses a two-fluid, nonequilibrium, six-equation hydrodynamic model. This model provides continuity, momentum, and energy equations for both the liquid and the vapor phases within a control volume. Noncondensable gases and boron in solution in the liquid are also modeled. The energy equation contains source terms that couple the hydrodynamic model to the heat structure conduction model by a convective heat transfer formulation.

RELAP5-3D has a fully integrated, multi-dimensional thermal-hydraulic and neutron kinetics modeling capability. Several specific component models are available in the code in addition to the basic control volumes and junctions, allowing the user more flexibility in modeling fluid systems. These include models for branching, turbines, pumps, compressors, accumulators, valves, separators, and jet mixers.

The code uses special process models to treat phenomena that involve large spatial gradients or that are sufficiently complex that empirical models are required. Special process models in the code address critical flow, countercurrent flow limitation (flooding), horizontal stratification and entrainment, crossflow, reactor kinetics, cladding oxidation and deformation, and molecular diffusion. The code also contains trip and control system models that can be used to simulate automatic or operator-initiated actions during a transient. The control systems can also be used to calculate parameters of interest (such as peak fuel temperature) to aid in the analysis of the code calculation.

System hardware is modeled using heat structures. Heat structures use a one-dimensional (radial) or two-dimensional (radial and axial) conduction solution internally, and can have a variety of boundary conditions applied on the surface, depending on the needs of the user. Energy can be transferred directly between heat structures using an enclosure model that models either radiation or conduction. An energy source term allows heat to be generated within a structure; direct (gamma/neutron) heating of the adjacent fluid volumes can also be modeled. A reflood model is also available that can be applied to the heat structures where needed. Thermophysical properties for the heat structures are normally input by the user.

Version 4.4.2ie of the code was used for the analyses; this was the most recent externally-released version of the code when the calculations were performed.

\subsection{HTTF Input Model}

A RELAP5-3D input model has been developed for the HTTF. The model includes hydrodynamic components, heat structures, trips, and control systems. Systems modeled are the PCS, secondary coolant system (SCS), RCCS, potable water system that supplies both the SCS and the RCCS, and reactor cavity. The RCST is considered part of the PCS. A detailed description of the model is provided in Bayless 2018.

The primary pressure vessel nodalization is shown in Figure 5. Flow enters from the cold duct (Component 270), passes through the core support structure under the outlet plenum bottom plate (Component 105), then flows up between the primary pressure vessel and core barrel (Component 115) to the inlet plenum (Component 120). Flow then passes down through various flow channels in the core 


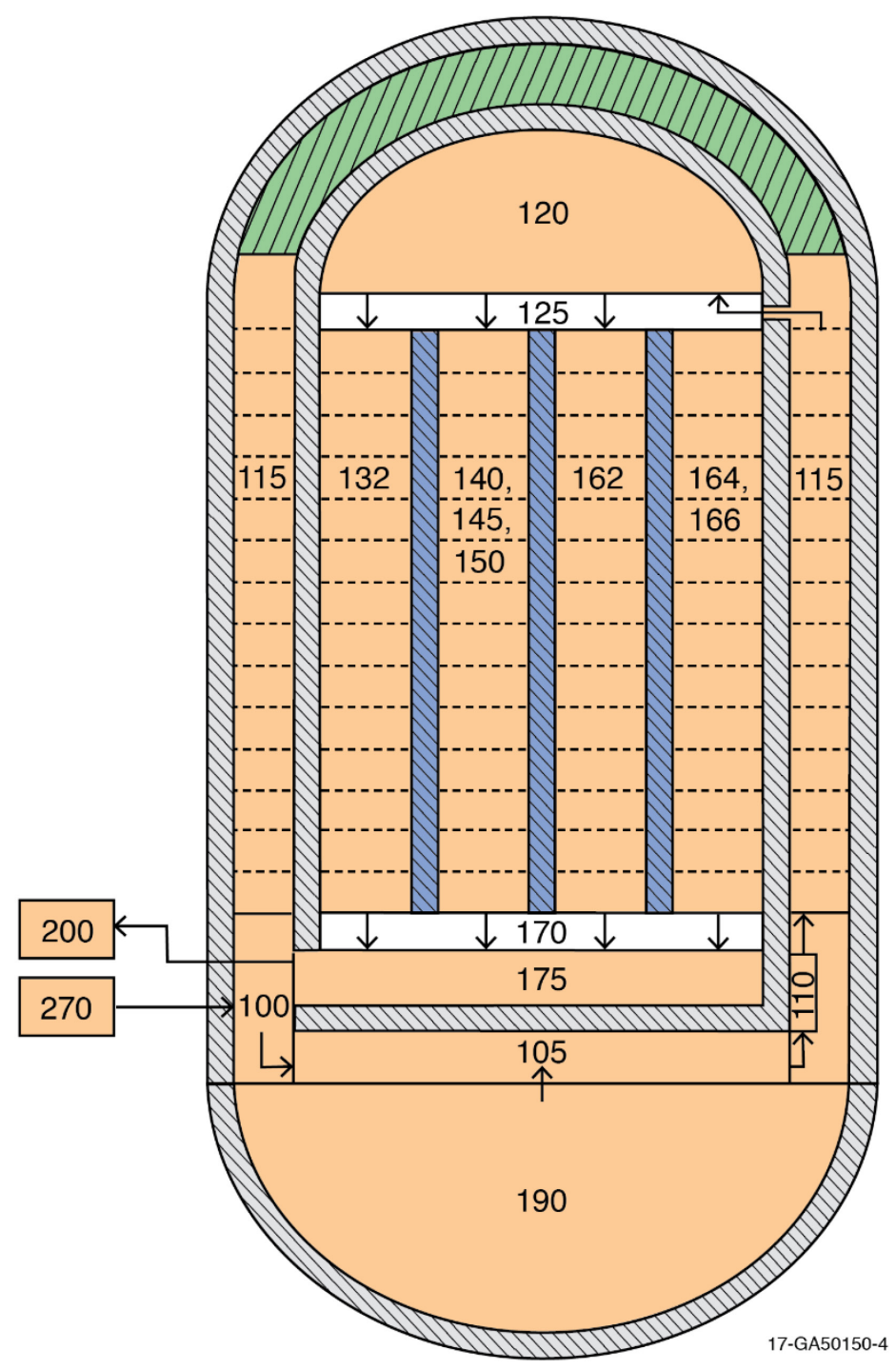

Figure 5. Primary pressure vessel nodalization.

(Components 140, 145, and 150) and reflectors (Components 132 and 162), recombines in the outlet plenum (Component 175), then flows out into the hot duct (Component 200).

The heated region of the core is divided into 10 equal-length axial segments, one for each block. The upper and lower reflectors each have two axial regions. This axial nodalization extends through each of the radial components in the vessel and in the RCCS.

The primary pressure vessel is divided into a number of different radial regions, as illustrated in Figure 6. The central reflector is divided into three regions: (1) a central solid cylinder, (2) a middle ring that contains the six 0.75 -in.-diameter gap simulation channels and the ceramic that is directly influenced by the holes, and (3) a solid outer ring that is adjacent to the core. The core is also divided into three rings, as it is designed on the hexagonal block pattern of the modular high-temperature gas-cooled reactor, which has three fueled rings. Figure 7 shows which blocks are included in each of the rings in a 60-degree sector; the boundaries of the inner and outer rings were extended beyond the full hexagonal 


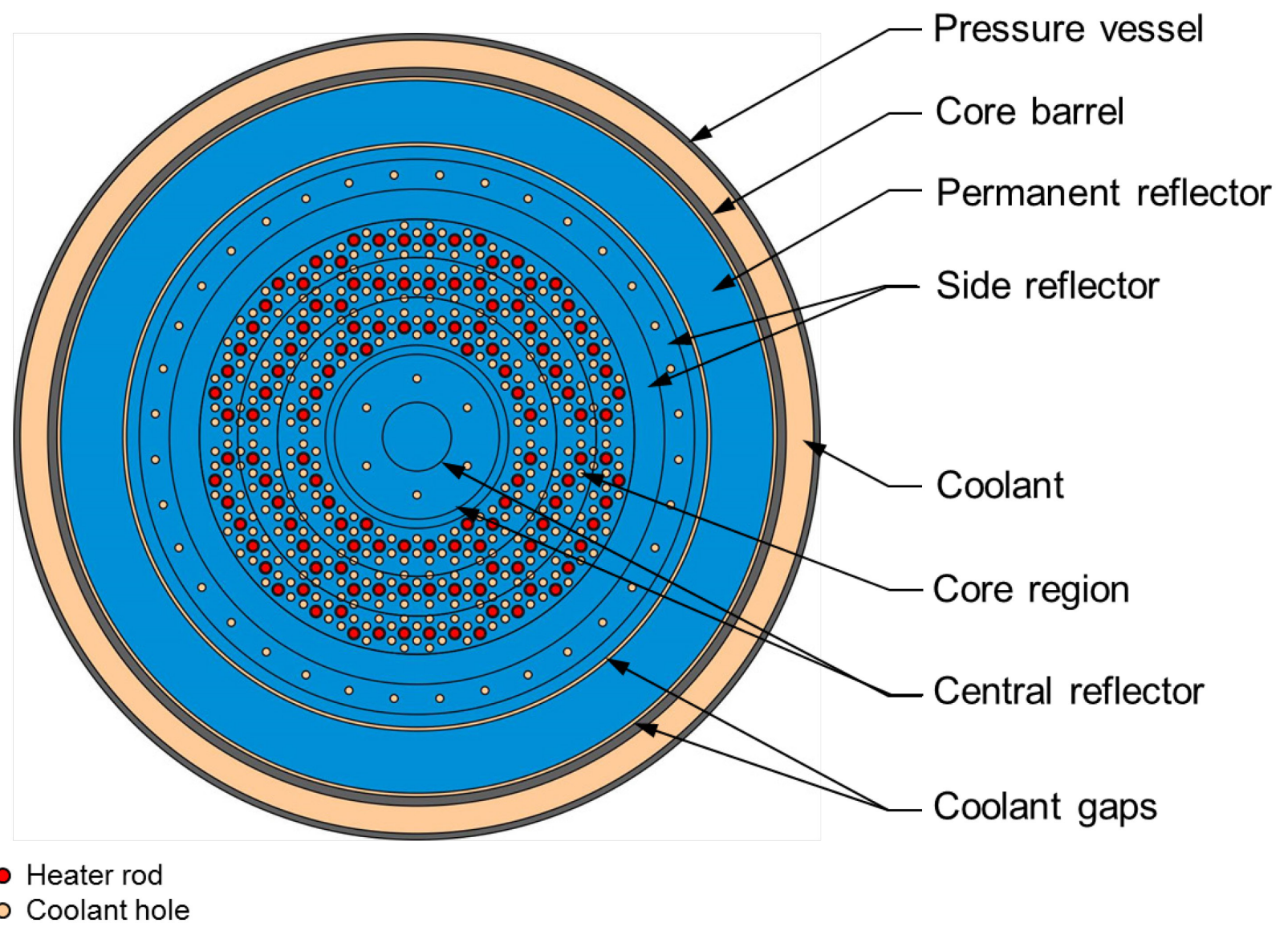

Figure 6. Primary pressure vessel radial nodalization.

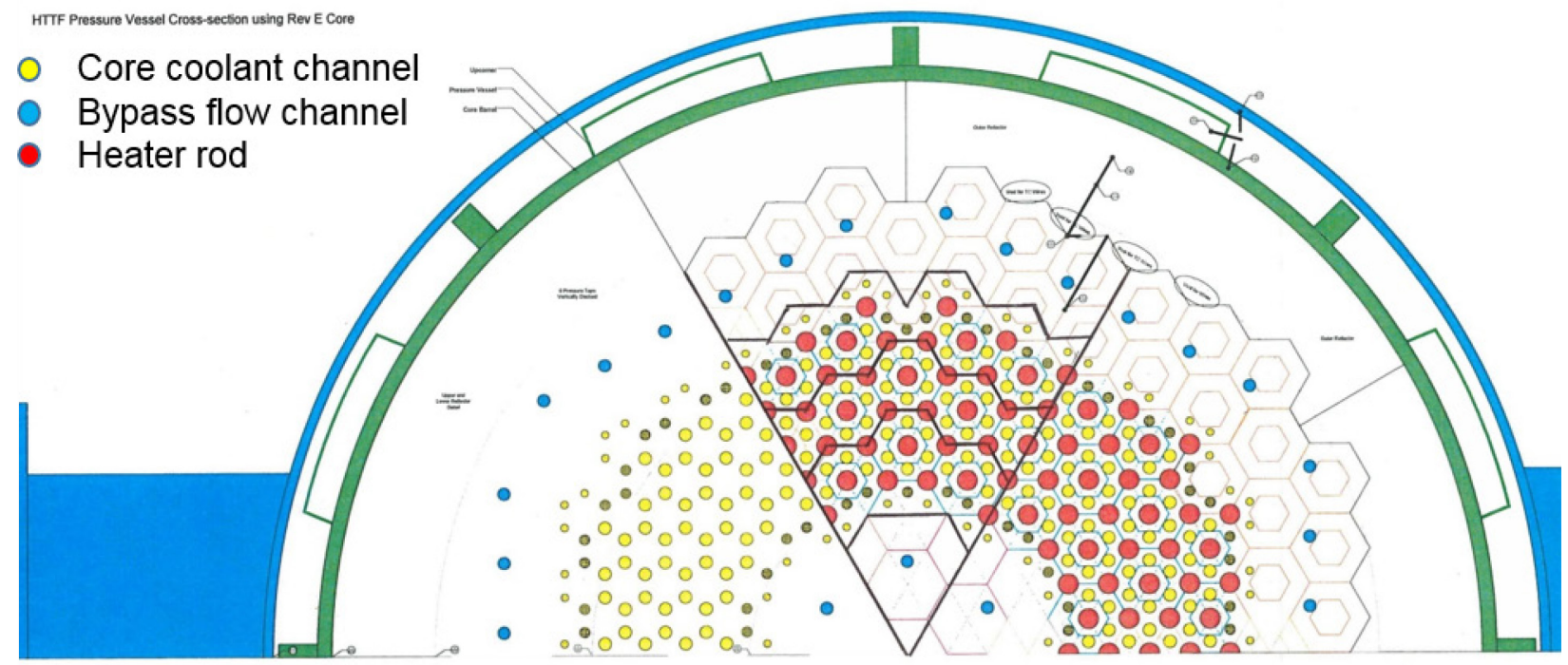

Figure 7. Core ring layout. 
block geometry to include all of the coolant channels. The inner ring includes 23 hexagonal blocks with 56 heater rods and 138 coolant channels, the middle ring models 24 blocks with 72 heater rods and 144 coolant channels, and the outer ring includes 39 blocks with 82 heater rods and 234 coolant channels. The side reflector is divided into three regions: (1) an inner solid ring next to the outer core ring, (2) a middle ring that contains the thirty-six 0.625-in.-diameter gap simulation channels and associated ceramic, and (3) a solid outer ring. The next radial structure is the permanent side reflector (PSR), also called the outer or permanent reflector, which has a coolant gap on either side (Components 164 and 166); these gaps do not have axial flow through them, as the top is covered by a plate (the upper plenum floor), leaving them open only to the outlet plenum. Continuing outward, the core barrel is next, followed by the coolant upcomer region between the core barrel and the pressure vessel wall, and finally the primary pressure vessel itself.

The nodalization of the PCS is shown in Figure 8. Hot gas exits the primary pressure vessel into the hot duct (Component 200), then flows up through a check valve (Component 217) and into the steam generator inlet plenum and tubes (Components 220 and 225). The cooled gas flows out of the steam generator outlet plenum (Component 228) into piping (Component 230) that leads to the gas circulator. Since the behavior of the circulator is not of general concern or interest (it only runs during steady-state operation), it is modeled using a branch (Component 235) and a time-dependent junction

(Component 237). From the circulator, flow proceeds through an isolation valve (Component 245), into a crossover pipe (Component 260), into an annulus around the hot duct (the cold duct, Component 270), and then back into the primary pressure vessel.

Break valves are located on the ends of the hot duct (Component 205) and the circulator discharge pipe (Component 255), connecting them to the RCST. These valves are closed during steady-state operation. The RCST (Component 280) is modeled as a two-volume pipe; the bottom volume represents the stagnant portion of the tank below the break valves, and the top volume includes the portion of the tank that will mix with the break effluent. Safety relief valves and a depressurization line are connected to the cold leg piping between the compressor and the loop isolation valve. These are modeled as a single line in the RELAP5-3D input model.

The nodalization of the SCS is also shown in Figure 8. The feedwater pump (Component 320), which is modeled using a time-dependent junction, draws suction from a water storage day tank and pumps it into the steam generator downcomer (Component 340). The downcomer extends to near the top of the tube sheet. The water is then boiled on the outside of the tubes (Component 350) as it flows upward to the steam dome at the top of the steam generator (Component 355). The steam then turns back downward before exiting out the side of the steam generator. The steam then flows through a pressure control valve (Component 370) in the steam line before flowing through more piping and being vented to the atmosphere. This downstream piping is not included in the RELAP5-3D input model. A safety relief valve (Component 395) is connected to a nozzle (Component 390) on the top of the steam generator. The piping downstream of the relief valve is not included in the input model.

The principal component in the potable water supply system is the water storage day tank (Component 450). This tank is the water source for both the SCS and the RCCS. The tank water level is maintained within a specified range. When the level gets too low, the supply line valve (Component 410) opens, allowing water from the public water system (Component 400) to flow into the tank through an inlet pipe (Component 420). When the level rises to a certain level, the supply line valve is closed. The tank also has an interior drain/vent line (Component 490) that extends from the bottom of the tank to near the top; it is modeled as being open to the atmosphere below the tank. An outlet line (Component 460) is connected to the bottom of the tank; both the feedwater and RCCS pumps take suction from this pipe.

The reactor cavity (Component 900, not shown) is modeled as a large air-filled volume at atmospheric pressure, and is located between the primary pressure vessel and the RCCS panels (Component 950). The RCCS draws flow from the water storage tank and pumps it through a series of 


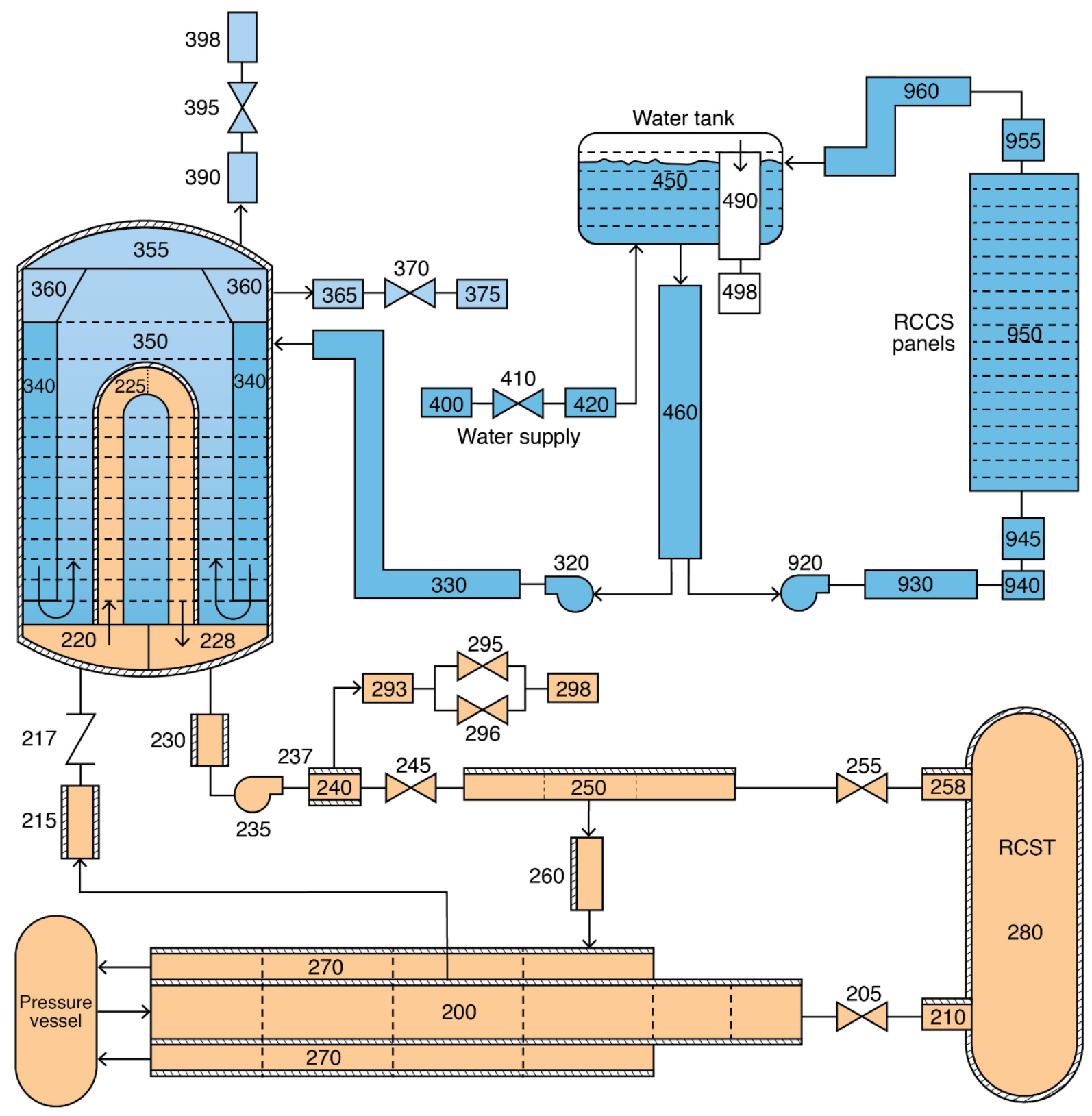

Figure 8. Nodalization of components outside the primary pressure vessel.

pipes (Components 930, 940, and 945) into the cooling panels surrounding the primary pressure vessel. The pump (Component 920) is modeled using a time-dependent junction. Water exiting the top of the panels is collected (Component 955) and returned (Component 960) to the water storage tank.

Heat structures are used to model the metallic and ceramic structures important to heat storage and transfer in the facility. These consist of the primary pressure vessel and its internal structures, including the heater rods; the PCS pipe walls; the steam generator tubes, internals, and shell; the gas circulator structure; the RCCS panels; and the RCST. Heat structure numbers generally match the numbers of the volume components to which they are attached. 
The Gnielinski correlation is being used for forced convection in the core coolant channels, with Dittus-Boelter being used elsewhere. Two-dimensional conduction (radial and axial) is used in all vertical structures. Insulation is modeled on the outside of the PCS piping, steam generator, gas circulator, RCST, and back side of the RCCS panels; a natural convection heat transfer coefficient $\left(15 \mathrm{~W} / \mathrm{m}^{2} \cdot \mathrm{K}\right)$ and sink temperature are applied to the outside of the insulation. The insulation between the hot and cold ducts, and between the upper plenum shield and the pressure vessel upper head, is also included in the model.

The core region is modeled with two heat structures in each channel. The first structure is centered on a coolant channel, and models the ceramic material. The second structure represents the heater rods, and is modeled as a solid cylinder that radiates heat to the outer surface of the ceramic structure. Both of these structures have a common boundary volume that represents the gas gap between the heater rods and the ceramic. The power to the heaters in the three core rings is provided by control variables and is assumed to be distributed uniformly over the heater rod length. Ten general tables, one for each of the heater rod banks, provide the power to individual banks; these are then apportioned to the three core rings based on how many of the heater rods in each bank are located in each core ring.

Conduction enclosures are used to transfer heat radially across the core ceramic blocks, and to transfer heat axially between the core blocks and the top and bottom reflectors. Radiation enclosures are used to transfer the heat radially from the core blocks to the outer reflector, from the outer reflector to the core barrel, from the core barrel to the primary pressure vessel, and from the pressure vessel to the RCCS panels. As mentioned above, radiation enclosures are also used between the heater rods and the surrounding core ceramic. Radiation view factors were calculated assuming only one-dimensional (radial) heat transfer for these enclosures. Radiation was also modeled from the upper plenum floor to the upper plenum shield and control rod guide tubes, and from the lower plenum roof to the bottom plate, the outlet plenum side reflector, and the support posts.

Trips and controls are used to operate the active components in the facility. To establish steady-state conditions, the steam generator feedwater flow is adjusted to achieve the desired pressure vessel coolant inlet temperature, the primary coolant flow rate is adjusted to achieve the desired outlet plenum coolant temperature, the primary coolant pressure is fixed, the steam generator steam valve is adjusted to establish the desired steam dome pressure, the RCCS flow is adjusted to match the desired panel outlet temperature, and the water supply valve is modulated to maintain a constant level in the water storage day tank. The relief valves have open and close pressure setpoints, and manual operation of some valves is modeled.

Some control variables are used to calculate parameters corresponding to facility measurements, such as differential pressures across components. Others are used to calculate parameters that may be useful for analyzing the code simulations. Control variables are also used to calculate a number of scaling parameters related to flow and heat transfer in the primary pressure vessel flow paths. 


\section{Simulations}

Calculations were performed for both steady state and the PCC transient. Sensitivity calculation were also performed. All of the transient simulations were run for 168 hours, although the actual experiment is expected to last less than half that time.

\subsection{Steady-state Calculation}

A steady-state calculation was performed to establish the initial conditions for the transient simulations that followed. The pressure at the circulator outlet was varied to establish the desired pressure vessel inlet pressure. The primary coolant flow rate was varied to provide the desired core outlet temperature, and the steam generator feedwater flow rate was adjusted to provide the desired cold duct (vessel inlet) temperature. The RCCS flow rate was held constant at what is anticipated to be a nominal flow rate in the facility. The steam generator pressure control valve area was adjusted to provide the desired steam dome pressure. Results of the steady-state calculation are provided in Table 1.

Table 1. Initial conditions for Test PG-26.

\begin{tabular}{|l|c|c|}
\hline \multicolumn{1}{|c|}{ Parameter } & $\begin{array}{c}\text { Expected Test } \\
\text { Conditions }\end{array}$ & Calculated Value \\
\hline Core power $(\mathrm{kW})$ & 700 & 700 \\
\hline Primary pressure vessel inlet pressure $(\mathrm{kPa})$ & 700 & 700 \\
\hline Primary pressure vessel coolant inlet temperature $\left({ }^{\circ} \mathrm{C}\right)$ & 258.6 & 687.6 \\
\hline Core outlet coolant temperature $\left({ }^{\circ} \mathrm{C}\right)$ & 687.0 & 0.306 \\
\hline PCS coolant flow rate $(\mathrm{kg} / \mathrm{s})$ & - & 1338 \\
\hline Peak heater rod temperature $\left({ }^{\circ} \mathrm{C}\right)$ & - & 500 \\
\hline Steam generator steam dome pressure $(\mathrm{kPa})$ & - & 0.247 \\
\hline Steam generator feedwater flow rate $(\mathrm{kg} / \mathrm{s})$ & - & $0.365 / 14.6$ \\
\hline Steam generator collapsed liquid level $(\mathrm{m} / \%)$ & - & 677 \\
\hline Steam generator heat removal $(\mathrm{kW})$ & - & 1.0 \\
\hline RCCS flow rate $(\mathrm{kg} / \mathrm{s})$ & - & 30.0 \\
\hline RCCS panel inlet temperature $\left({ }^{\circ} \mathrm{C}\right)$ & - & 34.6 \\
\hline RCCS panel outlet temperature $\left({ }^{\circ} \mathrm{C}\right)$ & - & 19 \\
\hline RCCS heat removal $(\mathrm{kW})$ & - & - \\
\hline
\end{tabular}

Expected steam generator conditions were not provided, as the steam generator conditions during steady state are important only in that they provide the desired vessel inlet coolant temperature. During the transient, the steam generator is essentially isolated from the rest of the PCS, and does not provide any cooling for the system. The conditions in the RCCS are expected to be varying, as warm water from the outlet of the panels is recirculated through the system. Additional cooling water will be added to the RCCS water tank at times to reduce the temperature. For modeling purposes, a constant flow rate and inlet temperature were assumed. The conditions in the RCST are immaterial for this transient. 
The total core power was distributed equally among four of the 10 heater banks. Heater banks 107 , 108,109 , and 110 were used, corresponding roughly to radial heater rings 2 and 4 (of five) and resulting in $21.43 \%$ of the power being deposited in the inner core ring, $33.33 \%$ in the middle ring, and $45.24 \%$ in the outer ring. The numbering of the heater banks is expected to change by the time the test is run, with the operating heater banks then being numbered 103, 104, 107, and 108.

\subsection{Base Case Transient Simulations}

The transient calculations were started by tripping the core power and initiating a 60 -s linear flow coastdown on the gas circulator. Full feedwater flow to the steam generator was maintained for $750 \mathrm{~s}$, followed by a 5 -s flow coastdown. Since the RCCS will be controlled manually during the test, a simplified model was used for the transient calculations in which the flow rate and inlet temperature were held constant at the steady-state values of $1.0 \mathrm{~kg} / \mathrm{s}$ and $30.0^{\circ} \mathrm{C}$, respectively.

Figure 9 shows the coolant velocities entering each of the five channels through the core: two in the reflectors and one in each of the three core rings. Flow in the middle and outer core rings reverses almost immediately, followed closely by that in the inner core ring. Flow in the outer core ring returned to downward flow within 3 hours. Flow in the side reflector remains downward throughout the transient, as a recirculating flow is established in the pressure vessel between the upper and outlet plenums. Flow in the central reflector slowly decreases before reversing near 6 hours. For the rest of the transient, helium flowed up through the three innermost flow channels and down through the outer two.

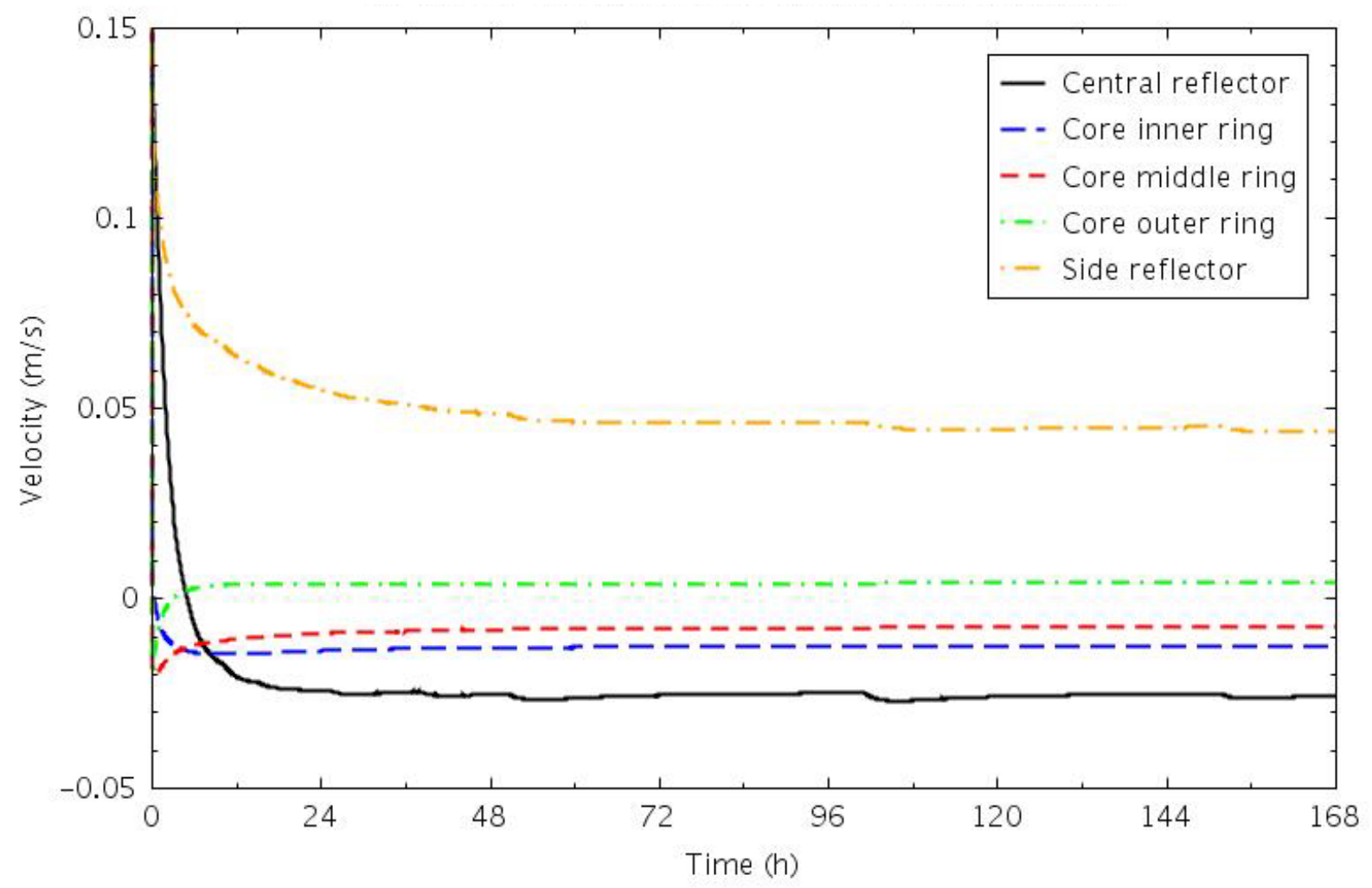

Figure 9. Coolant velocities at the top of the upper reflector for the Test PG-26 pre-test calculation.

Figure 10 presents the peak temperatures for the ceramic and heater rods in each of the three core rings. The heater rod temperatures in all three rings dropped immediately after the transient began, as the power reduction was faster than the flow coastdown. The principal phenomenon in the first 8 to 10 hours was a redistribution of the stored energy in the core. During steady state, the outer ring had higher temperatures because the power density was higher in that ring, while the lowest temperatures were in the 


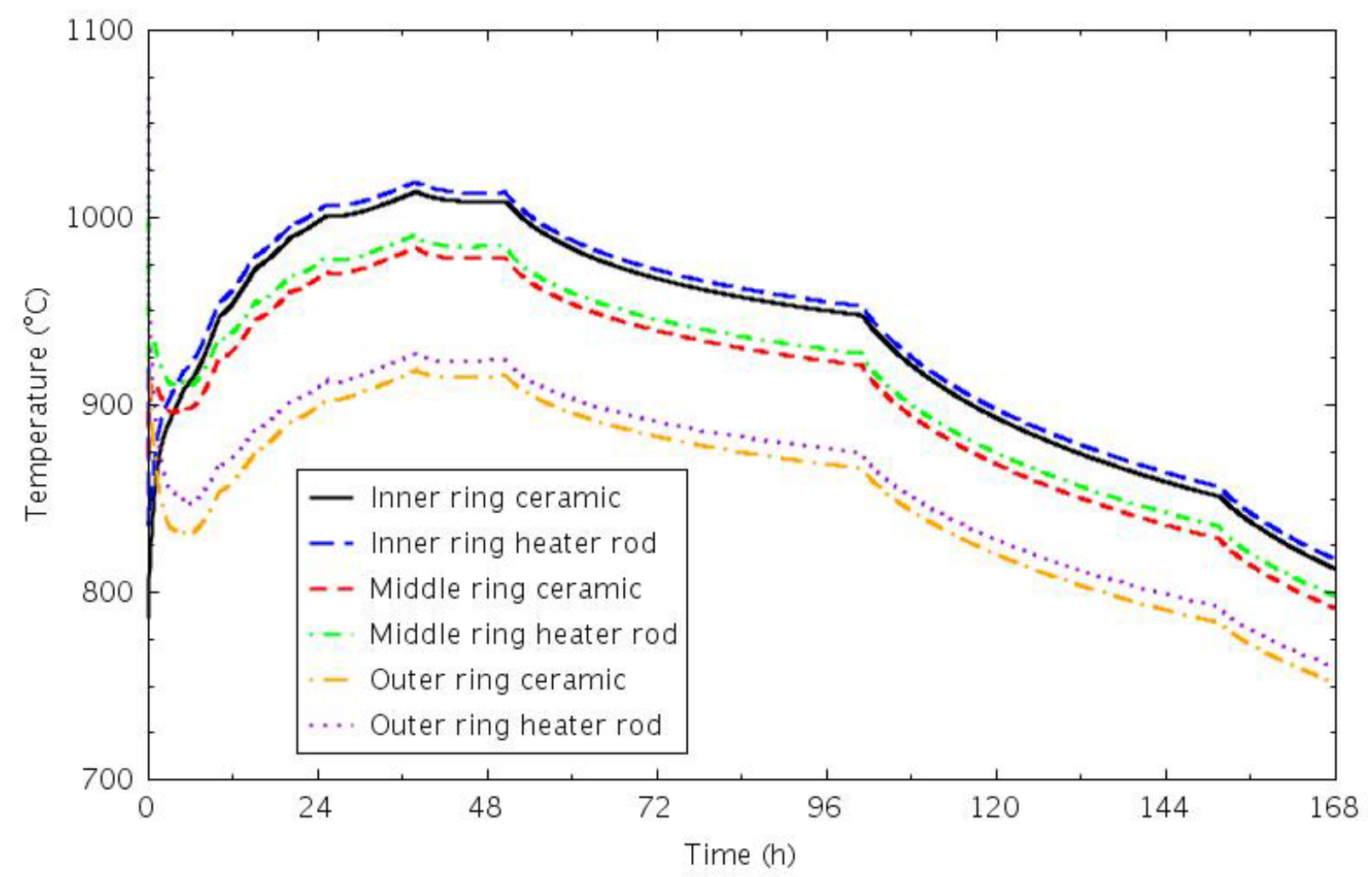

Figure 10. Peak temperatures in the three core rings for the Test PG-26 pre-test calculation.

inner core ring, where the heater power density was the lowest. This profile is reversed through most of the transient. With the transient heat removal being primarily in the radial direction, the highest temperatures will be in the middle of the vessel, with the temperatures decreasing as distance from the center of the vessel increases. The peak core temperatures during steady state are at the bottom of the core, whereas they will be near the middle of the core after forced convection cooling is lost, so there is also an axial redistribution of the stored energy. The energy redistribution resulted in the peak temperatures in the middle and outer rings decreasing for a few hours, while those in the inner ring increased continuously. Peak transient temperatures in all of the channels were reached just before 38 hours. The peak heater rod temperatures were $1019^{\circ} \mathrm{C}$ in the inner ring, $991^{\circ} \mathrm{C}$ in the middle ring, and $927^{\circ} \mathrm{C}$ in the outer ring; the steady-state values were 921,1008 , and $1065^{\circ} \mathrm{C}$, respectively. The peak ceramic temperatures were $1014^{\circ} \mathrm{C}$ in the inner ring, $984^{\circ} \mathrm{C}$ in the middle ring, and $918^{\circ} \mathrm{C}$ in the outer ring; the steady-state values were 786,872 , and $925^{\circ} \mathrm{C}$, respectively. The temperatures then slowly decreased through the rest of the transient, as heat was conducted and radiated out through the pressure vessel to the RCCS. Most of the inflection points in the curves correspond to the step reductions in the heater rod power (see Figure 3).

Peak temperatures in each of the three rings of the central and side reflectors are presented in Figure 11; the middle ring in each contains the bypass/cooling channels. The central reflector peak temperatures increase about $300^{\circ} \mathrm{C}$ in the first 12 hours of the transient, then increase more slowly, reaching maximum values of $1009^{\circ} \mathrm{C}$ in the center region and middle ring, and $1011^{\circ} \mathrm{C}$ in the outer ring, around 40 hours. The peak temperatures then remain close together and decrease through the rest of the transient, although they are well above the steady-state values at the end of the simulation. The outer ring heats up faster because the heat in the central reflector is being conducted in from the inner core ring. A much larger temperature spread occurs in the side reflector, where the inner ring peak temperature of $831^{\circ} \mathrm{C}$, the middle ring peak temperature of $759^{\circ} \mathrm{C}$, and the outer ring peak temperature of $705^{\circ} \mathrm{C}$ all occur around 51 hours. The side reflector inner ring peak temperature at the end of the transient 


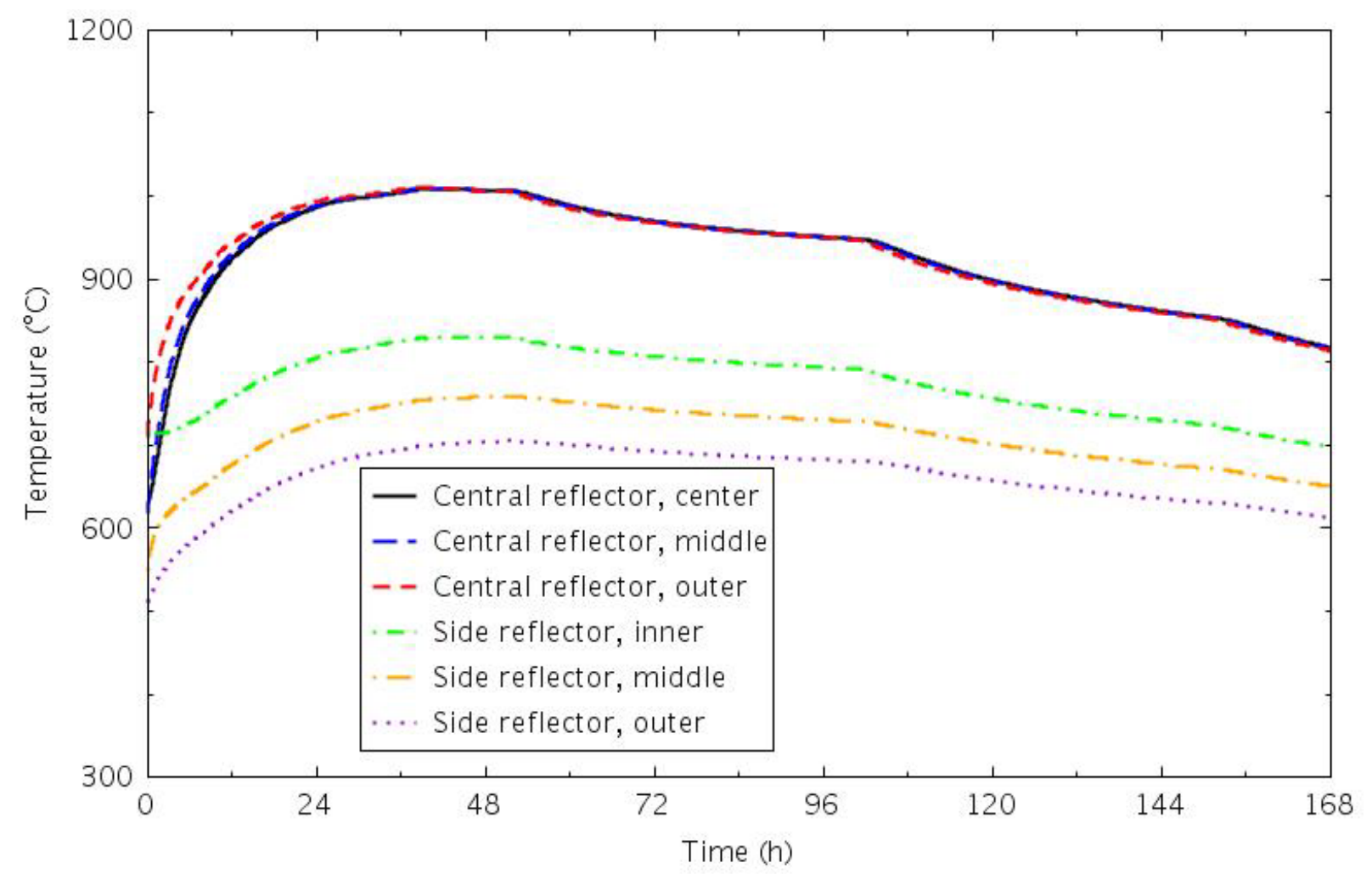

Figure 11. Peak temperatures in the central and side reflectors for the Test PG-26 pre-test calculation.

calculation is about $10^{\circ} \mathrm{C}$ below the steady-state value, while the middle and outer ring temperatures are about $100^{\circ} \mathrm{C}$ above those at the start of the transient.

Figure 12 shows the peak temperatures in the PSR, core barrel, and primary pressure vessel wall. The peak temperatures in each structure rose during the first 50 hours of the transient before decreasing through the remainder. The PSR reached its peak temperature of $634^{\circ} \mathrm{C}$ at 53.4 hours, the core barrel peak temperature of $569^{\circ} \mathrm{C}$ occurred at 54.2 hours, and the pressure vessel attained it peak temperature of $381^{\circ} \mathrm{C}$ at 54.9 hours. At the end of the calculation at 168 hours, the three peak temperatures ranged from 91 to $148^{\circ} \mathrm{C}$ above their steady-state values.

Ceramic temperatures near the bottom (block 1), middle (block 6) and top (block 10) of the inner and outer core rings are shown in Figure 13. The initial axial temperature profile, with the hottest temperatures at the bottom of the core, changes to a middle-peaked profile with the top and bottom near the same temperatures; it takes 24 to 48 hours to make the transition. Convective heat transfer associated with the small recirculating flow in the core was insufficient to establish a monotonically increasing (or decreasing) temperature in the flow channels.

Axial average temperatures for six of the radial ceramic regions are presented in Figure 14. The axial average temperature is a simple arithmetic average of the volume-average temperatures in the ten axial nodes over the heated length of the heater rods. All of the temperatures increased when forced convection cooling was lost at the beginning of the transient, with a much more rapid increase in the core rings around the heater rods. In the core, all three rings reached their peak temperatures shortly before 38 hours. In the reflectors, the inner reflector temperature peaked earliest, near 41 hours, followed by the side (51 hours) and outer reflectors ( 54 hours), as heat from the inner portion of the core blocks was conducted radially outward toward the pressure vessel.

Axial average temperatures for some of the structures outside the core and for the cavity air are presented in Figure 15. The RCCS panels maintain a nearly constant temperature a little below the steady- 


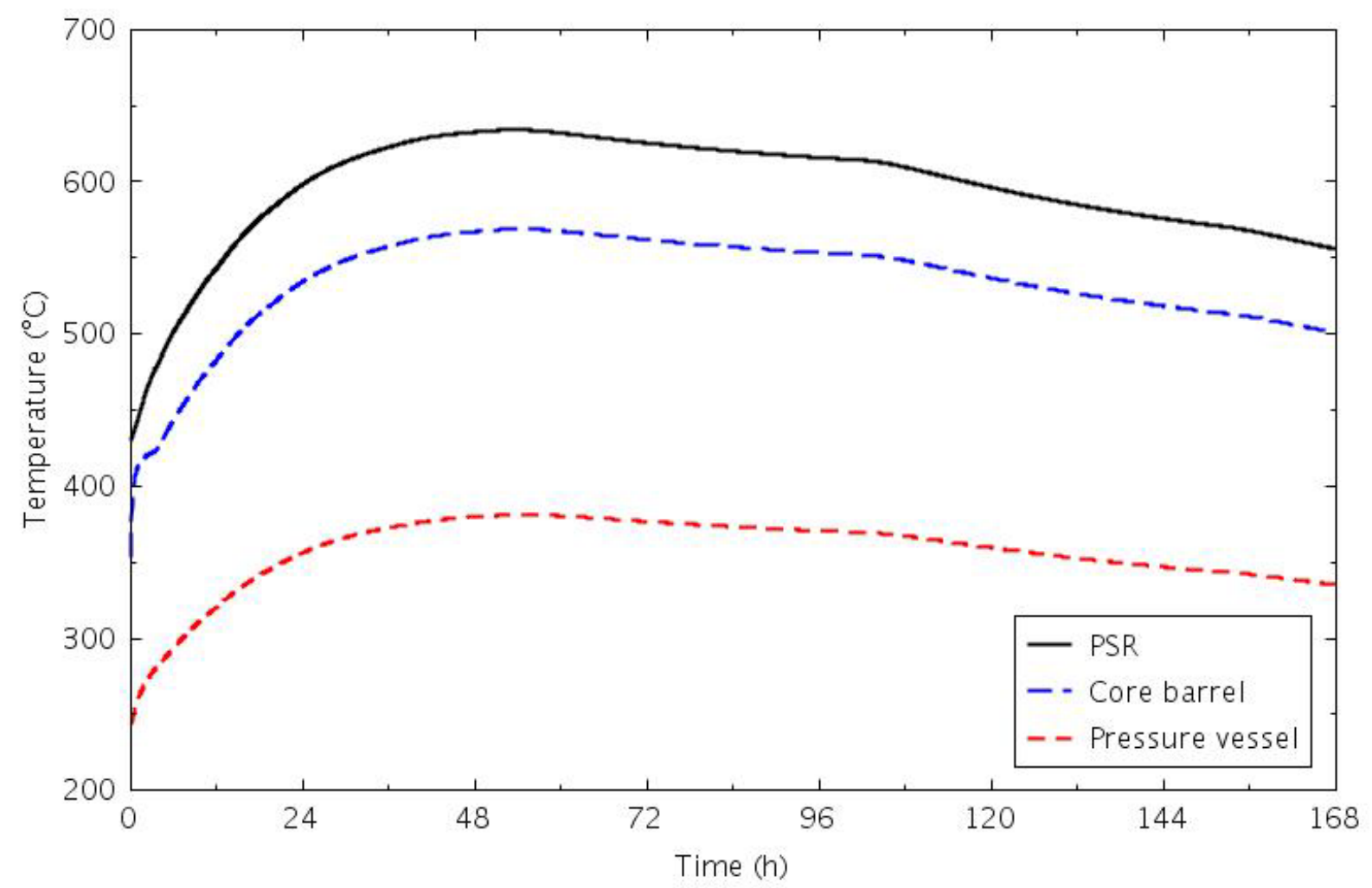

Figure 12. Peak temperatures in the PSR, core barrel, and pressure vessel wall for the Test PG-26 pre-test calculation.

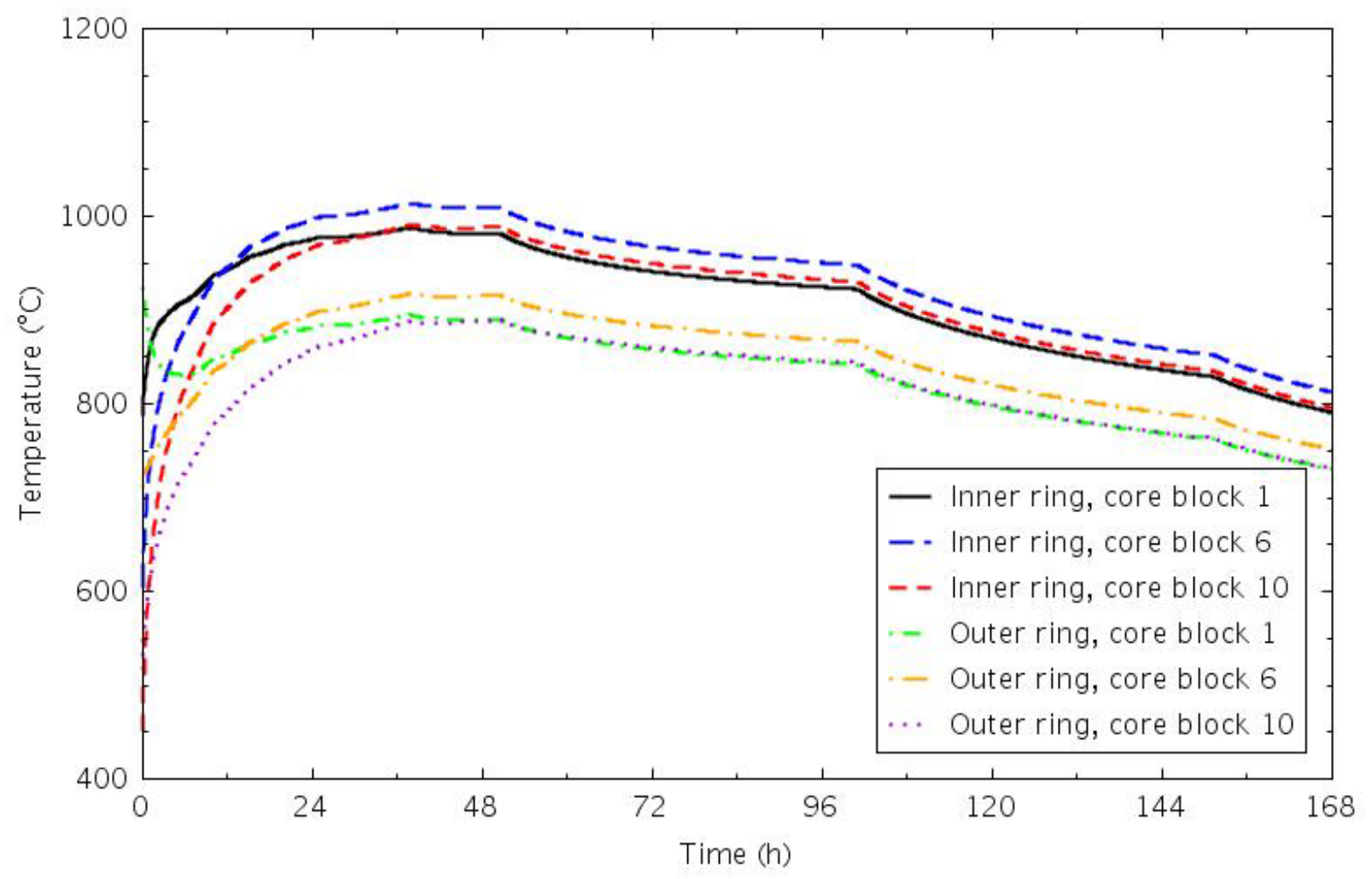

Figure 13. Core ceramic temperature distribution for the Test PG-26 pre-test calculation. 


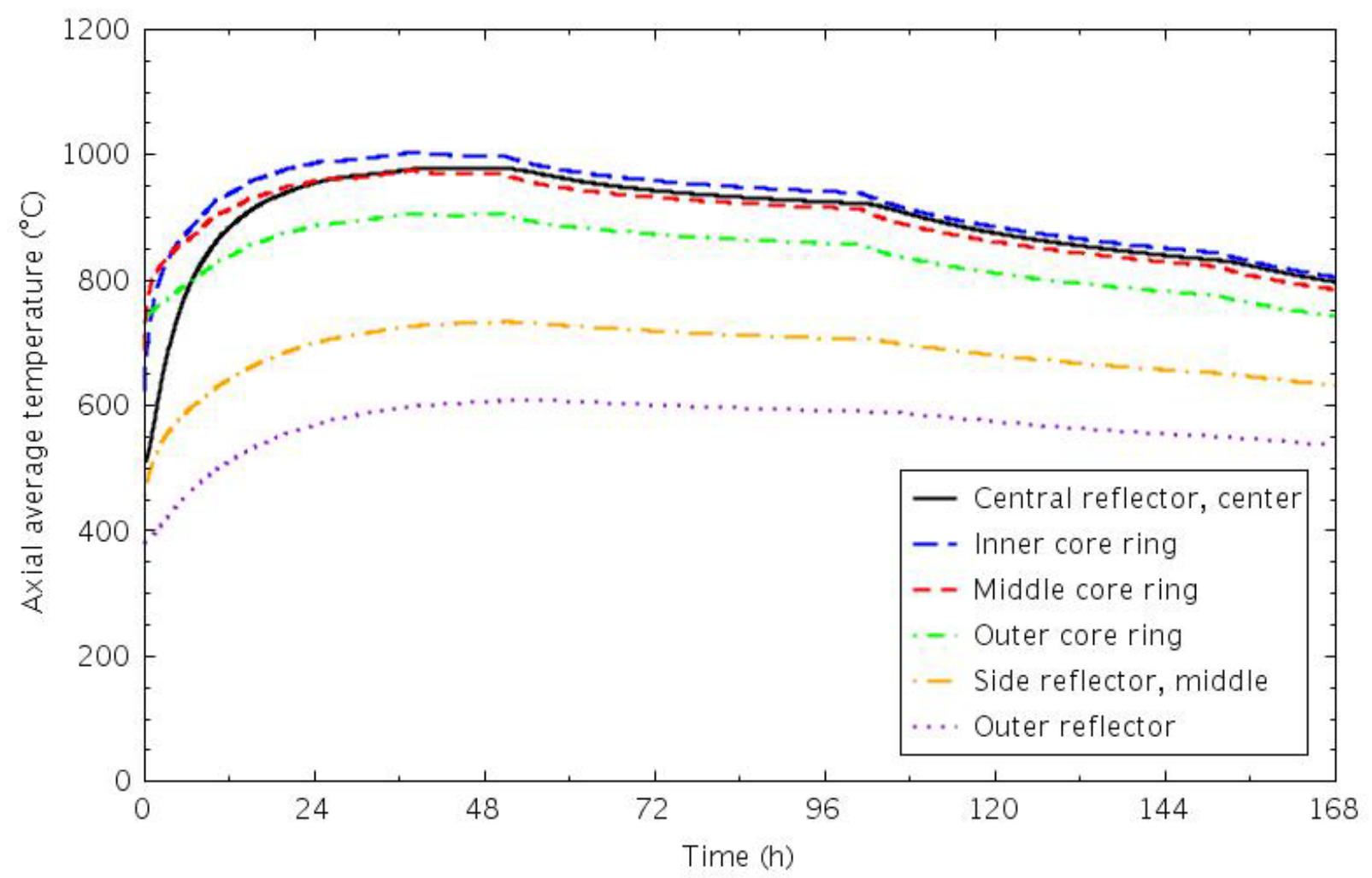

Figure 14. Core ceramic radial temperature distribution for the Test PG-26 pre-test calculation.

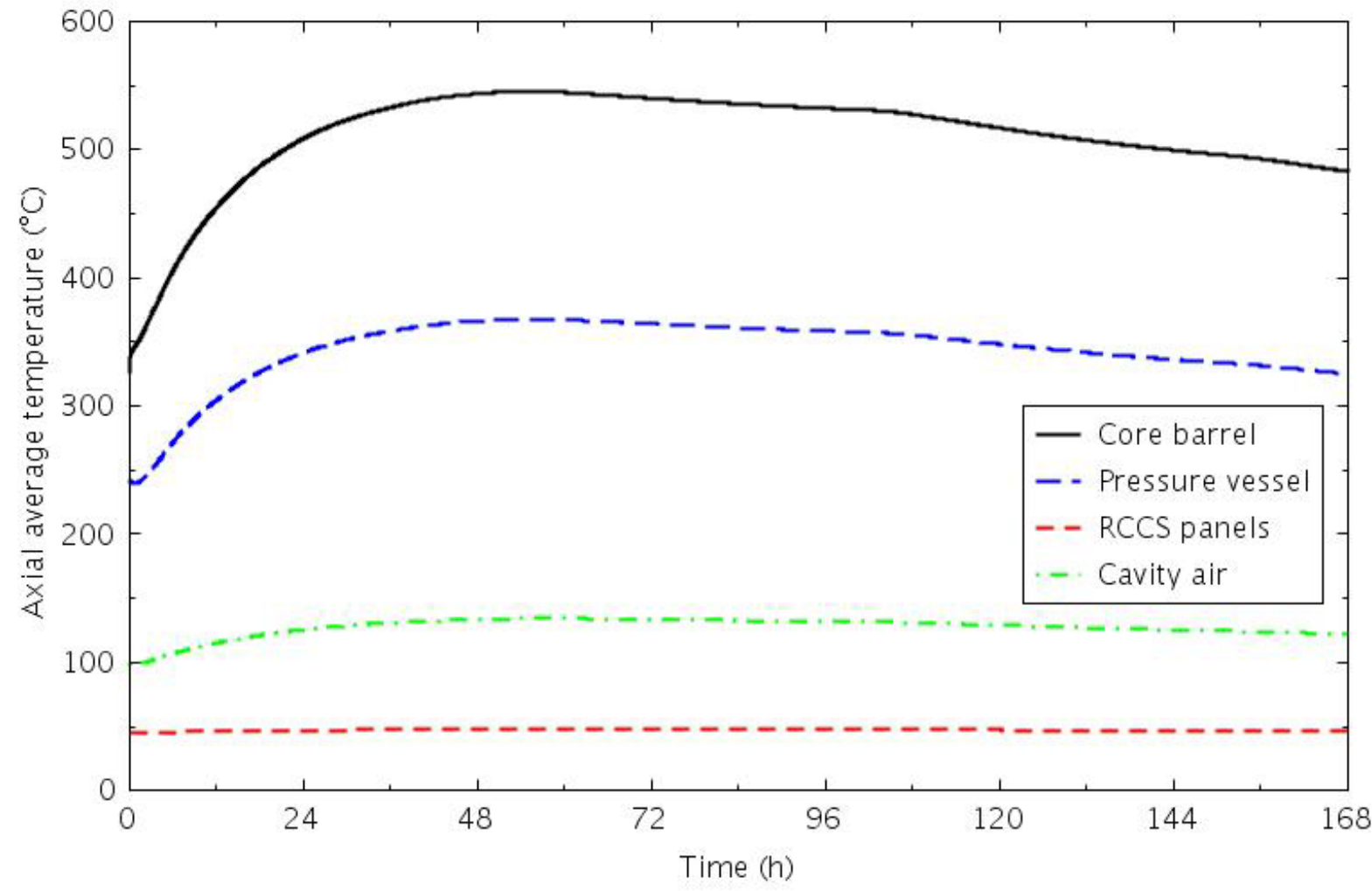

Figure 15. Axial average temperatures for some ex-core components for the Test PG-26 pre-test calculation. 
state value, with a constant cooling flow on the inside of the panels and a decreasing heat generation in the core. The core barrel, pressure vessel, and cavity air temperatures peak at 54.7, 55.4, and 57.3 hours, respectively. The peak core barrel average temperature is about $220^{\circ} \mathrm{C}$ above the steady-state temperature, and the peak vessel temperature is about $125^{\circ} \mathrm{C}$ higher than the initial value.

Coolant temperatures at the top and bottom of the core heated length in the three core rings are presented in Figure 16. After forced convection cooling is lost, heat is redistributed in the core, moving from the bottom toward the top. The bulk of the redistribution occurs within the first 24 hours. After about 48 hours, there is no noticeable difference in temperature between the top and bottom of the core in the inner and middle rings, while the bottom of the outer ring remains slightly hotter than the top. With very little coolant flow in the core (see Figure 9), the coolant temperatures will be close to those of the adjacent ceramic.

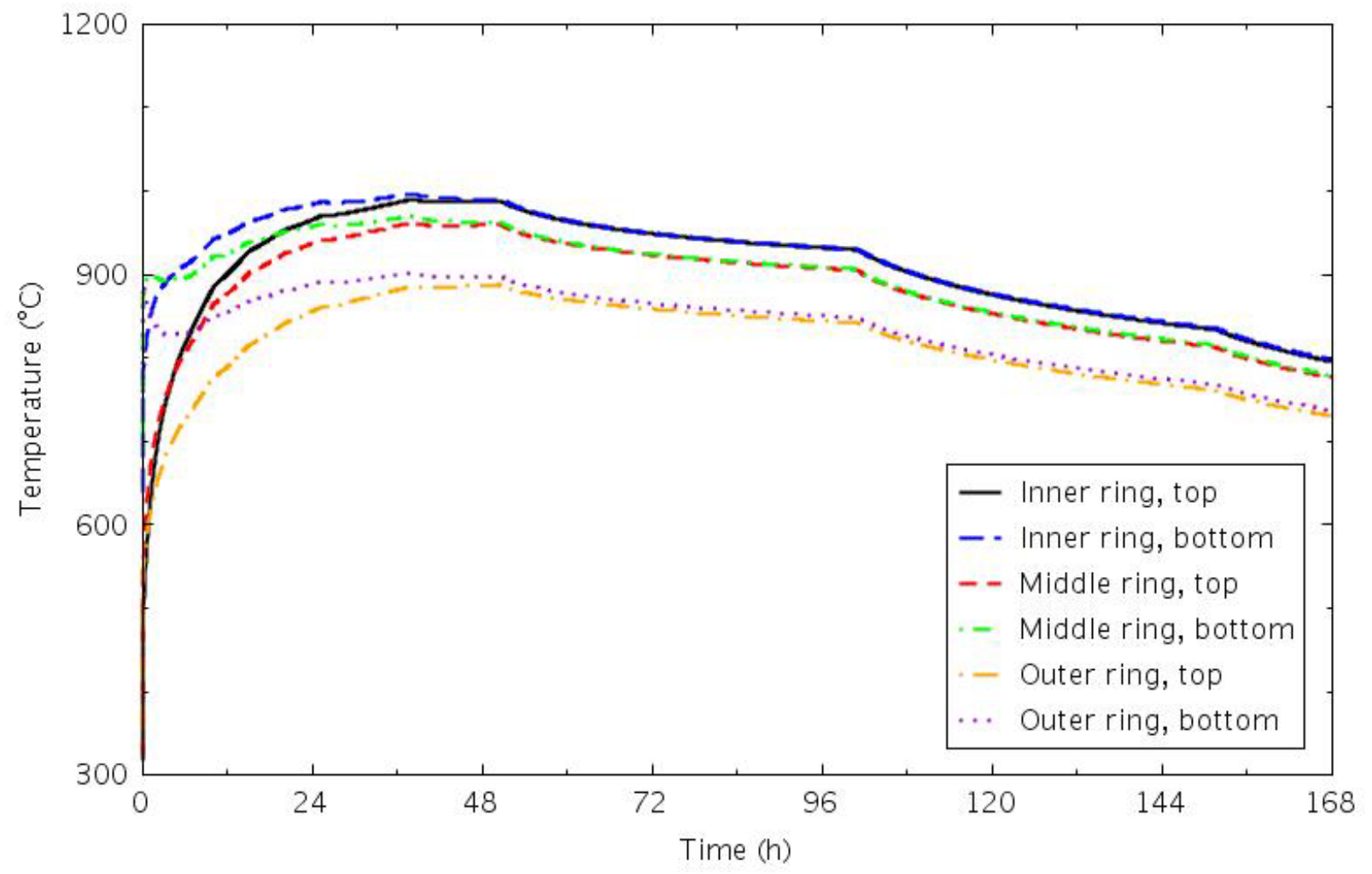

Figure 16. Coolant temperatures at the top and bottom of the core for the three core rings for the Test PG-26 pre-test calculation.

Figure 17 shows the coolant temperatures at the top and bottom of the channels in the central and side reflectors. The energy redistribution from the bottom of the core upwards occurred more slowly in the reflectors than in the core (see Figure 16). A temperature difference between the top and bottom was also maintained throughout the transient in the central reflector. The temperatures at the top of the reflectors peaked around 64 hours, while those at the bottom peaked shortly after the transient began.

Coolant temperatures in the pressure vessel upper and outlet plenums are shown in Figure 18. The temperatures in both locations dropped at the beginning of the transient, as the core power was reduced and flow coasted down. After the initial decrease, the temperature in the outlet plenum did not change much; it slowly decreased in the latter half of the simulation as cooler helium flowed in from the side reflector cooling channels. The upper plenum temperature also decreased in the first few hours of the transient, as heat was being transferred out through the vessel upper head. As the energy redistribution continued, heating the top portion of the core, and with a small flow entering from the hotter core 


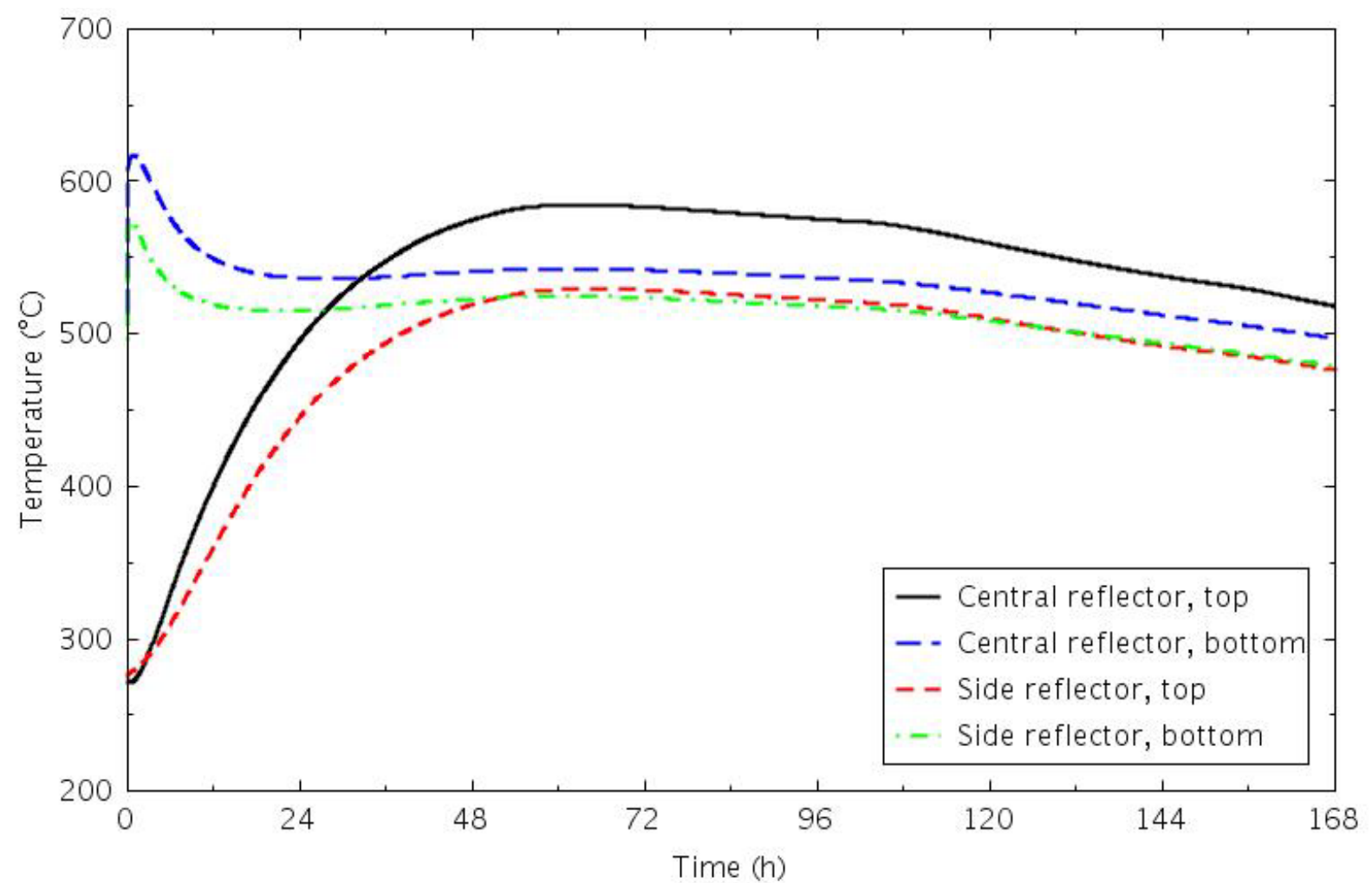

Figure 17. Coolant temperatures at the top and bottom of the reflectors for the Test PG-26 pre-test calculation.

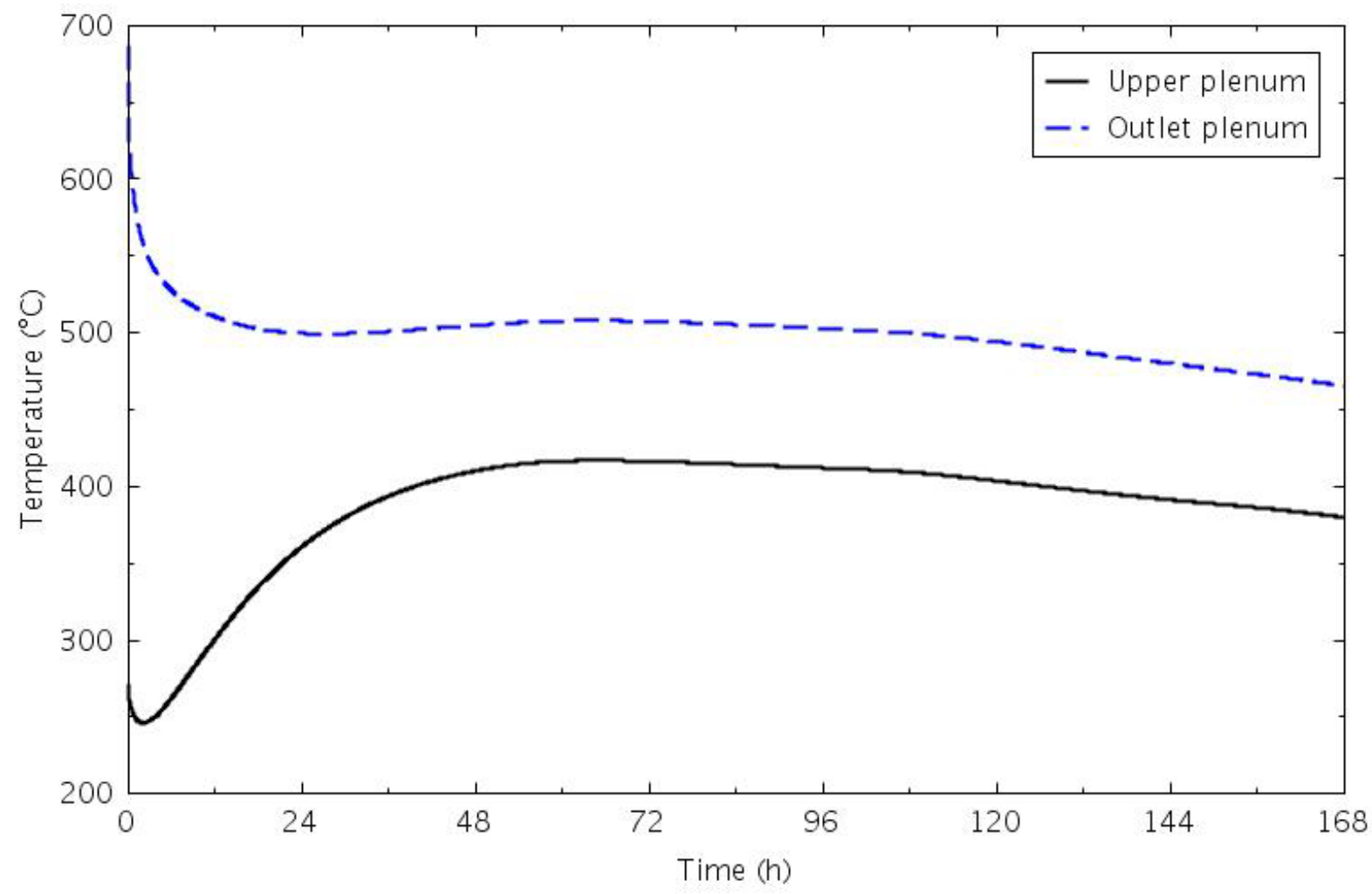

Figure 18. Coolant temperatures in the pressure vessel upper and outlet plenums for the Test PG-26 pretest calculation. 
channels, the upper plenum gas temperature began to increase, reaching its peak near 65 hours. With almost no coolant flow up from the core, the upper plenum gas temperature remained $400-600^{\circ} \mathrm{C}$ below that at the top of the core heated region (see Figure 16) and about $150^{\circ} \mathrm{C}$ below the gas temperatures at the top of the central reflector (see Figure 17). With that large a temperature difference, a thermal plume would be expected to occur in the upper plenum; however, the one-dimensional modeling of the upper plenum precludes that in the calculation, resulting in a likely underprediction of the gas temperature.

Coolant temperatures at the inlet and outlet of the RCCS panels are shown in Figure 19. The inlet temperature was held constant, and the outlet temperature reflected the total energy being absorbed by the RCCS. Most of the heat transfer was via radiation from the pressure vessel, and the shape of the curve, with a peak near 57 hours and an inflection near 106 hours, reflects that of the pressure vessel average temperature shown in Figure 15. The small temperature rise across the panels was the result of a relatively high coolant flow rate.

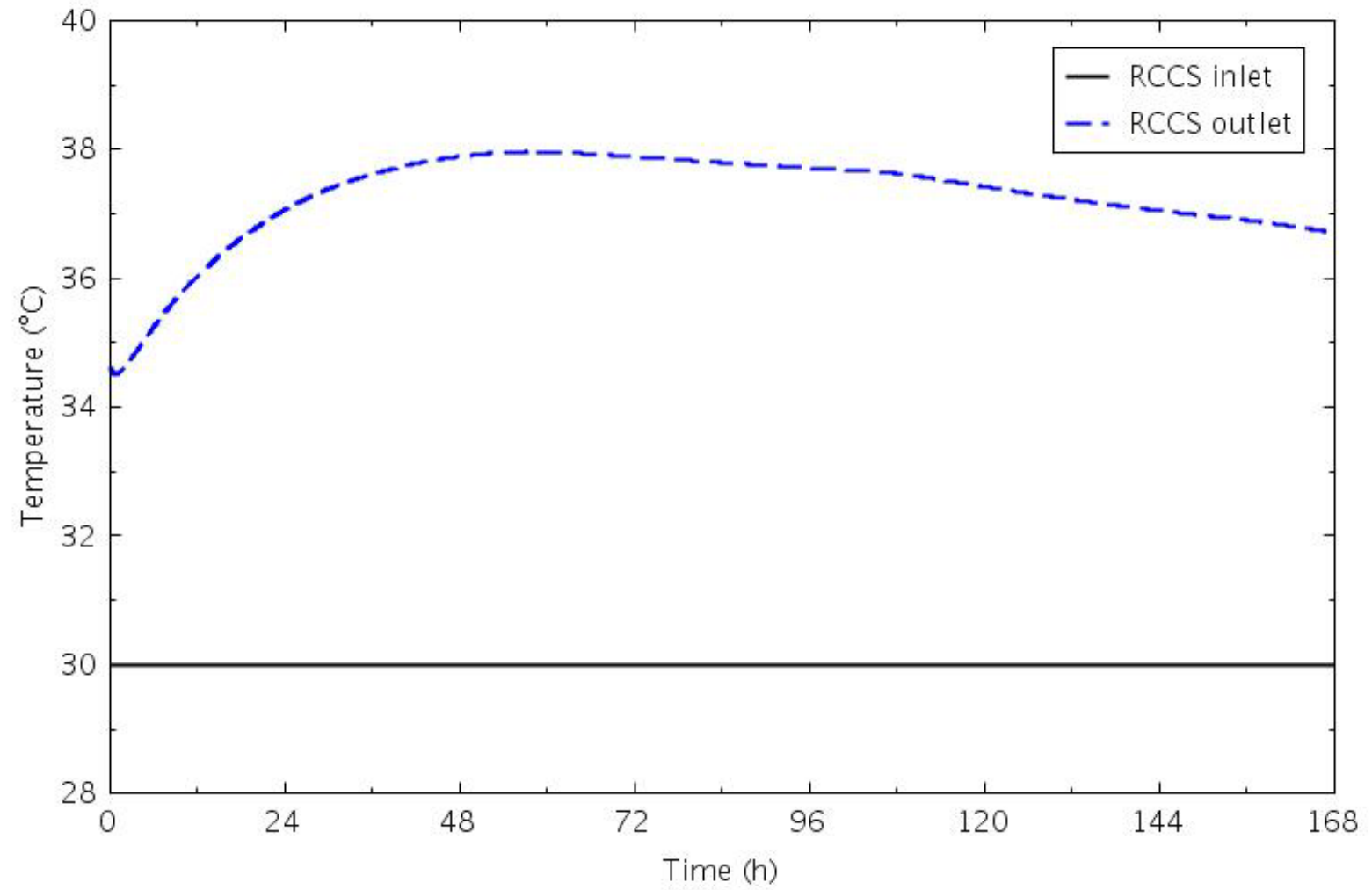

Figure 19. RCCS panel coolant inlet and outlet temperatures for the Test PG-26 pre-test calculation.

The core decay power and RCCS heat removal are compared in Figure 20. The RCCS heat removal peaked near 57 hours, about 19 hours after it exceeded the decay power.

The PCS pressure at the vessel inlet is presented in Figure 21. The pressure drops initially as forced flow is lost, then increases as the coolant heats up. The peak pressure of $710 \mathrm{kPa}$ occurs near 36 hours, after which the pressure slowly decreases as the coolant temperature decreases. 


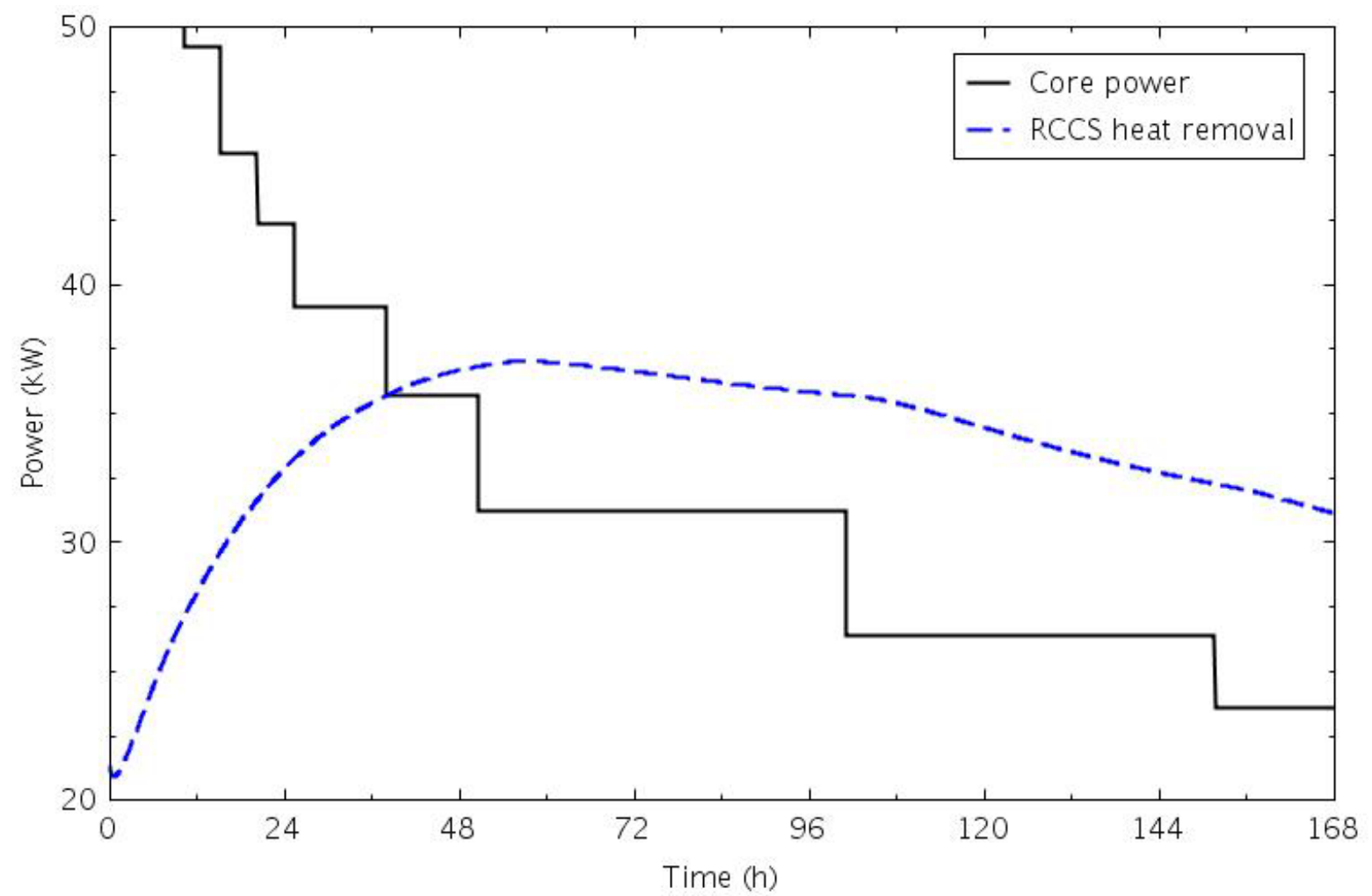

Figure 20. Core decay power and RCCS heat removal for the Test PG-26 pre-test calculation.

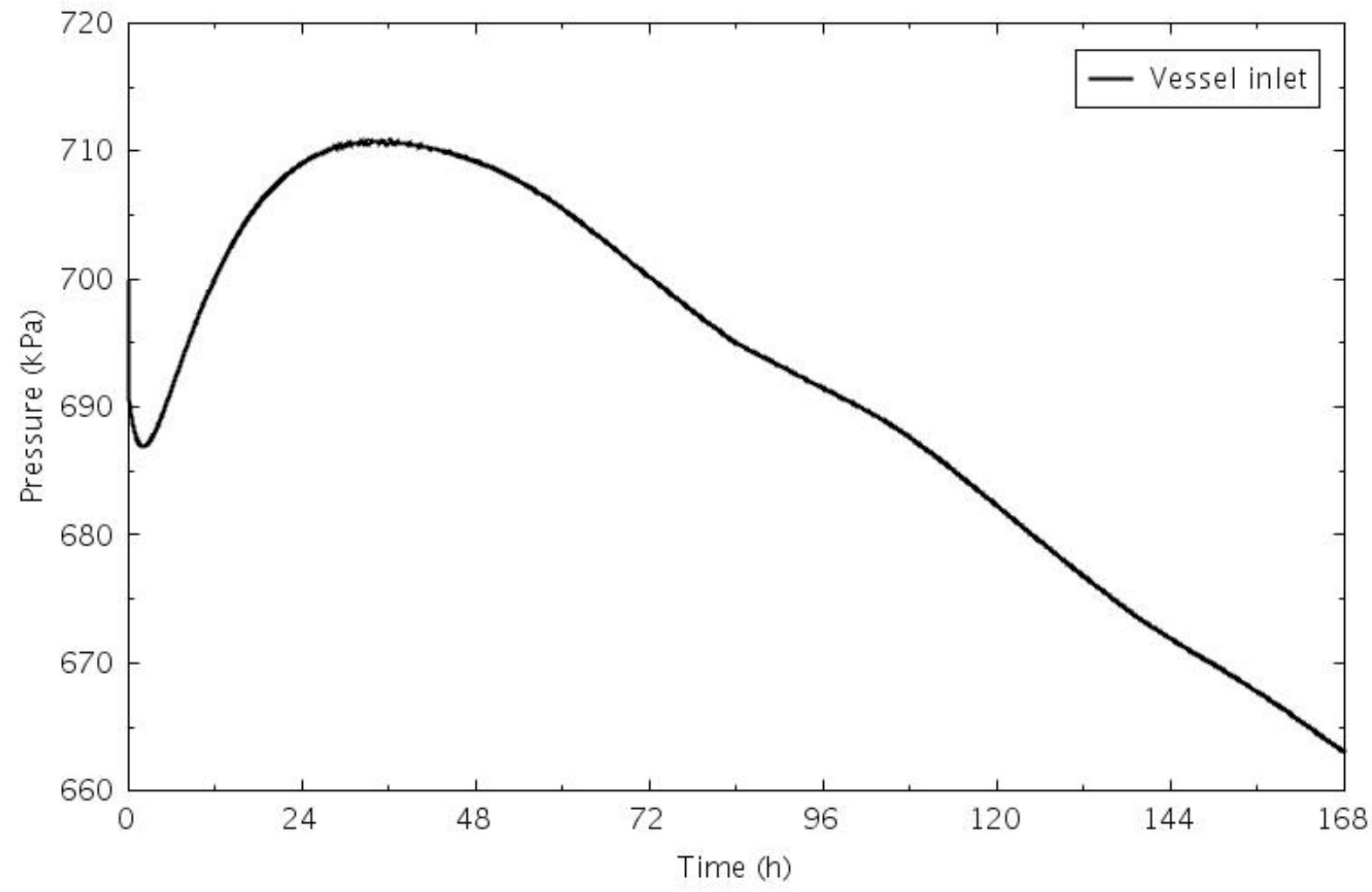

Figure 21. Primary pressure vessel inlet pressure for the Test PG-26 pre-test calculation. 


\subsection{Sensitivity Calculations}

Four sets of sensitivity calculations were performed. In the first set, the forced flow coastdown time was reduced. In the second set, the RCCS flow rate was reduced. In the third case, the RCCS inlet temperature was increased. The final set of calculations investigated different options for turning off the heaters when they get below their controllable power range.

\subsubsection{Forced Flow Coastdown}

The 60 -s forced flow coastdown from the base case was reduced to $10 \mathrm{~s}$ in this calculation. The objective was to examine the effect of reducing the amount of stored energy removed from the core during the flow coastdown.

Peak heater rod temperatures from this calculation and the base case are presented in Figure 22 . The temperatures are nearly identical, with the shorter flow coastdown yielding a peak temperature $1^{\circ} \mathrm{C}$ higher than the base case. Similarly small differences were observed in the peak ceramic temperatures in the three core rings, shown in Figures 22-24.

Figure 26 presents the pressure vessel wall peak temperatures, which are essentially identical. With no difference in pressure vessel wall temperature or RCCS boundary conditions, the heat removed by the RCCS is the same in both cases, as shown in Figure 27.

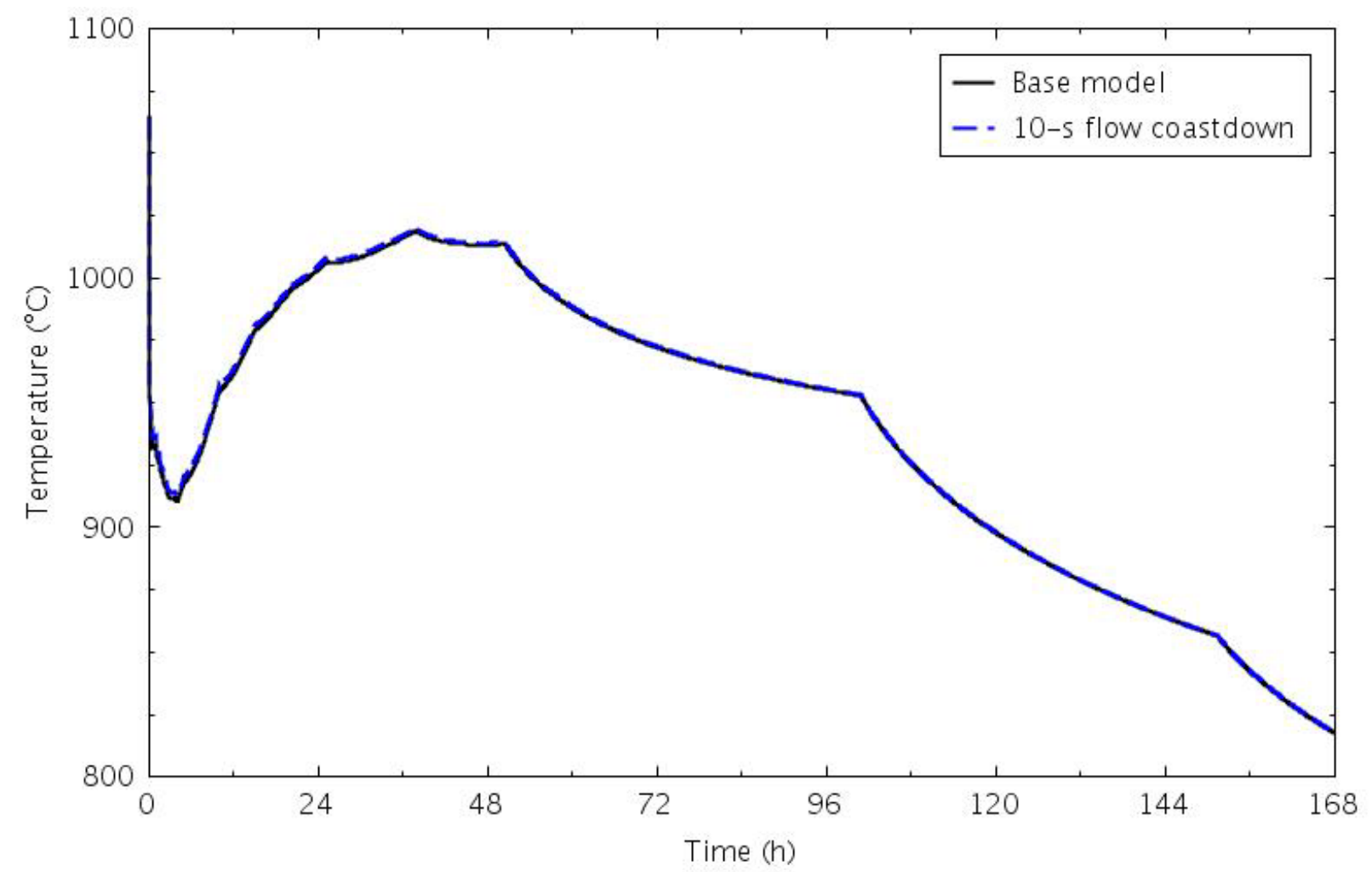

Figure 22. Peak heater rod temperatures for the Test PG-26 pre-test calculation base and 10-s flow coastdown cases. 


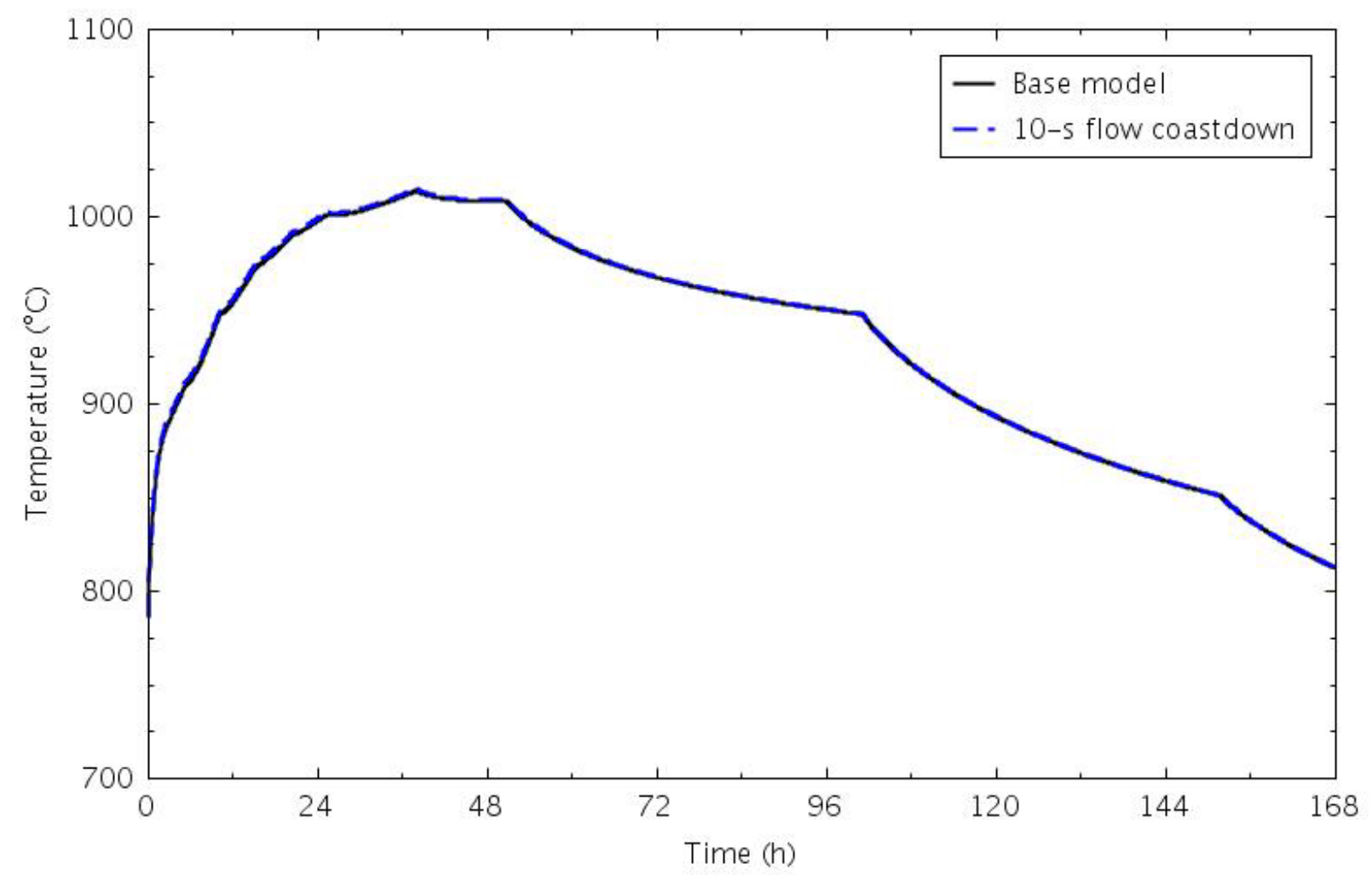

Figure 23. Peak inner core ring ceramic temperatures for the Test PG-26 pre-test calculation base and 10-s flow coastdown cases.

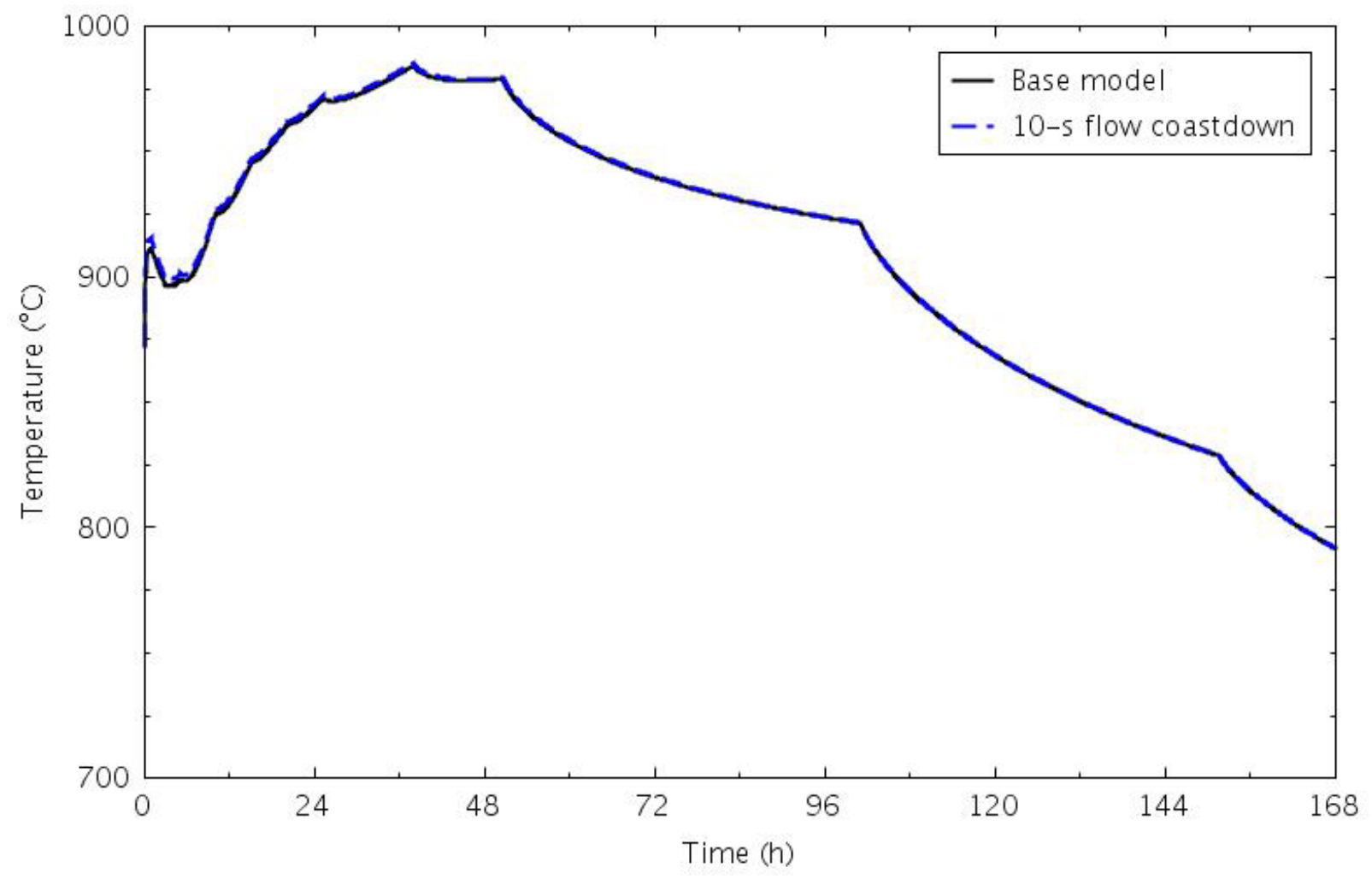

Figure 24. Peak middle core ring ceramic temperatures for the Test PG-26 pre-test calculation base and 10-s flow coastdown cases. 


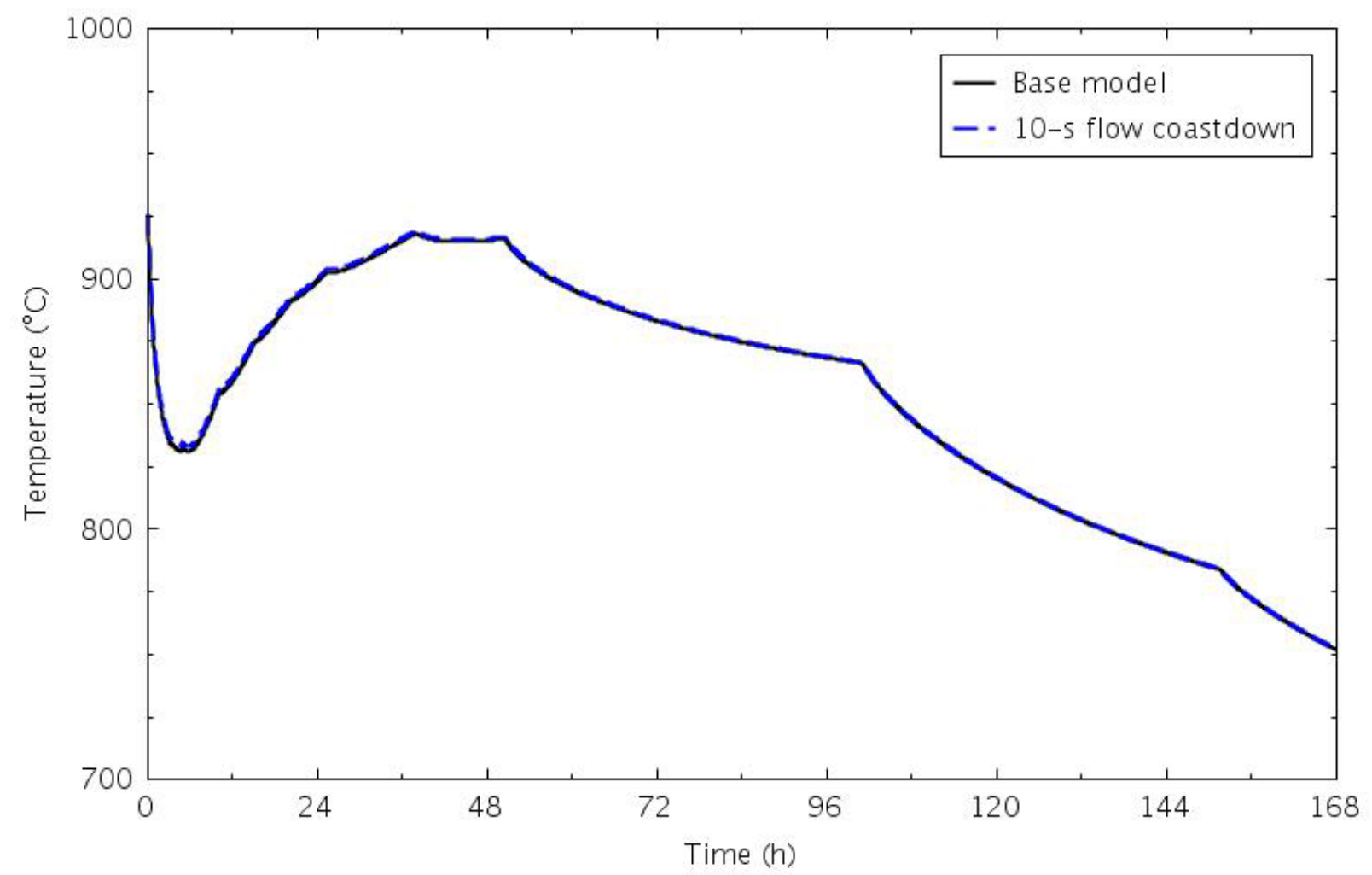

Figure 25. Peak outer core ring ceramic temperatures for the Test PG-26 pre-test calculation base and 10-s flow coastdown cases.

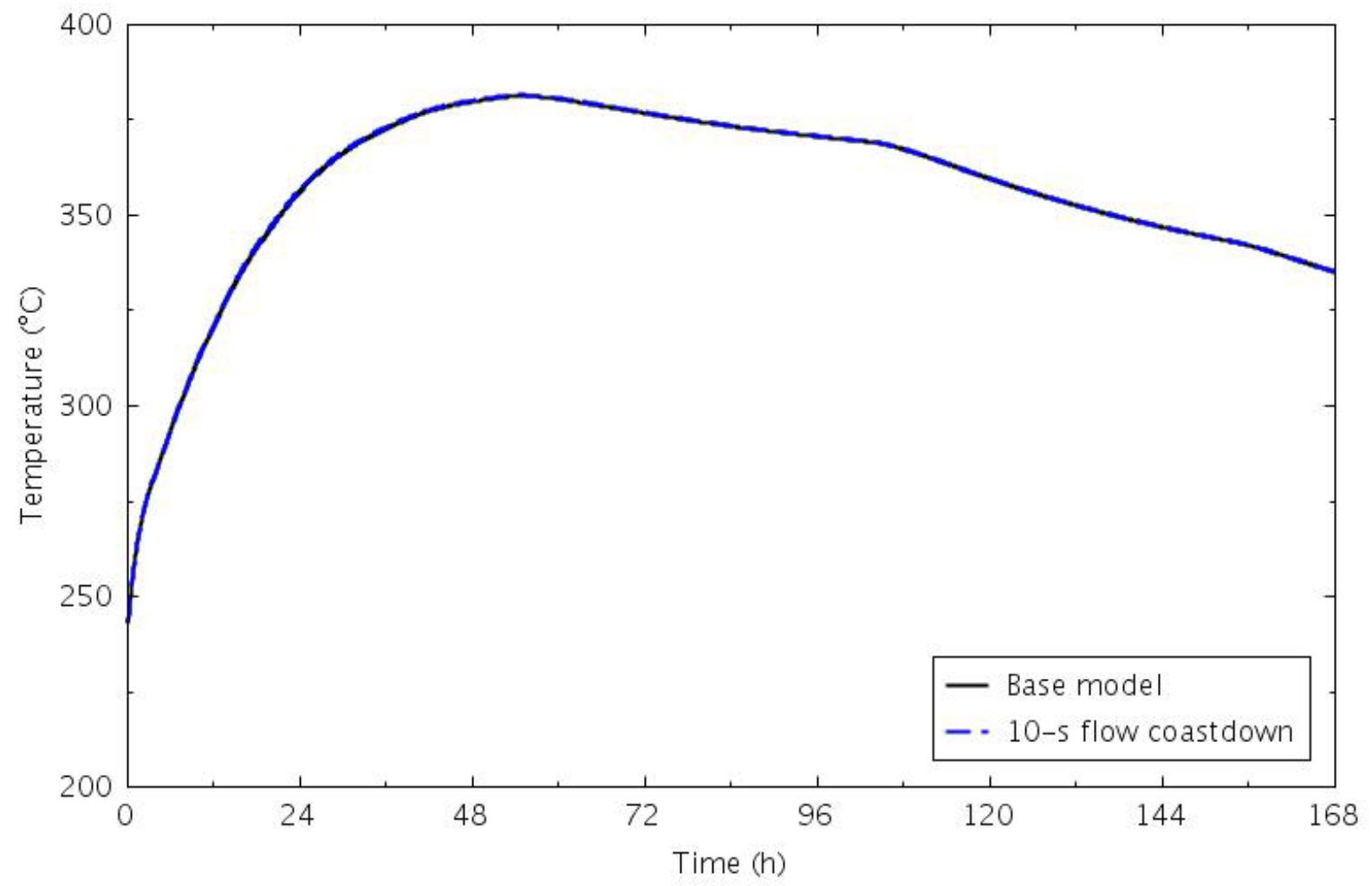

Figure 26. Pressure vessel peak wall temperatures for the Test PG-26 pre-test calculation base and 10-s flow coastdown cases. 


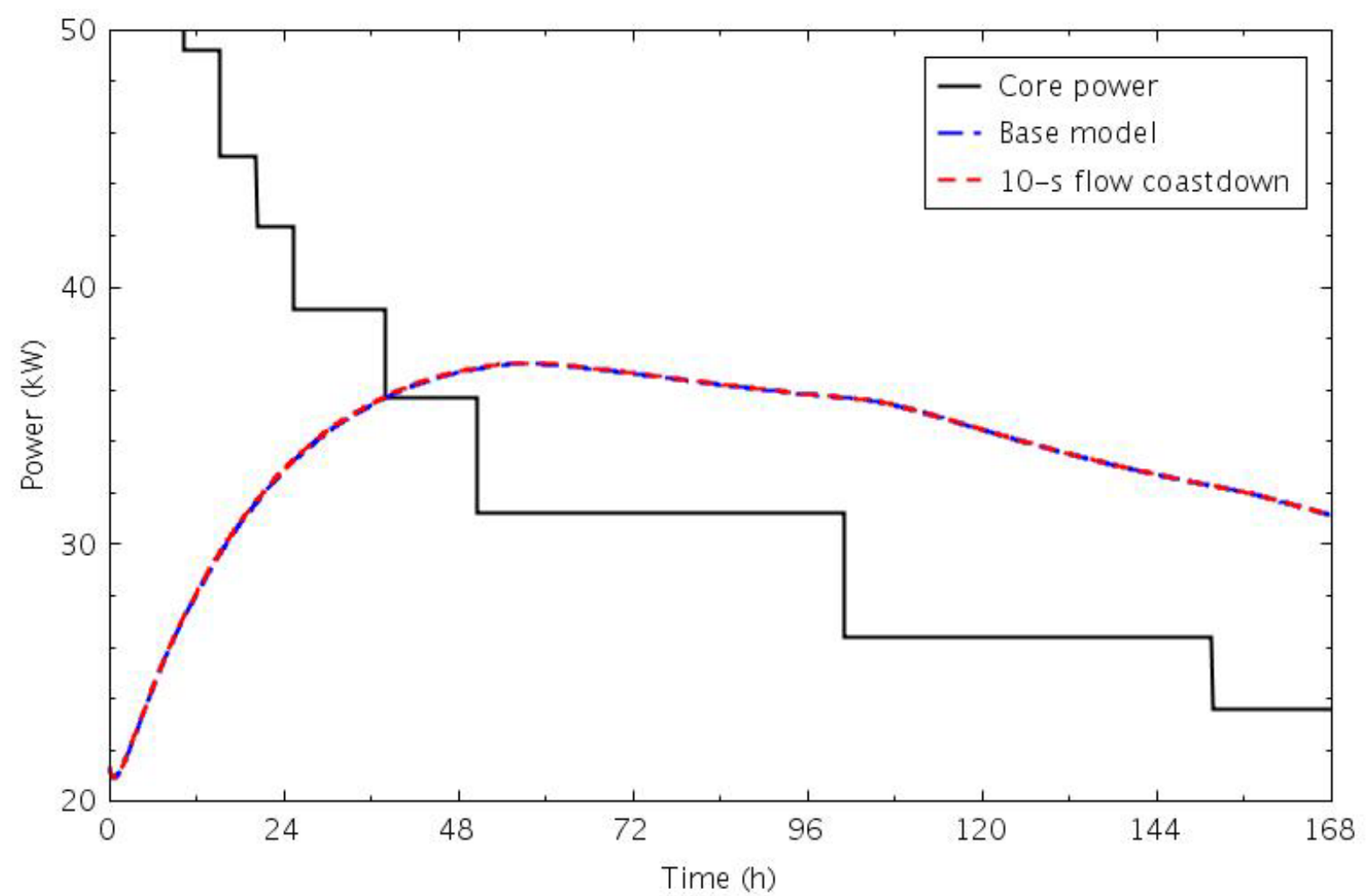

Figure 27. Core power and RCCS heat removal for the Test PG-26 pre-test calculation base and 10-s flow coastdown cases.

\subsubsection{RCCS Flow}

In the base case calculation, a constant RCCS flow rate of $1.0 \mathrm{~kg} / \mathrm{s}$ was modeled. For this sensitivity calculation, the flow rate was reduced to $0.2 \mathrm{~kg} / \mathrm{s}$; a steady-state calculation with this reduced flow rate was also performed. The lower flow rate will result in higher temperatures in the RCCS panels, which will reduce the heat transfer from the pressure vessel. This is observed in Figure 28, which compares the RCCS heat removal to the core power. The $80 \%$ flow reduction only changed the heat removal by a few percent. It did, however, increase the temperature rise across the RCCS panels by about $80 \%$, as seen in Figure 29.

Figure 30 shows the peak heater rod temperature. The peak transient value increased $4{ }^{\circ} \mathrm{C}$ compared to the base case calculation, although the difference between the two cases continued to increase as the transient progressed. The peak ceramic temperatures exhibited similar behavior, as shown in Figures 30-32.

Peak pressure vessel wall temperatures are presented in Figure 34. With the reduced RCCS flow, the peak vessel temperature was $13^{\circ} \mathrm{C}$ higher and occurred about an hour later. 


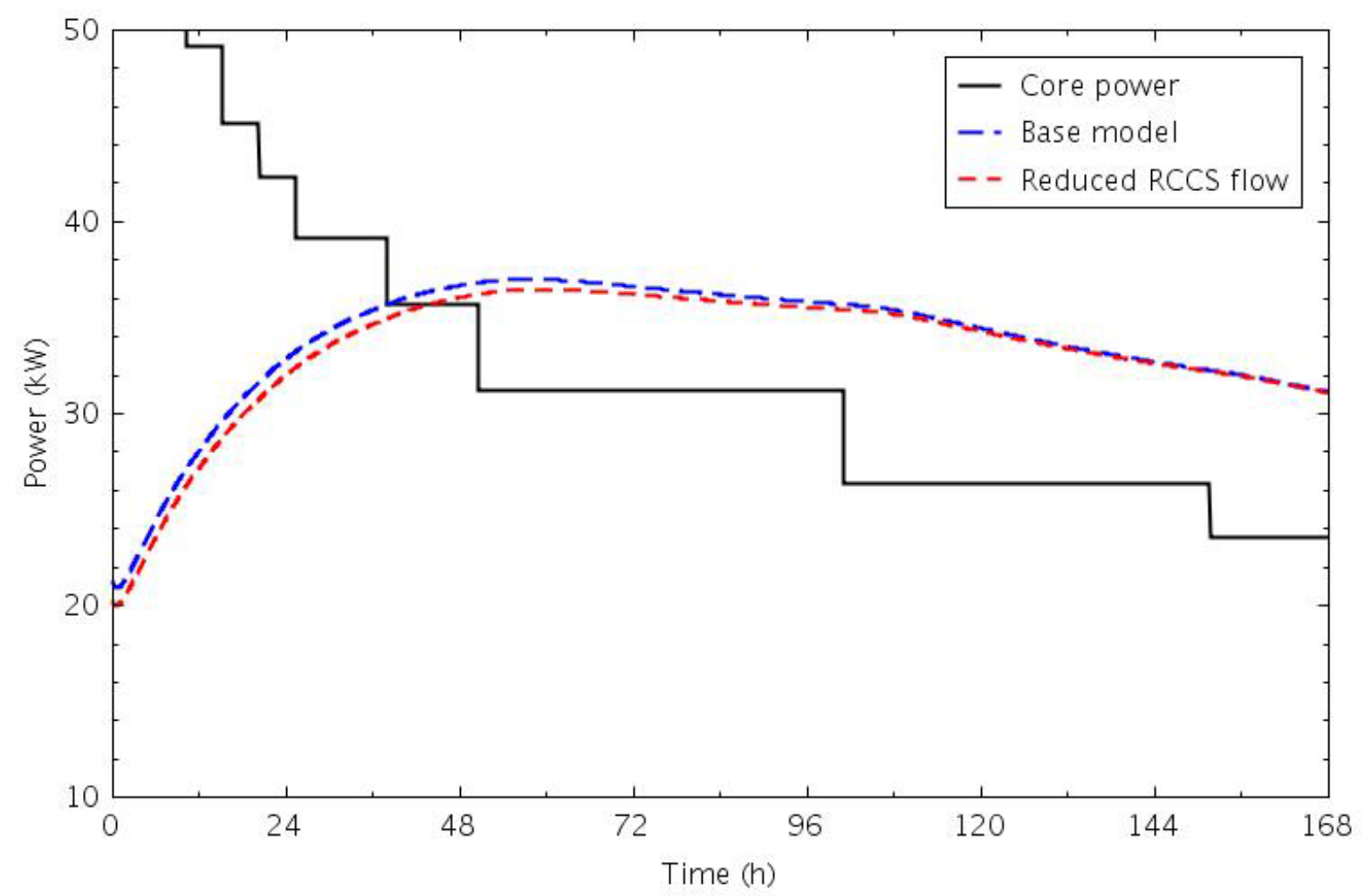

Figure 28. Core power and RCCS heat removal for the Test PG-26 pre-test calculation base and reduced RCCS flow cases.

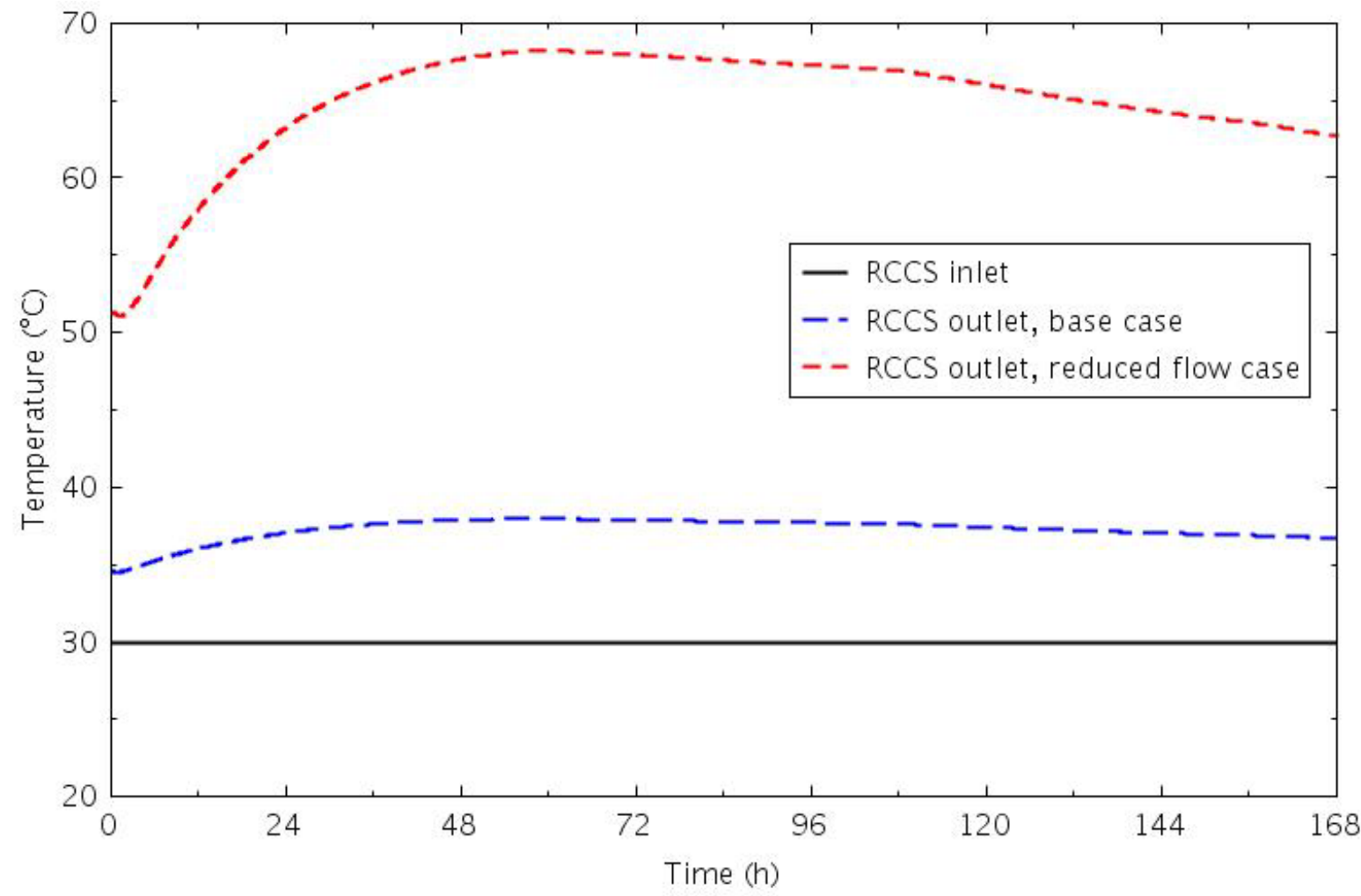

Figure 29. RCCS panel coolant inlet and outlet temperatures for the Test PG-26 pre-test calculation base and reduced RCCS flow cases. 


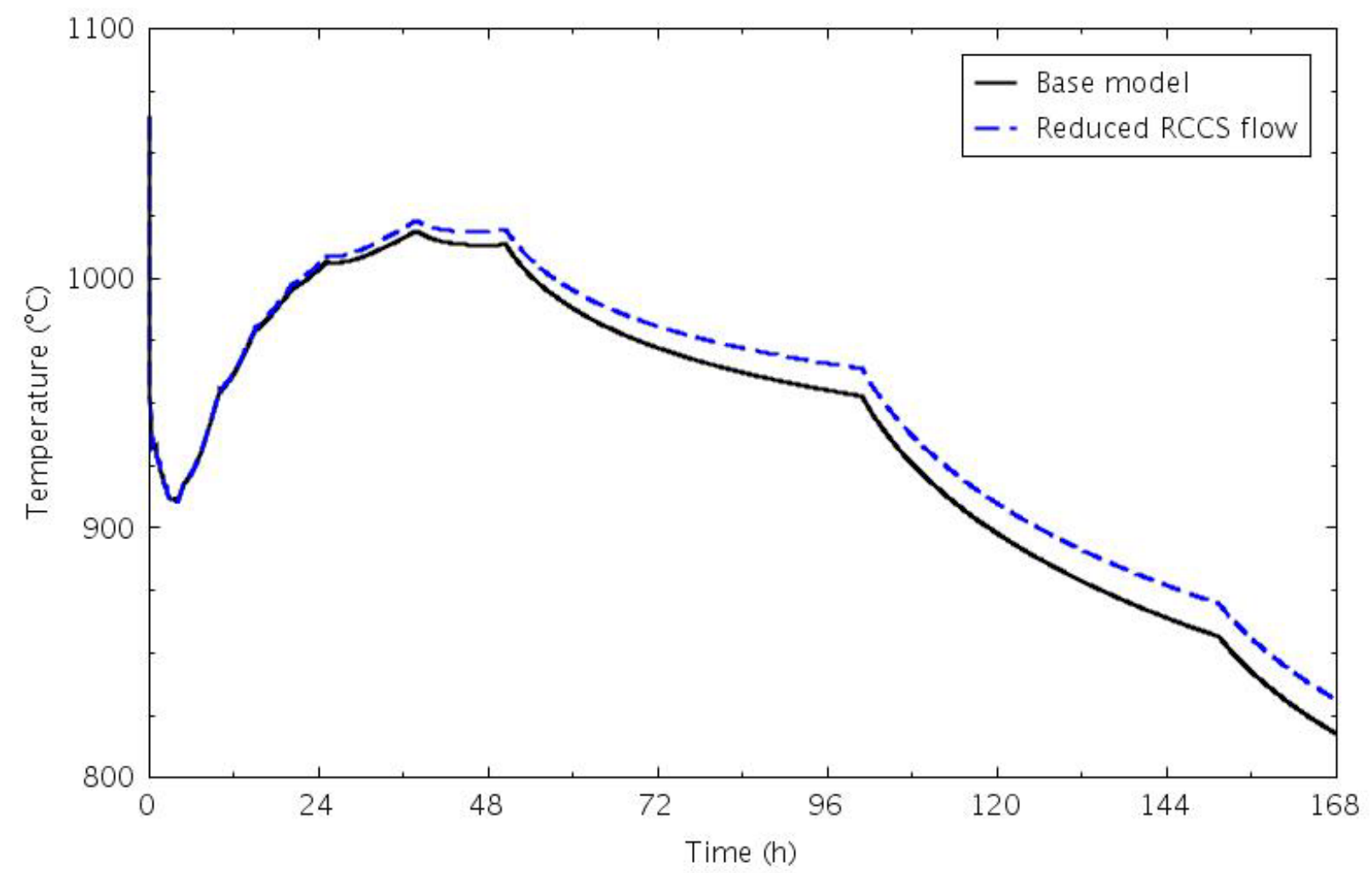

Figure 30. Peak heater rod temperatures for the Test PG-26 pre-test calculation base and reduced RCCS flow cases.

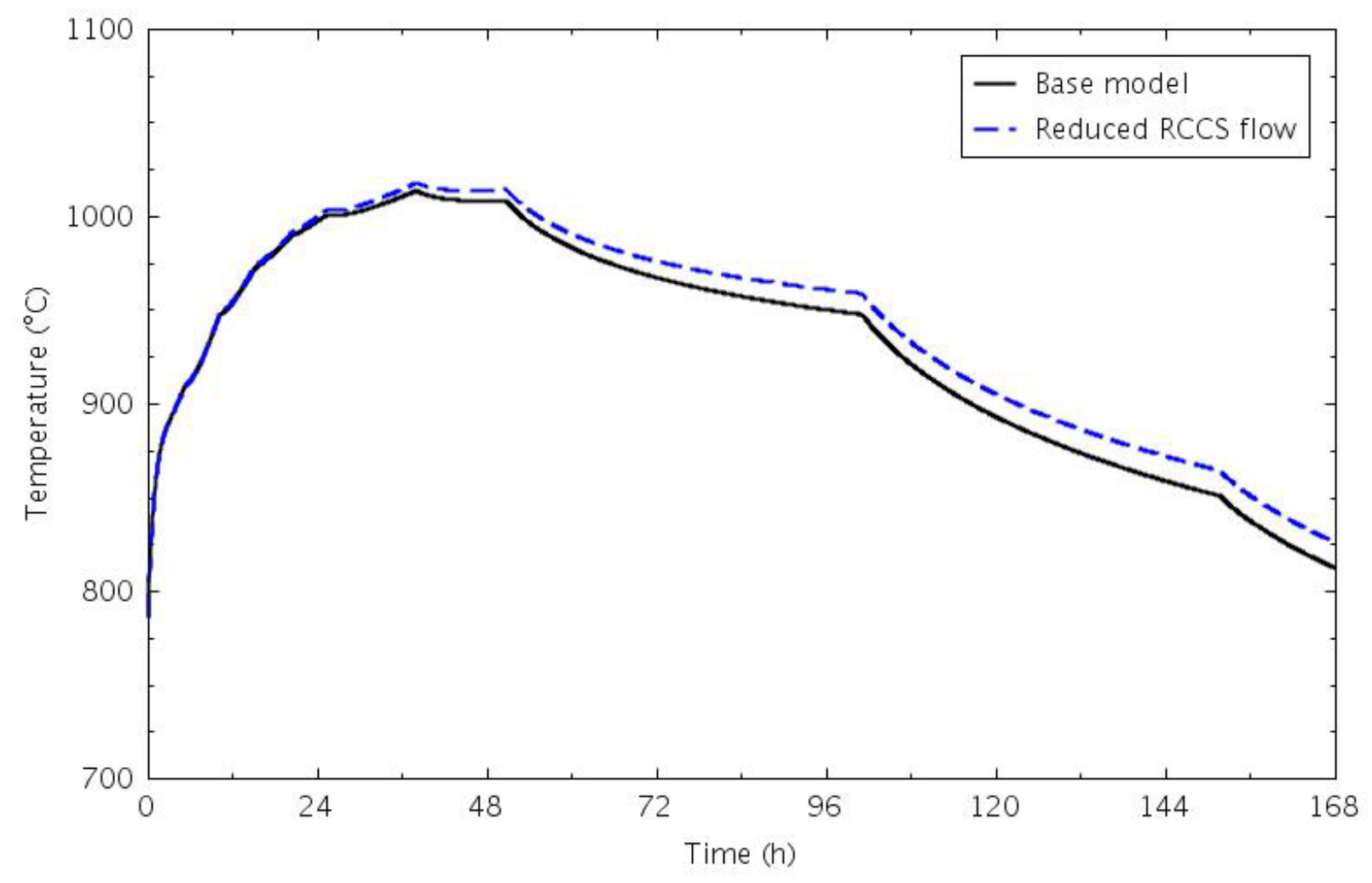

Figure 31. Peak inner core ring ceramic temperatures for the Test PG-26 pre-test calculation base and reduced RCCS flow cases. 


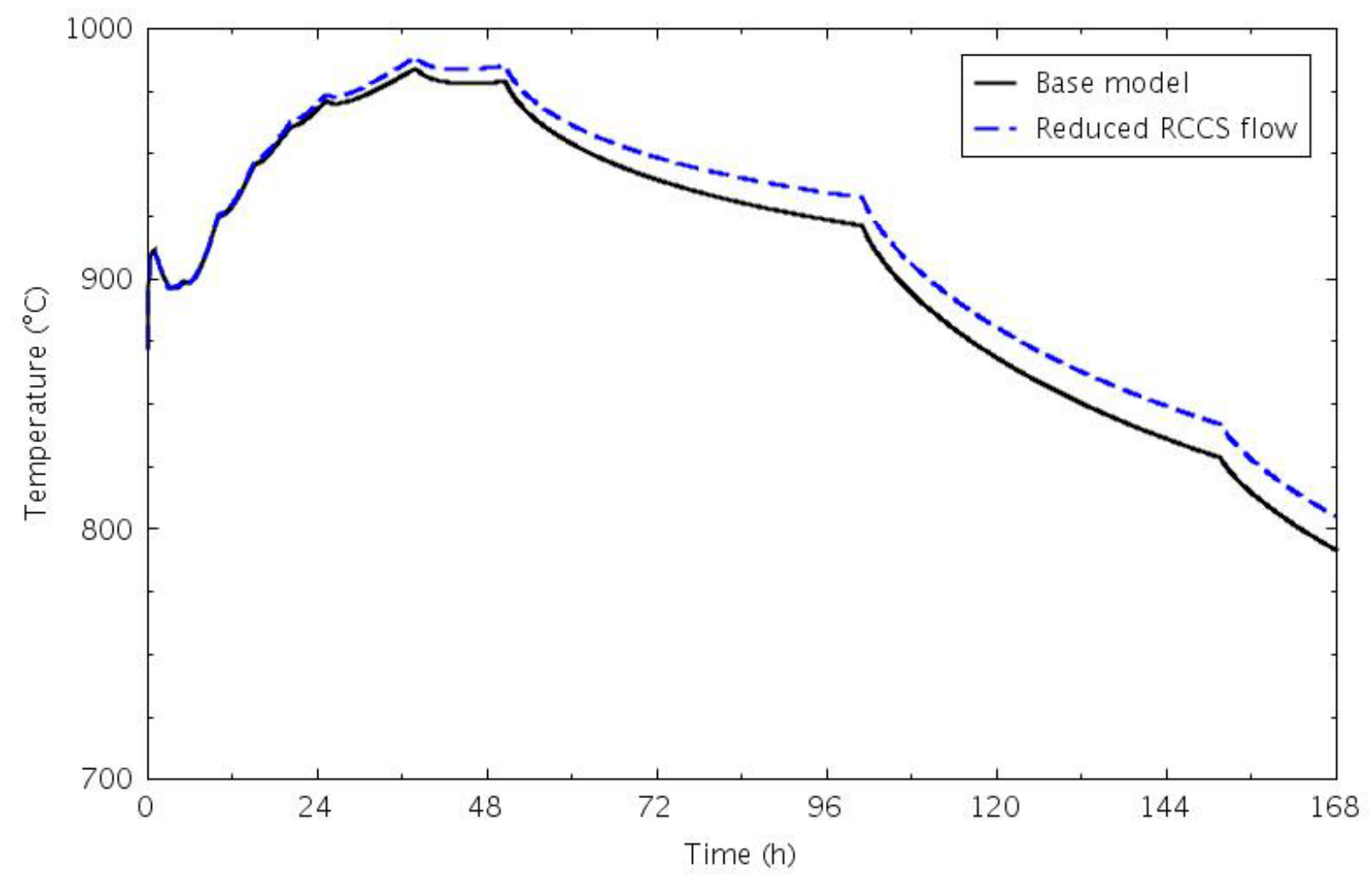

Figure 32. Peak middle core ring ceramic temperatures for the Test PG-26 pre-test calculation base and reduced RCCS flow cases.

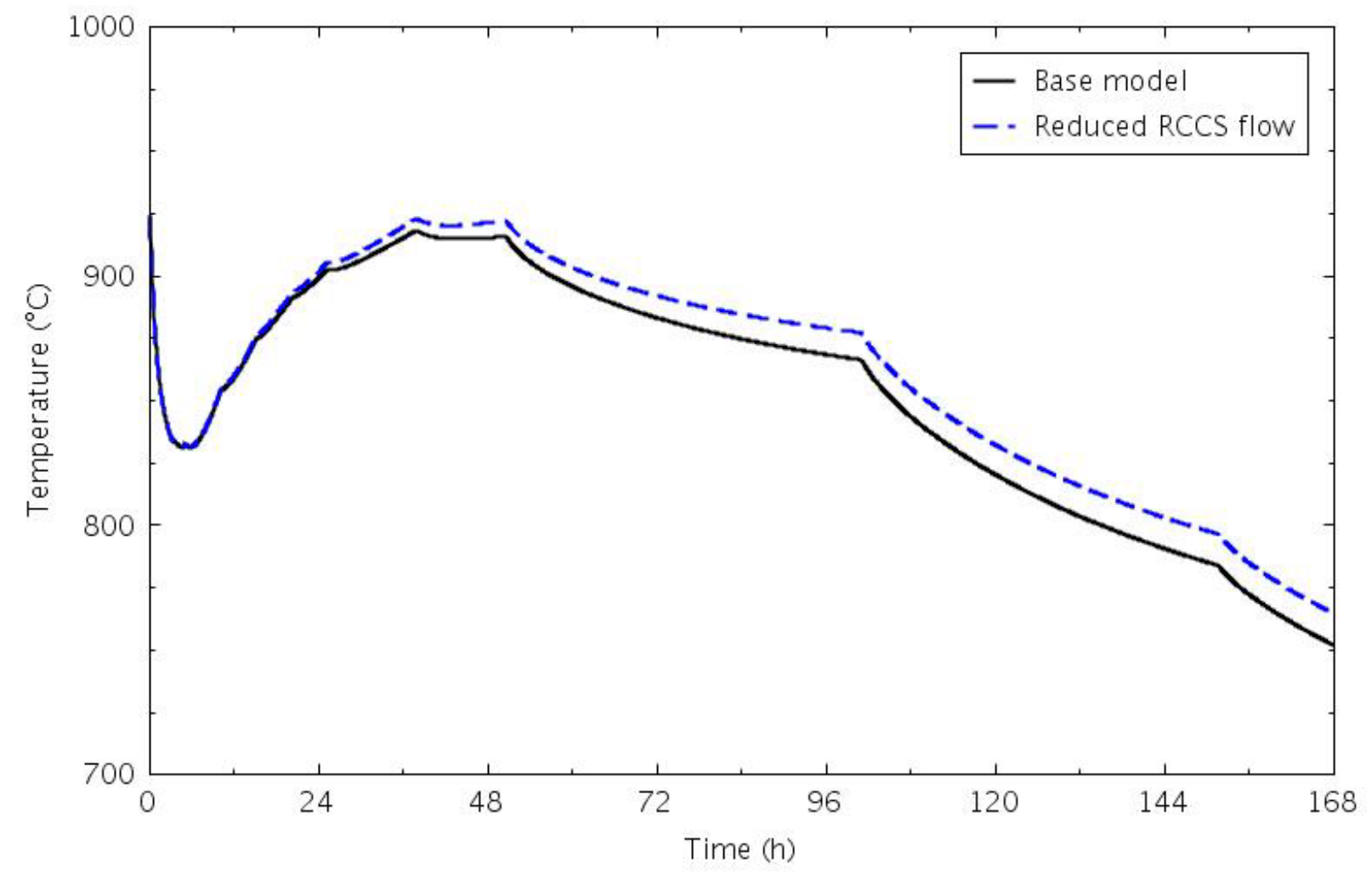

Figure 33. Peak outer core ring ceramic temperatures for the Test PG-26 pre-test calculation base and reduced RCCS flow cases. 


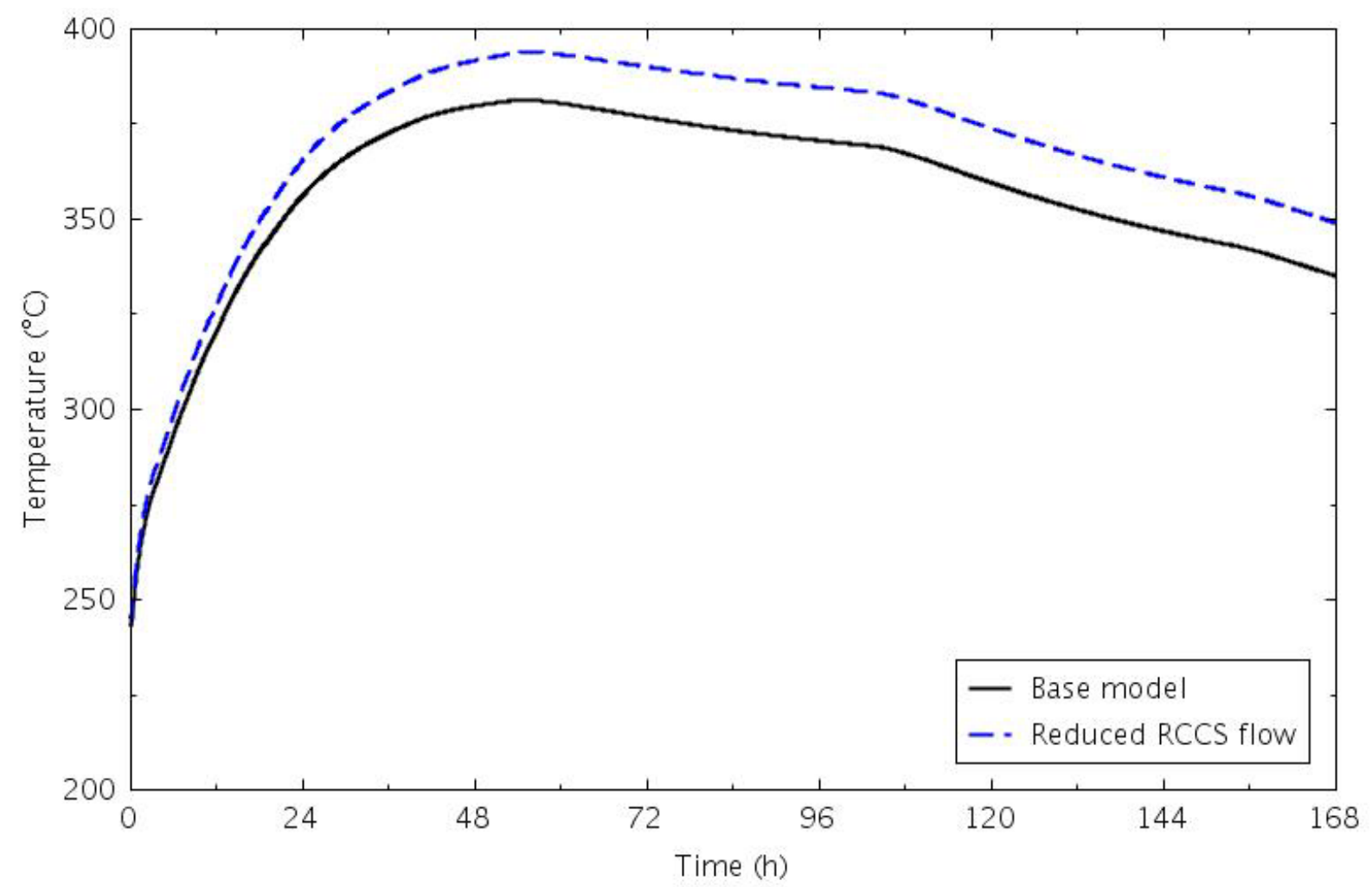

Figure 34. Peak pressure vessel wall temperatures for the Test PG-26 pre-test calculation base and reduced RCCS flow cases.

\subsubsection{RCCS Temperature}

Since the temperature at the RCCS inlet will likely vary during the test, a sensitivity calculation was run with a constant RCCS inlet temperature of $60^{\circ} \mathrm{C}$, rather than the base case value of $30^{\circ} \mathrm{C}$; a steadystate calculation was also run with this increased temperature. As with the lower flow rate of the previous sensitivity calculation, this case will result in higher temperatures in the RCCS panels, which will reduce the heat transfer from the pressure vessel.

Figure 35 presents the RCCS panel inlet and outlet coolant temperatures. The peak increase in the outlet temperature during the transient was $3.8^{\circ} \mathrm{C}$ in the sensitivity case, compared to $3.4^{\circ} \mathrm{C}$ in the base case; that maximum temperature also occurred 2 hours later. Heat removal by the RCCS is compared in Figure 36. As expected, the higher coolant inlet temperature resulted in less heat removal from the PCS.

The impact of the reduced heat removal on the peak heater rod temperatures is shown in Figure 36. The peak temperature at 37.8 hours increased $10^{\circ} \mathrm{C}$, and the second peak at 50.5 hours is only $2^{\circ} \mathrm{C}$ lower than the first peak in the increased RCCS temperature case. The temperature difference between the two cases continues to increase as the transient progresses.

Similar behavior is observed in the peak core ceramic temperatures, presented in Figures 37-39. There was almost no difference in the value or timing of the temperature peaks. Slightly higher temperatures were predicted later in the transient, with the effect diminishing closer to the center of the vessel.

Figure 40 shows the effect on the primary pressure vessel wall temperature. The peak temperature of $403^{\circ} \mathrm{C}$ in the sensitivity case is $12^{\circ} \mathrm{C}$ higher than in the base case, and it occurs an hour later. 


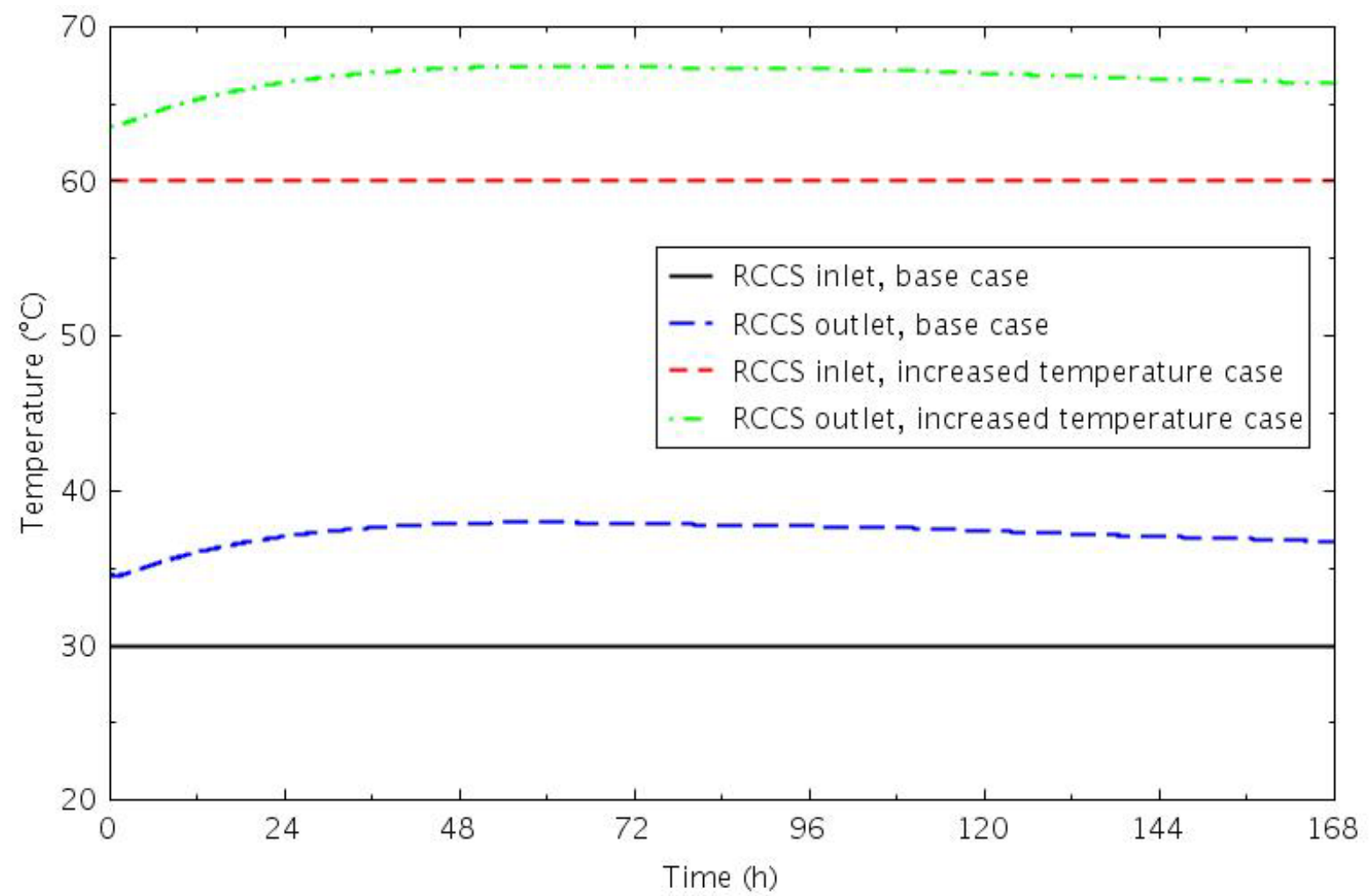

Figure 35. RCCS panel inlet and outlet coolant temperatures for the Test PG-26 pre-test calculation base and increased RCCS temperature cases.

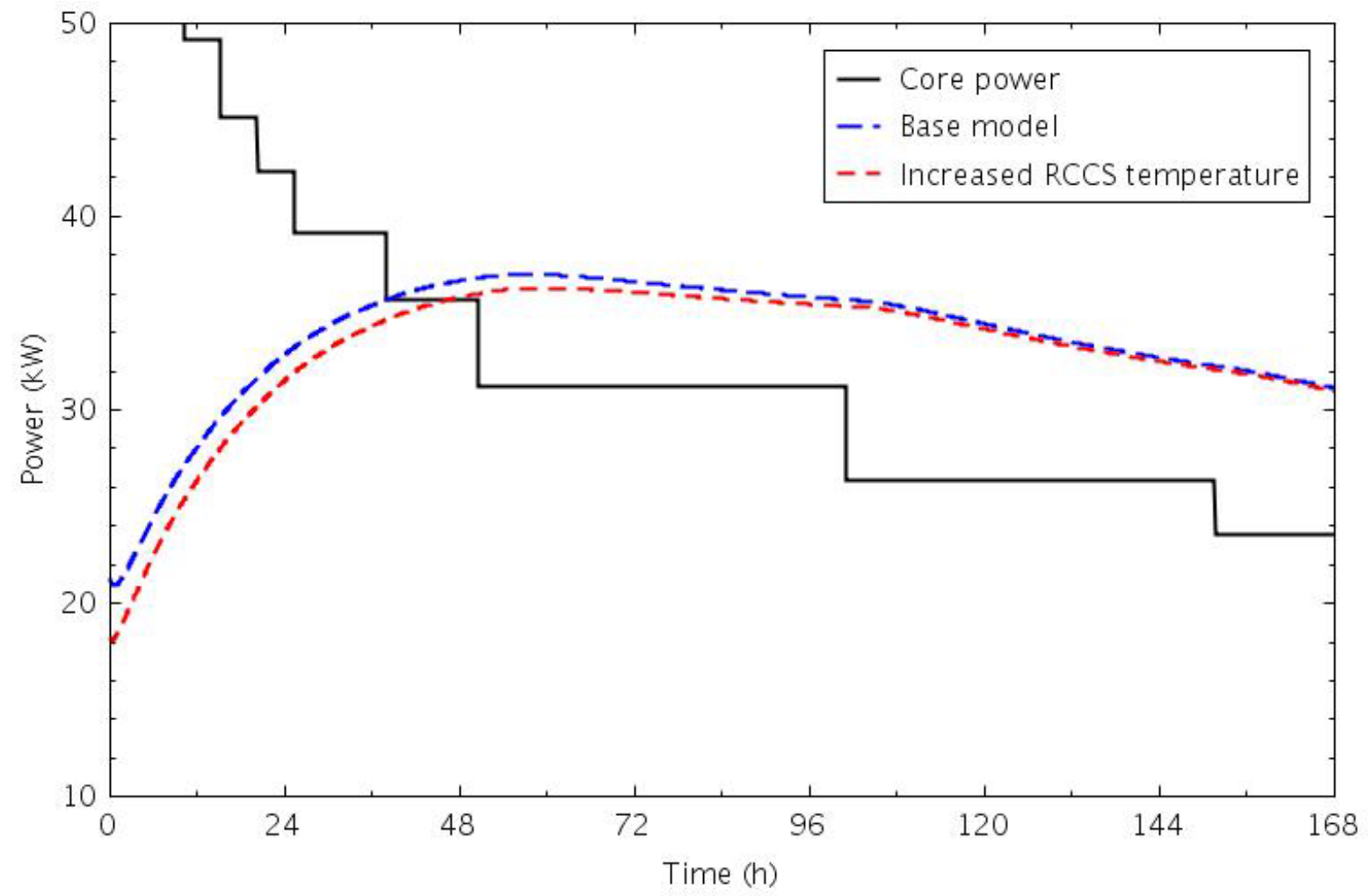

Figure 36. Core power and RCCS heat removal for the Test PG-26 pre-test calculation base and increased RCCS temperature cases. 


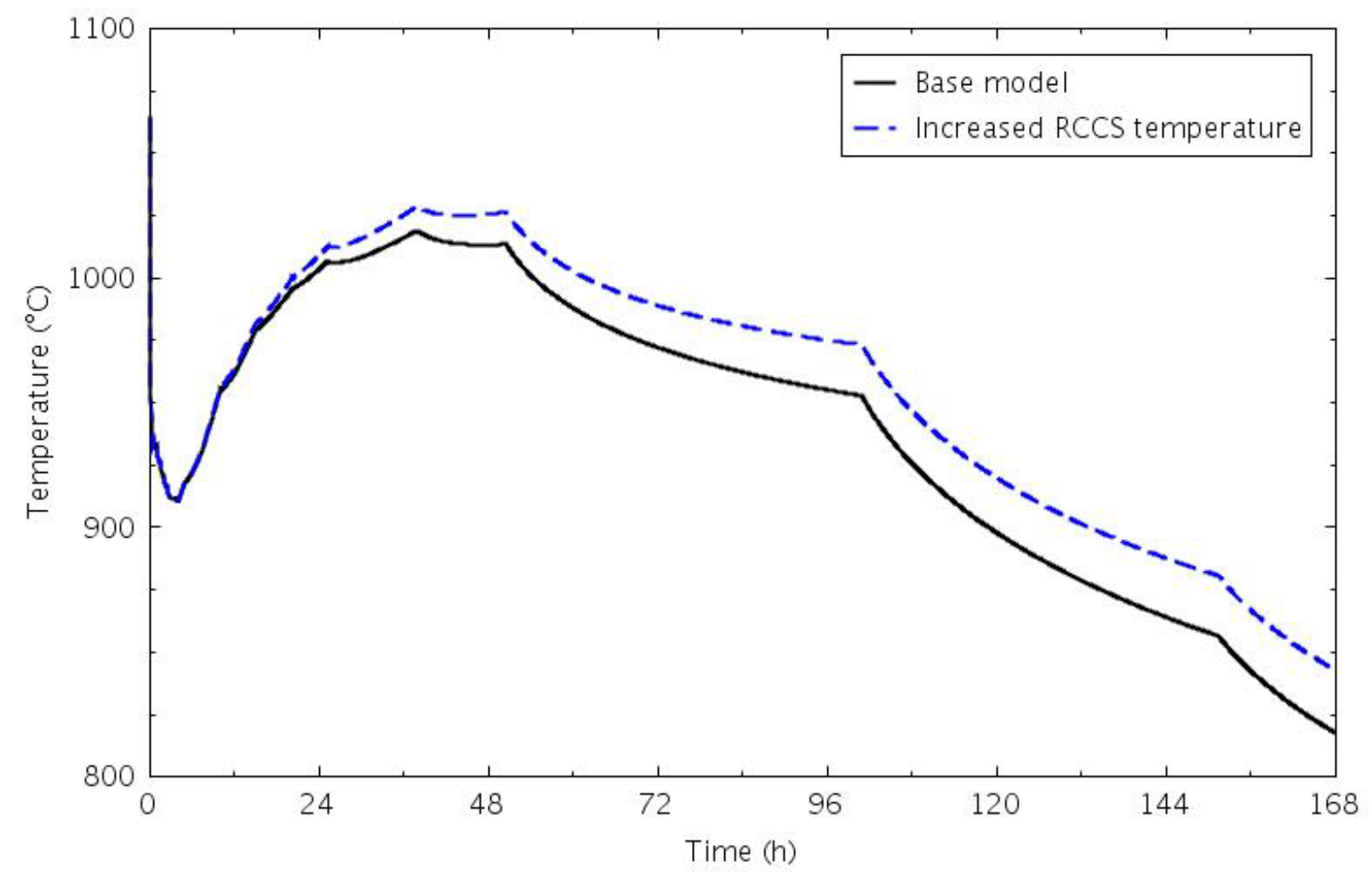

Figure 37. Peak heater rods temperatures for the Test PG-26 pre-test calculation base and increased RCCS temperature cases.

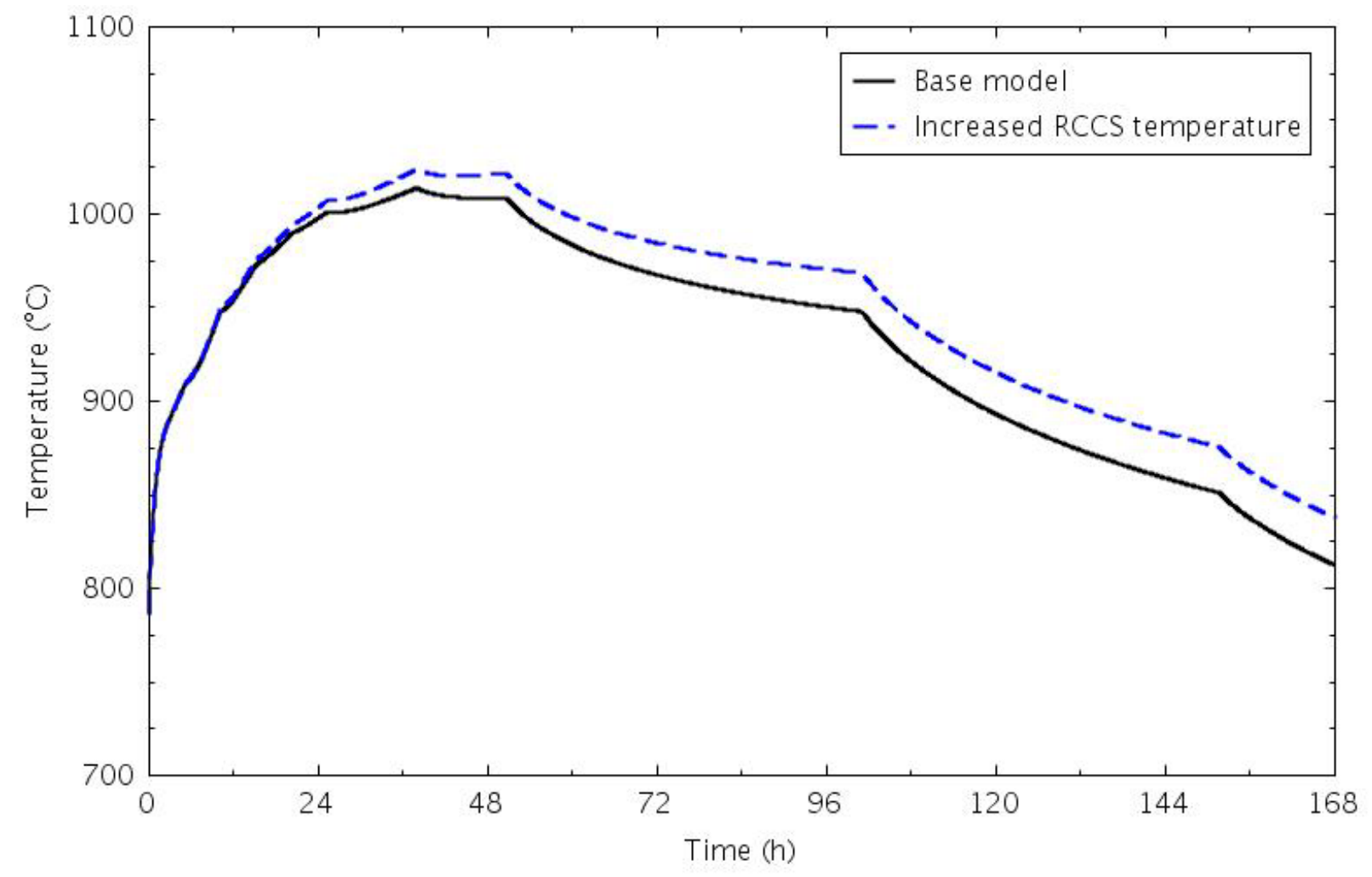

Figure 38. Peak inner core ring ceramic temperature for the Test PG-26 pre-test calculation base and increased RCCS temperature cases. 


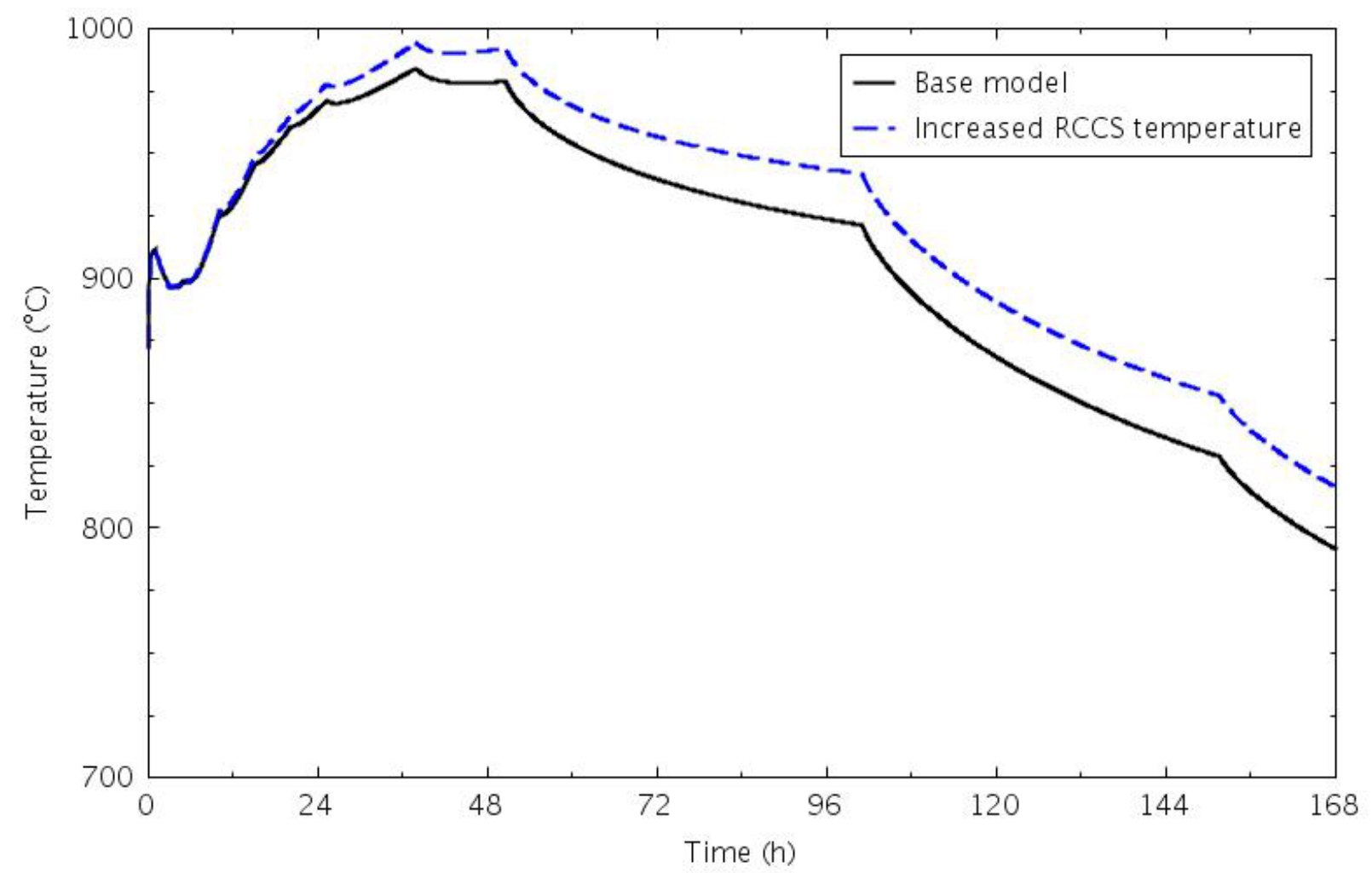

Figure 39. Peak middle core ring ceramic temperatures for the Test PG-26 pre-test calculation base and increased RCCS temperature cases.

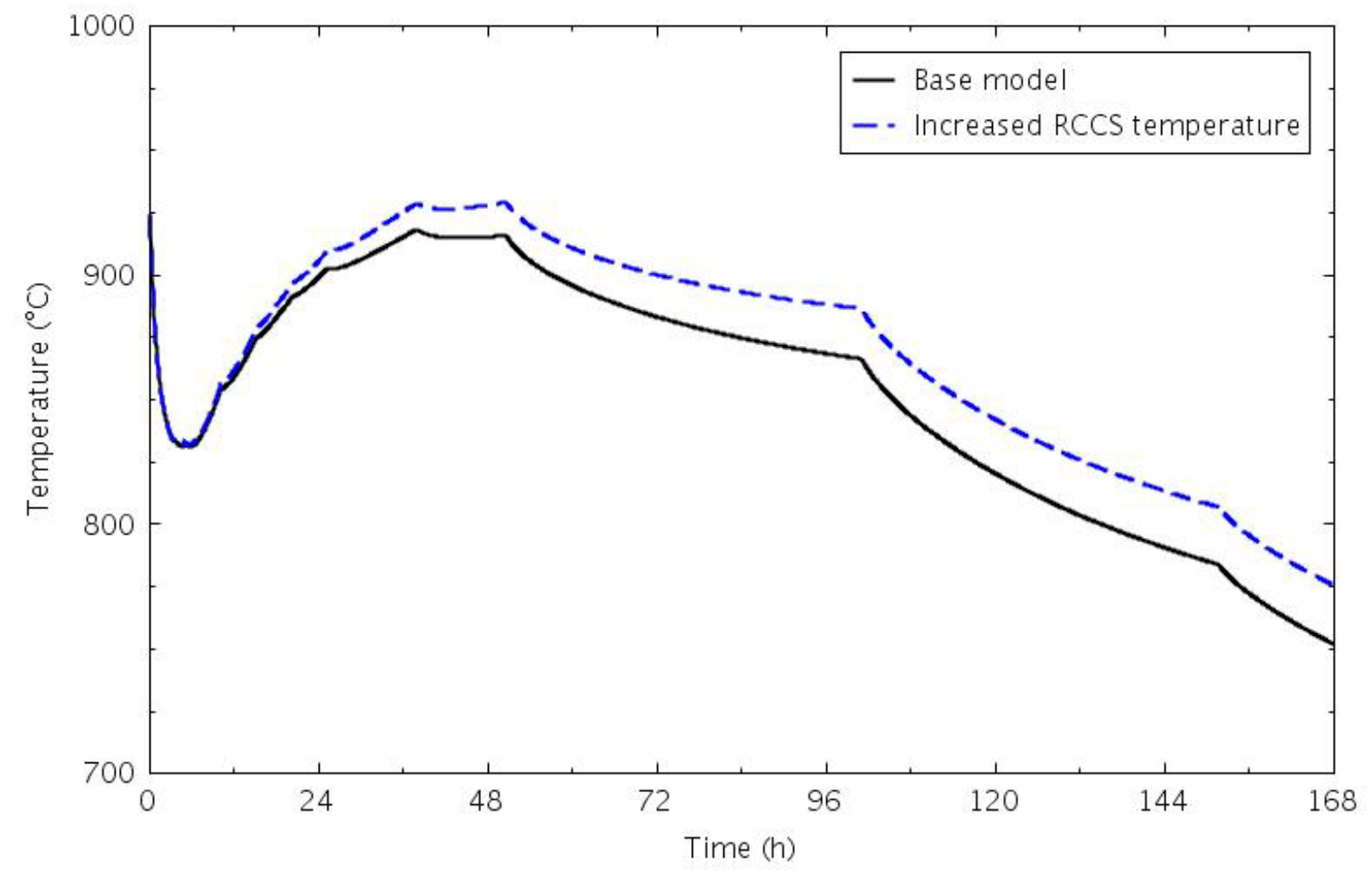

Figure 40. Peak outer core ring ceramic temperatures for the Test PG-26 pre-test calculation base and increased RCCS temperature cases. 


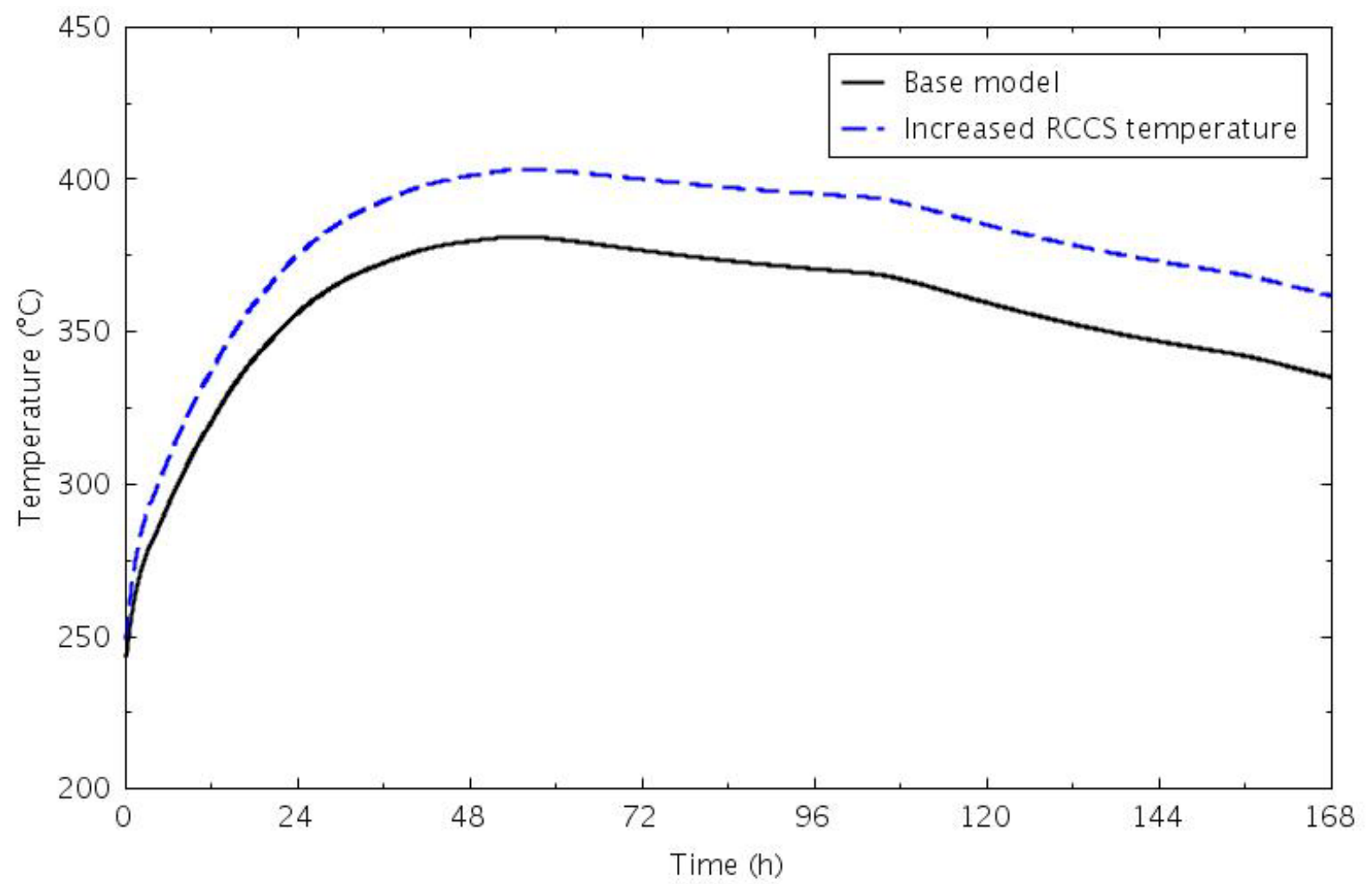

Figure 41. Peak pressure vessel wall temperature for the Test PG-26 pre-test calculation base and increased RCCS temperature cases.

\subsubsection{Decay Power}

The base case calculation modeled the scaled decay power through the full simulation time. However, there is a question about how well the heaters can be controlled at low power. Sensitivity calculations were therefore performed that investigated two options for terminating decay power input to the heaters, assuming that the heater bank power cannot be accurately controlled below $20 \mathrm{~kW}$ and that heater banks will be operated in pairs to maintain core symmetry. In the first case, the power was terminated when the total decay power dropped below $80 \mathrm{~kW}(20 \mathrm{~kW}$ per heater bank). In the second case, when the total decay power dropped below $80 \mathrm{~kW}$, two of the heater banks were turned off, and their scaled power was transferred to the remaining two heaters, which were then turned off when the decay power dropped below $40 \mathrm{~kW}$. Figure 42 shows the power for the various cases.

\subsubsection{80-kW Case}

The overall scaled decay power dropped below $80 \mathrm{~kW}$ shortly after 2 hours, so that all of the power to the heater rods was turned off at $7273 \mathrm{~s}$. The early power cutoff led to a rather benign transient.

Coolant velocities at the top of the five core flow channels are presented in Figure 43. The final flow pattern is the same as in the base case (see Figure 9), with flow upward in the inner three channels and downward in the outer two, but that pattern is established more quickly, and the velocities are lower, except in the central reflector. The velocities are also decreasing after the final flow pattern is established, while they remained fairly steady in the base case calculation.

Figure 43 shows the peak heater rod temperatures for the base and $80-\mathrm{kW}$ power cases. The peak temperature drops immediately and continuously after the power is turned off, with no subsequent heatup. Similar behavior is observed in the peak ceramic temperatures in the three core rings, shown in Figures 44-46. 


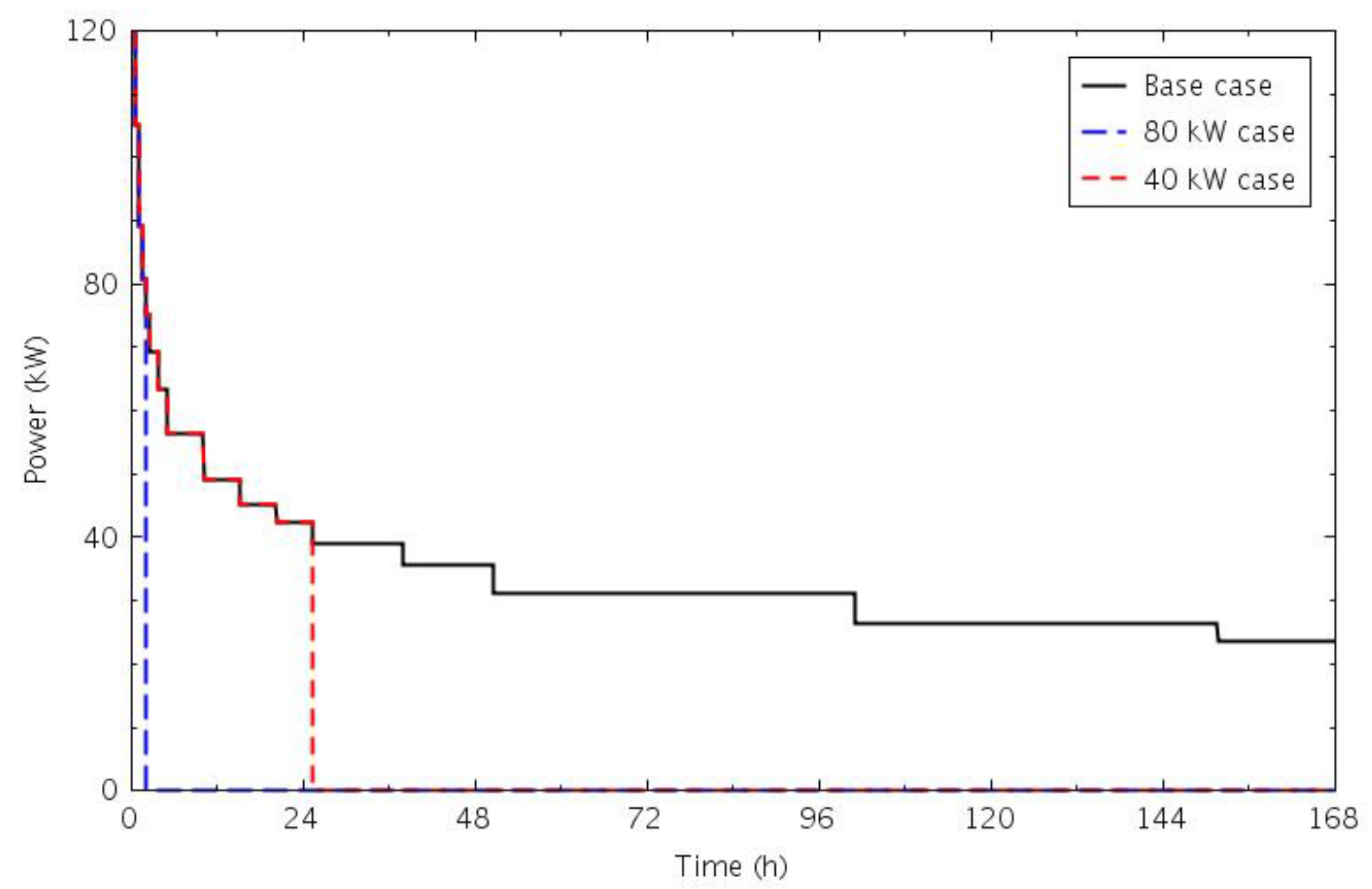

Figure 42. Core power for the Test PG-26 pre-test calculation base and decay power cases.

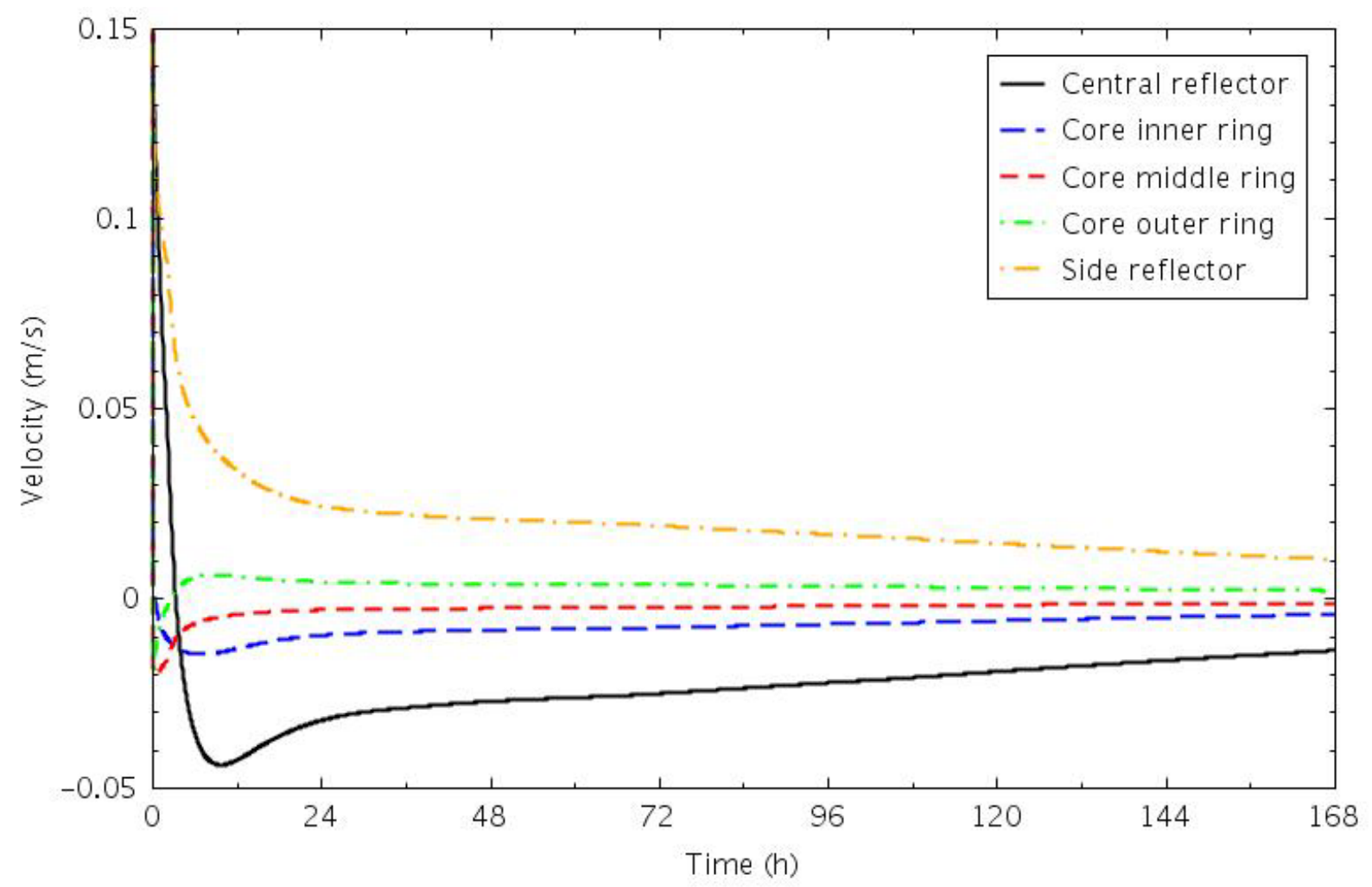

Figure 43. Coolant velocities at the top of the upper reflector for the Test PG-26 pre-test calculation 80$\mathrm{kW}$ power case. 


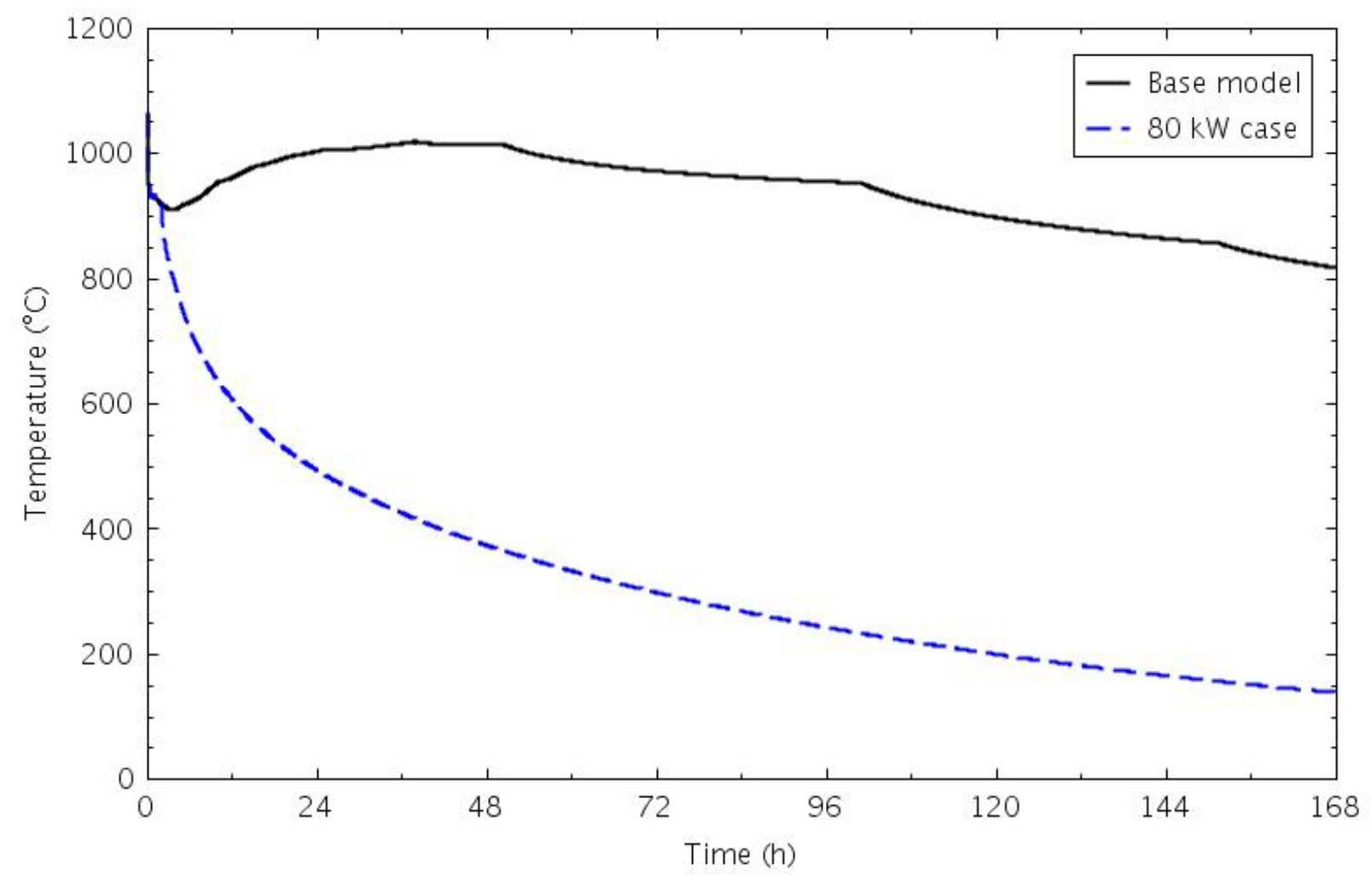

Figure 44. Peak heater rod temperatures for the Test PG-26 pre-test calculation base and $80-\mathrm{kW}$ power cases.

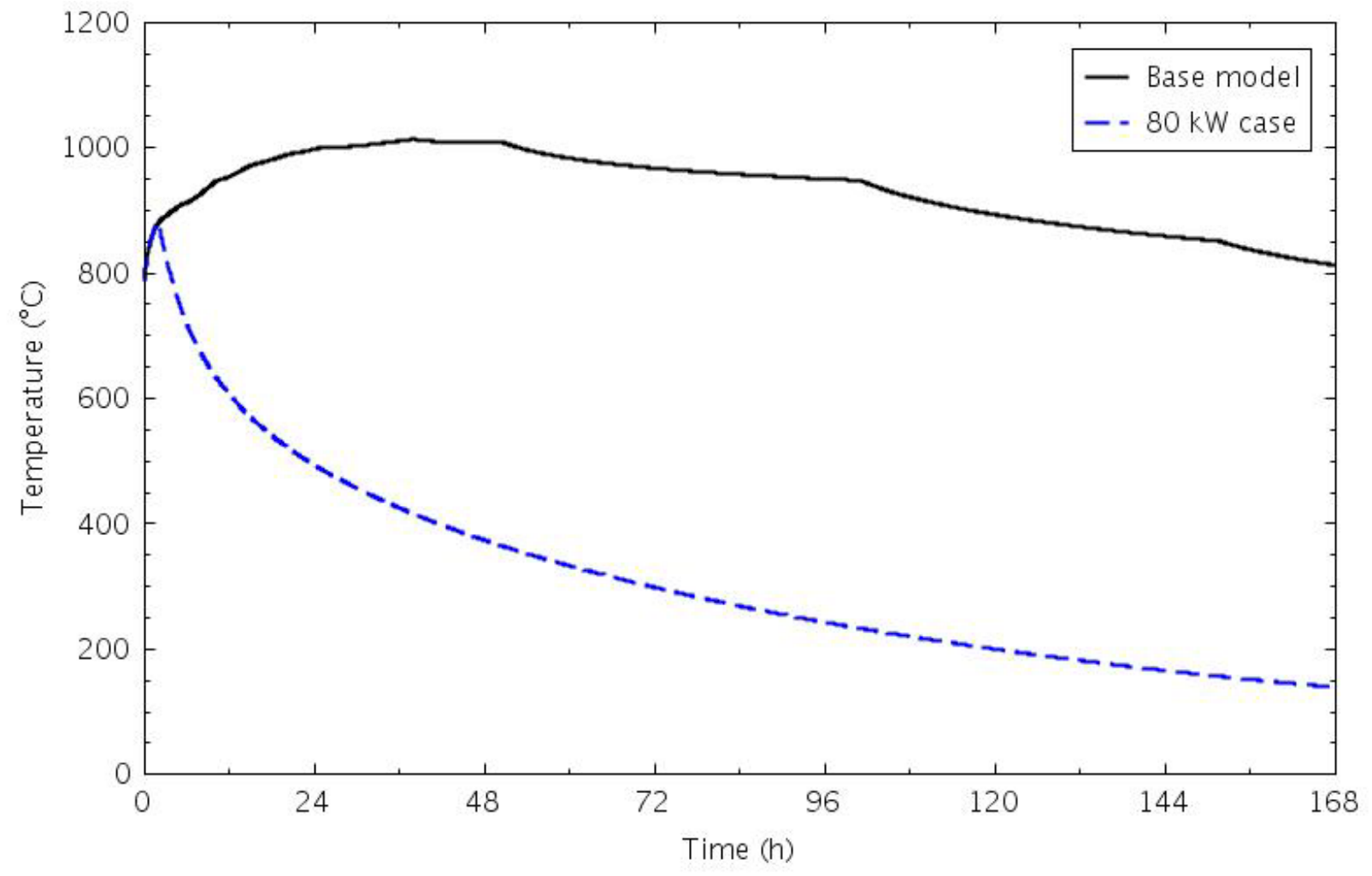

Figure 45. Peak inner core ring ceramic temperatures for the Test PG-26 pre-test calculation base and 80$\mathrm{kW}$ cases. 


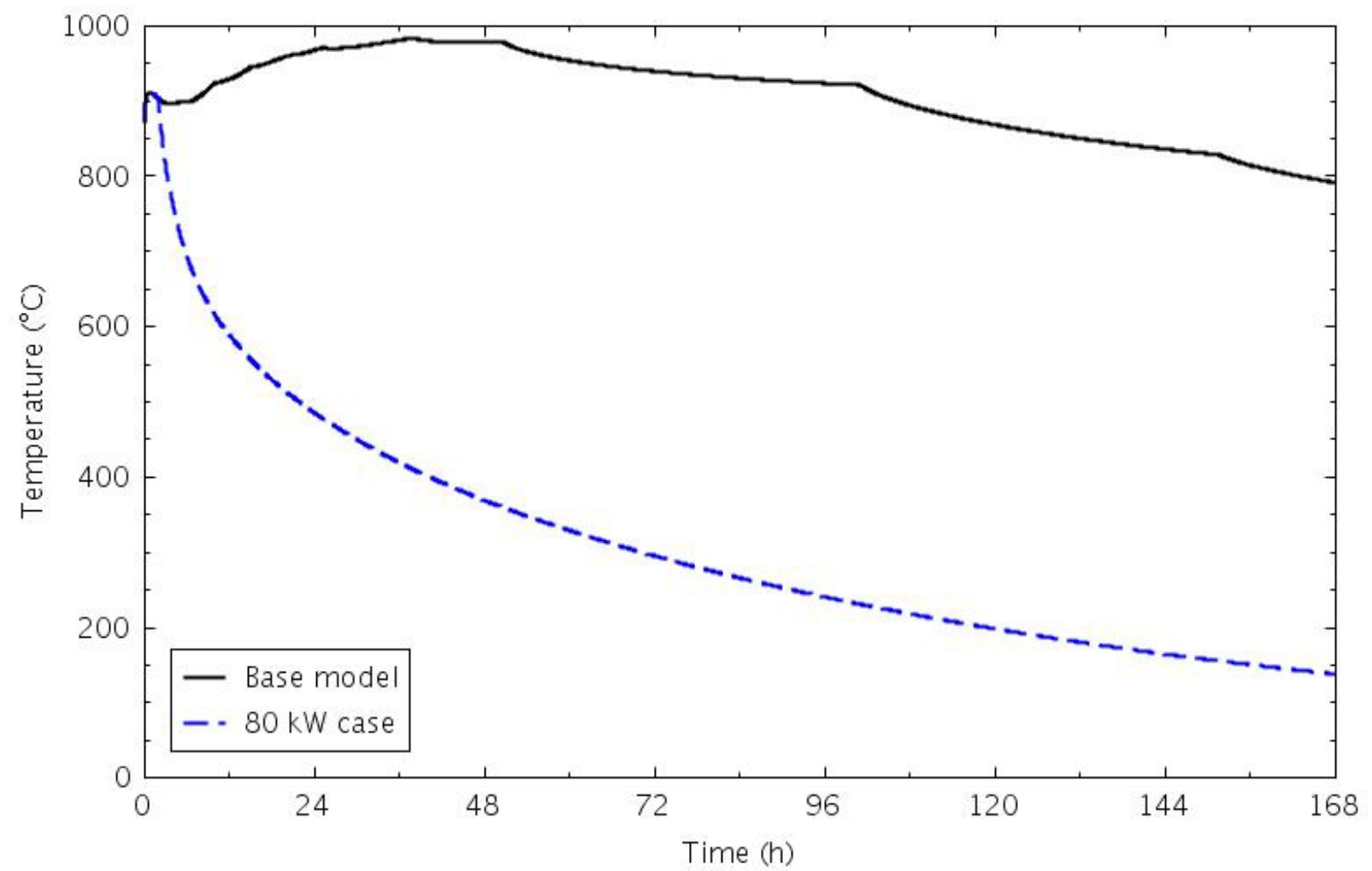

Figure 46. Peak middle core ring ceramic temperatures for the Test PG-26 pre-test calculation base and $80-\mathrm{kW}$ cases.

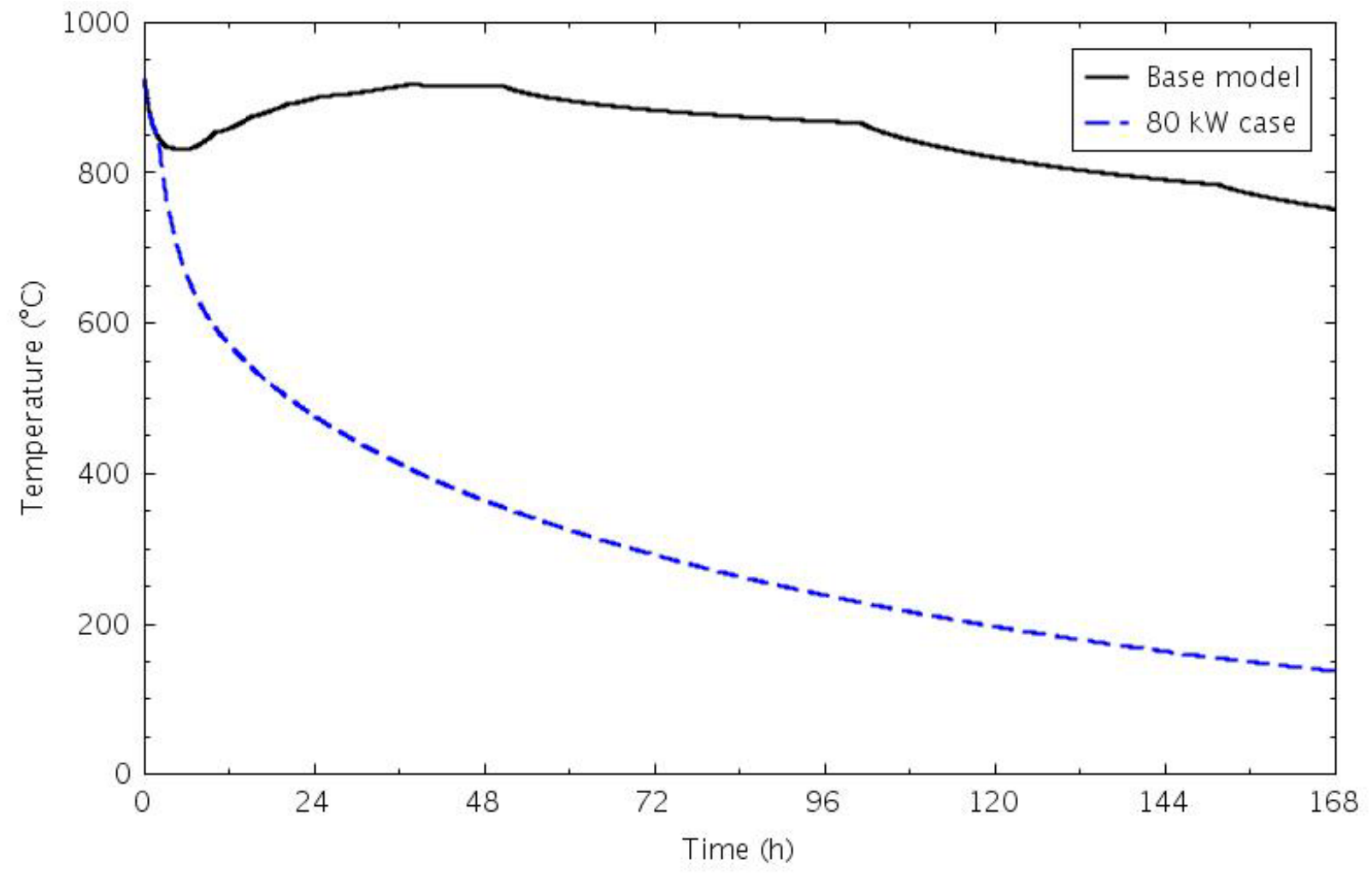

Figure 47. Peak outer core ring ceramic temperatures for the Test PG-26 pre-test calculation base and $80-\mathrm{kW}$ cases. 
Figure 48 presents the peak temperatures in the central and side reflectors. The reflectors continued to heat up for a short time after the power was turned off. Peak temperatures occurred earlier for the rings closest to the core: the central reflector outer ring and the side reflector inner ring.

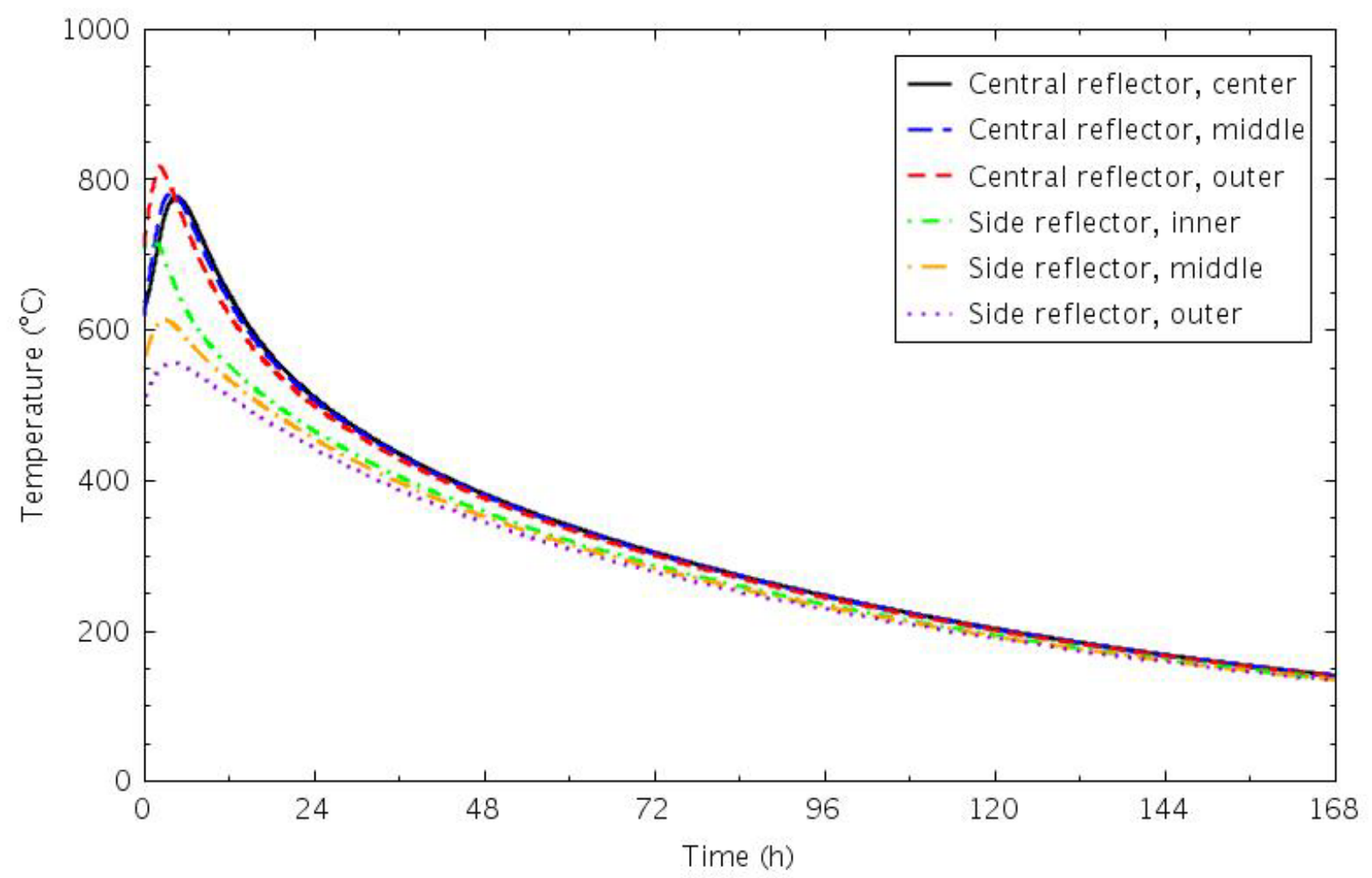

Figure 48. Peak ceramic temperatures in the central and side reflectors for the Test PG-26 pre-test calculation $80-\mathrm{kW}$ case.

The primary pressure vessel wall temperature also continued to heat up after the power was turned off, as seen in Figure 48 . The peak temperature of $294^{\circ} \mathrm{C}$ was reached around 9 hours, 7 hours after the power shutoff, and was $87^{\circ} \mathrm{C}$ lower than in the base case.

Heat removal through the RCCS is compared to the core power in Figure 50. Reflecting the pressure vessel wall temperature, the RCCS heat removal continued to increase for about 7 hours before decreasing through the rest of the transient.

The lack of heatup in most of the system indicates that this approach to accommodating the accuracy of the heater controls is probably not viable. This has assumed that the accuracy of the heater controls is $20 \mathrm{~kW}$, or about $9 \%$ of full power (2200 kW total core power).

\subsubsection{40-kW Cases}

Two calculations were run for this sensitivity, changing which heaters were turned off and left on. For Case A, the remaining decay power from heaters 108 and 109 was transferred to heaters 107 and 110 after 2.02 hours $(7273 \mathrm{~s})$, which allowed those heaters to run until 25.25 hours $(90,909 \mathrm{~s})$. For Case B, the power to heaters 107 and 110 was turned off at 2.02 hours, and heaters 108 and 109 ran until 25.25 hours. In Case A, after the power transfer the power fractions were $42.86 \%$ in the inner core ring, $52.38 \%$ in the middle ring, and $4.76 \%$ in the outer ring. In Case B, the power fractions were $0 \%$ in the inner ring, $14.29 \%$ in the middle ring, and $85.71 \%$ in the outer core ring. 


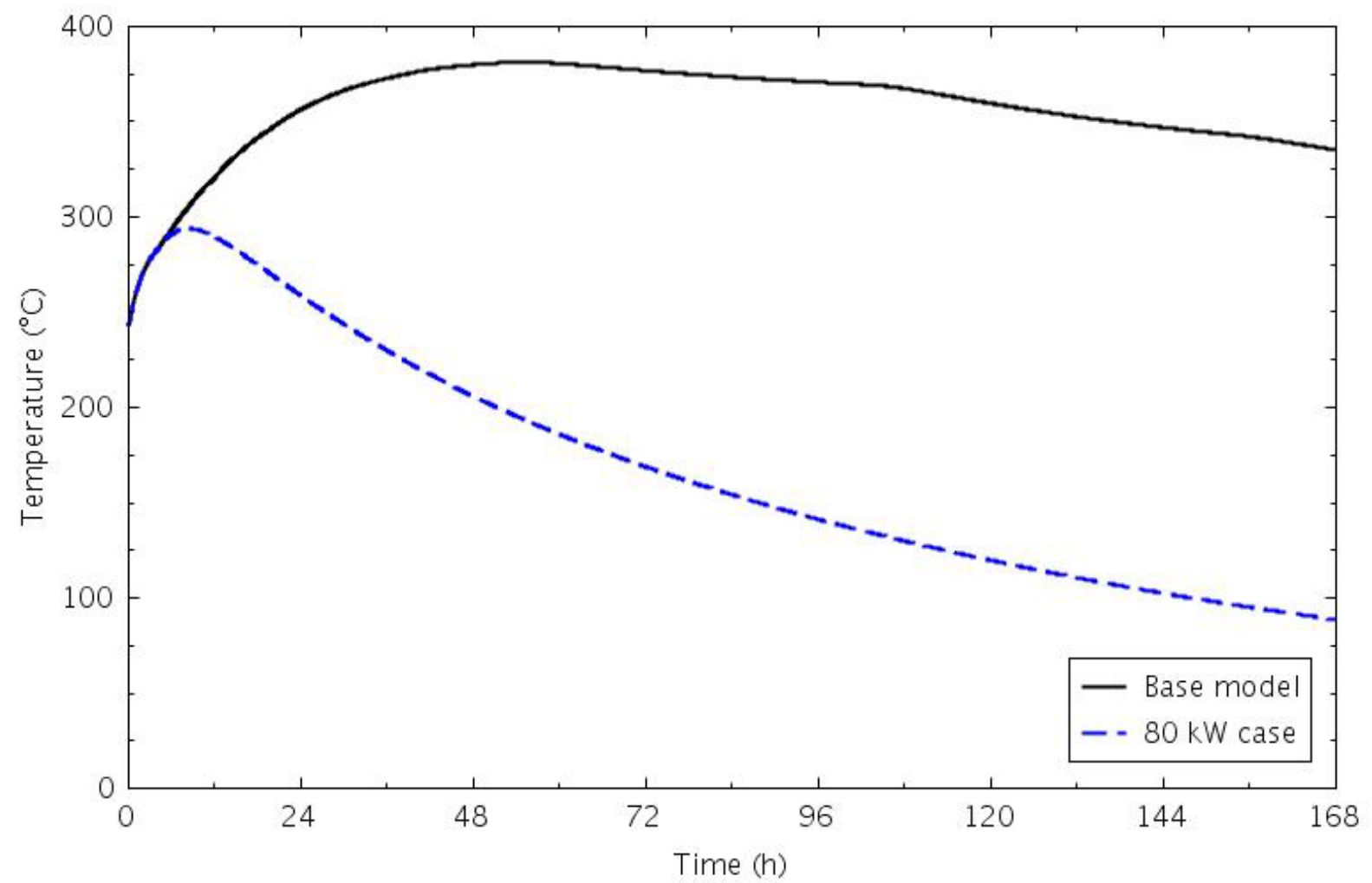

Figure 49. Peak primary pressure vessel wall temperatures for the Test PG-26 pre-test calculation base and $80-\mathrm{kW}$ cases.

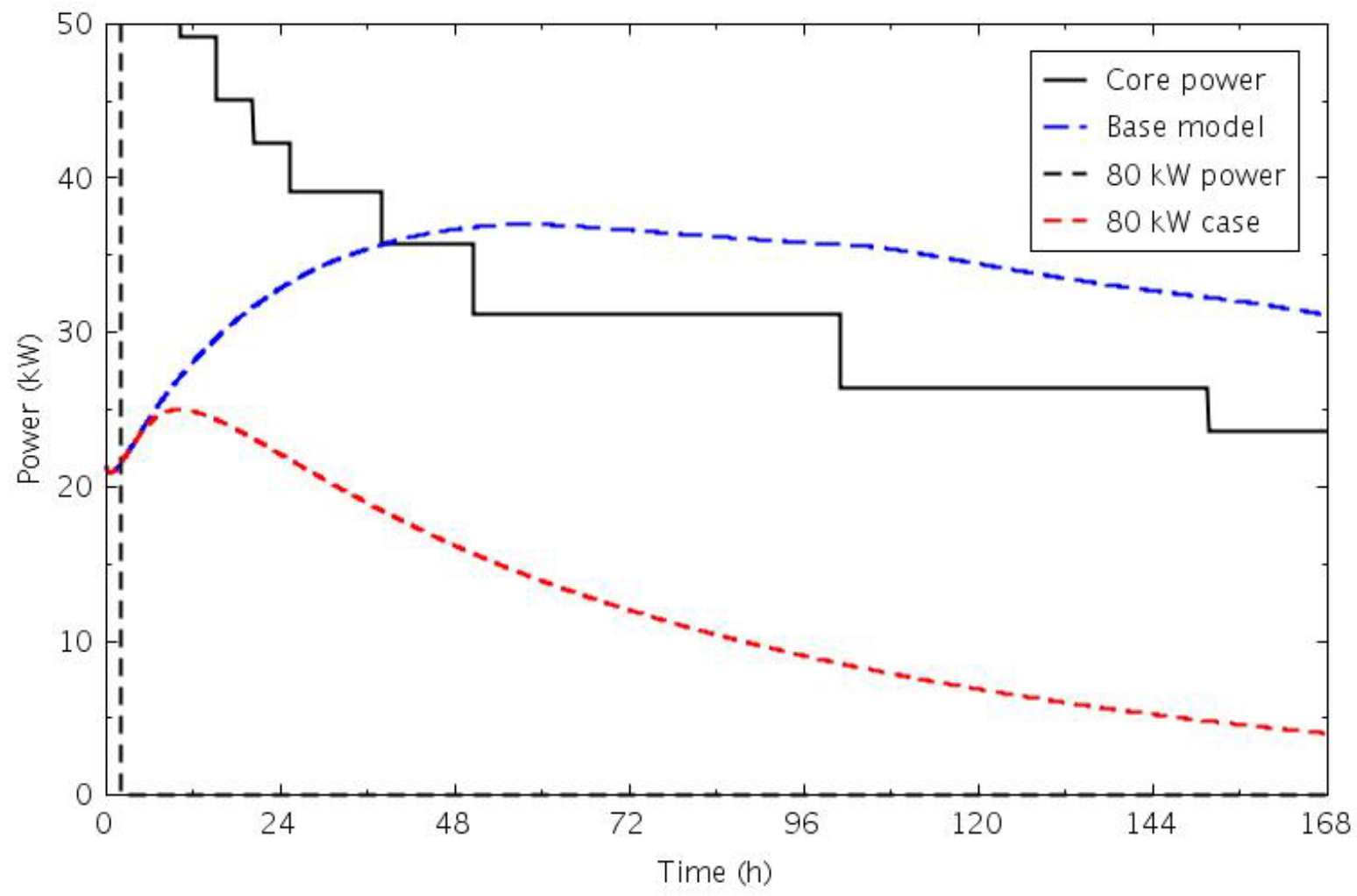

Figure 50. Core power and RCCS heat removal for the Test PG-26 pre-test calculation base and 80-kW cases. 
Maintaining some core power for a longer period should result in a more representative transient response. Figure 51 compares the core power from the $40-\mathrm{kW}$ cases with the base case. When the power was shifted between heater banks shortly after 2 hours, the temperature increased in Case A, while decreasing slightly in Case B. With the power concentrated more toward the center of the core in Case A, there is more resistance to get the heat out through the pressure vessel wall to the RCCS, and thus higher temperatures. The peak temperature of $1103^{\circ} \mathrm{C}$ in Case A was $37^{\circ} \mathrm{C}$ higher than the steady-state temperature and $84^{\circ} \mathrm{C}$ higher than the base case. In Case B, there was a slower increase than in the base case, reaching a peak temperature of $945^{\circ} \mathrm{C}$ before the power was turned off.

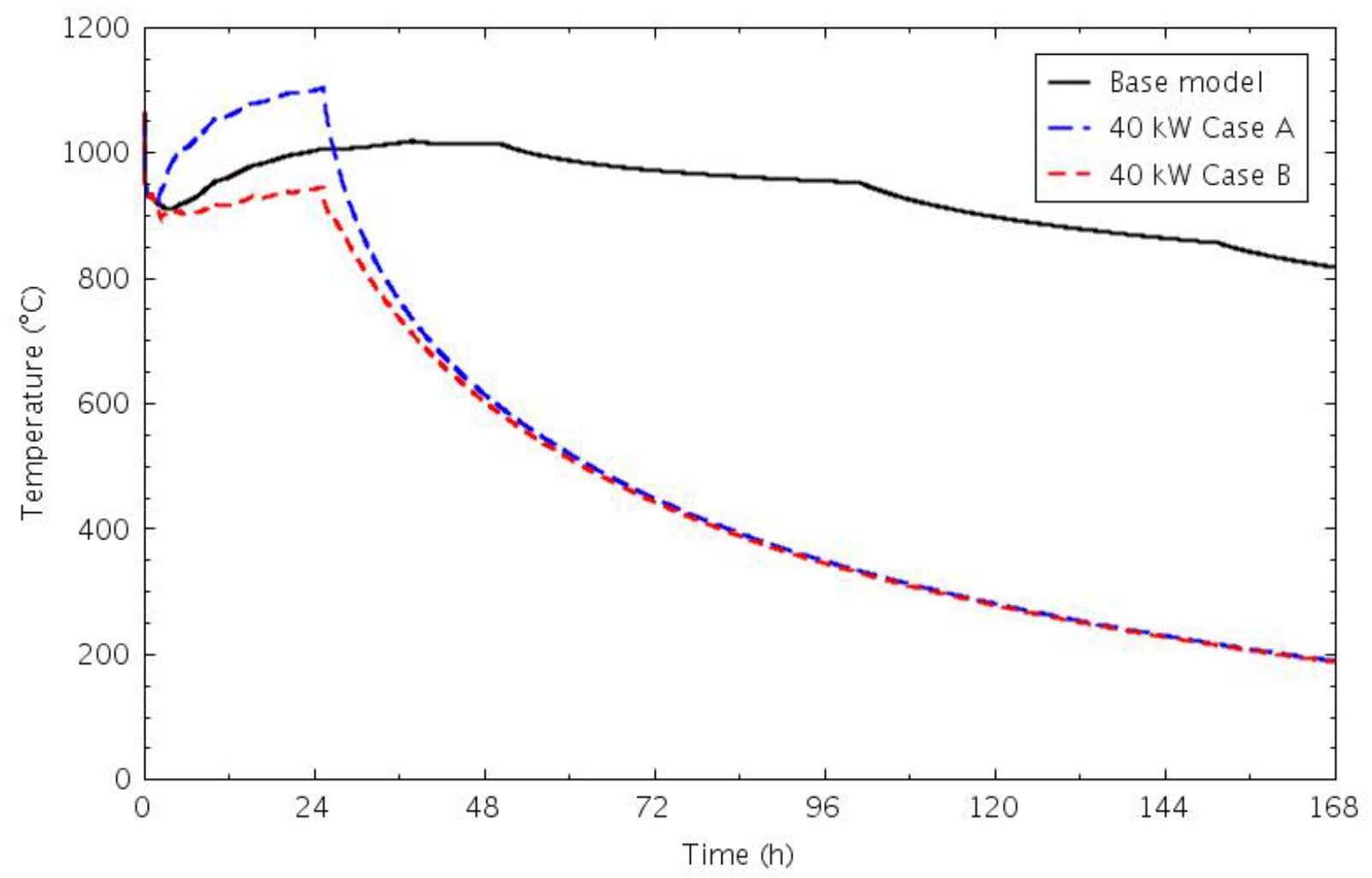

Figure 51. Peak heater rod temperatures for the Test PG-26 pre-test calculation base case and 40-kW Cases A and B.

Peak ceramic temperatures in the inner core ring are presented in Figure 52. As for the peak heater rod temperature, the temperature increased rapidly in Case $\mathrm{A}$, while decreasing in Case $\mathrm{B}$. The peak temperature of $1093^{\circ} \mathrm{C}$ was $79^{\circ} \mathrm{C}$ higher than in the base case, and was the highest ceramic temperature calculated in all of the cases. A similar response was calculated for the middle core ring, as shown in Figure 53. The difference between Cases A and B is not as pronounced as in the inner ring because the power difference is smaller in the middle ring. The peak temperature in Case A was $31^{\circ} \mathrm{C}$ higher than the base case.

Peak ceramic temperatures in the outer core ring, presented in Figure 54, were higher in Case B than in Case A. The peak transient temperature was $9^{\circ} \mathrm{C}$ higher than the base case, and was only $3^{\circ} \mathrm{C}$ higher than the steady-state value.

Figure 55 shows the peak pressure vessel wall temperatures. The Case B temperatures were higher than Case A before the power was turned off because of the increased power closer to the pressure vessel wall. The base case peak temperature was higher than either of the sensitivity calculations. 


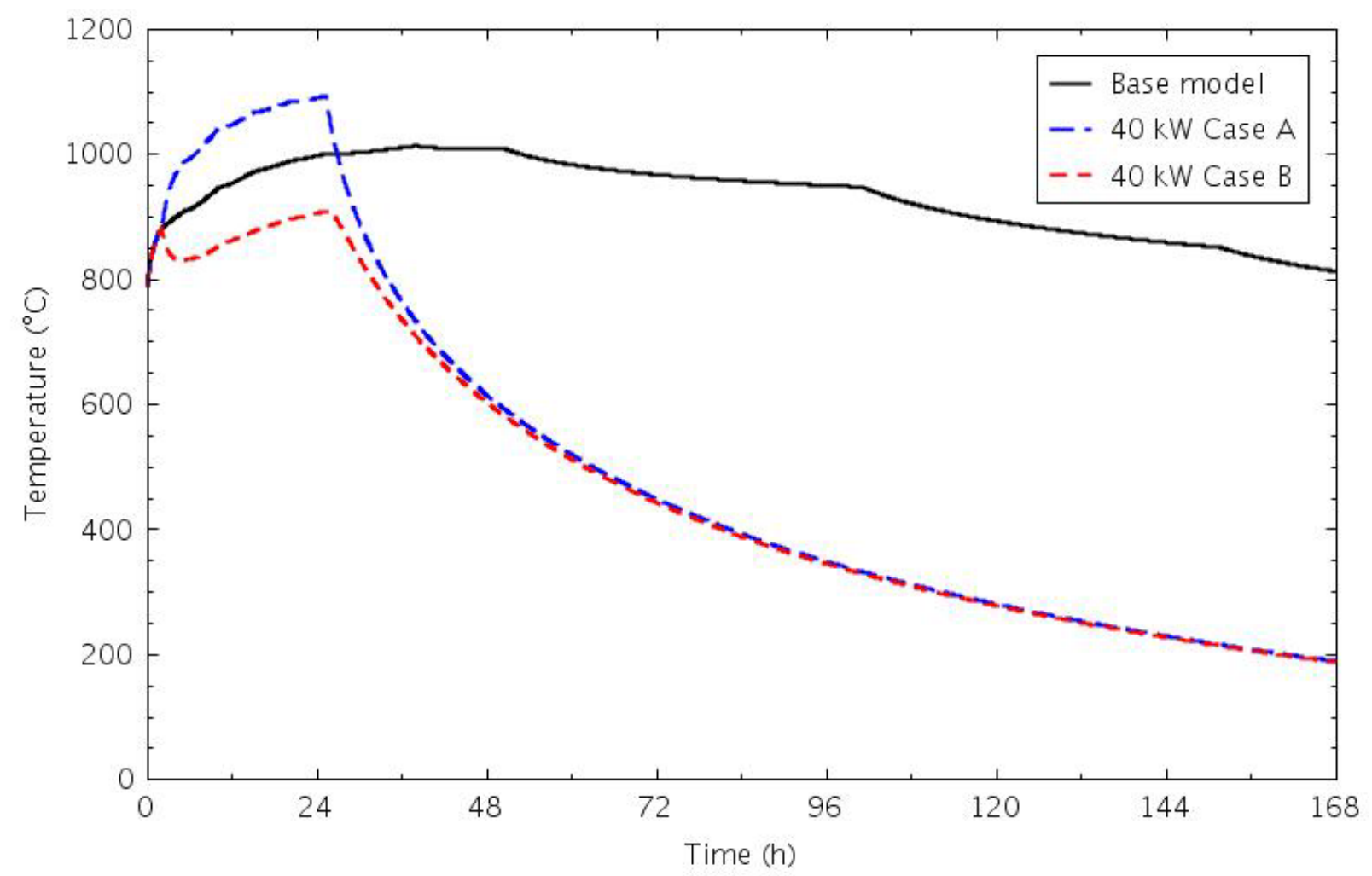

Figure 52. Peak inner core ring ceramic temperatures for the Test PG-26 pre-test calculation base case and 40-kW Cases A and B.

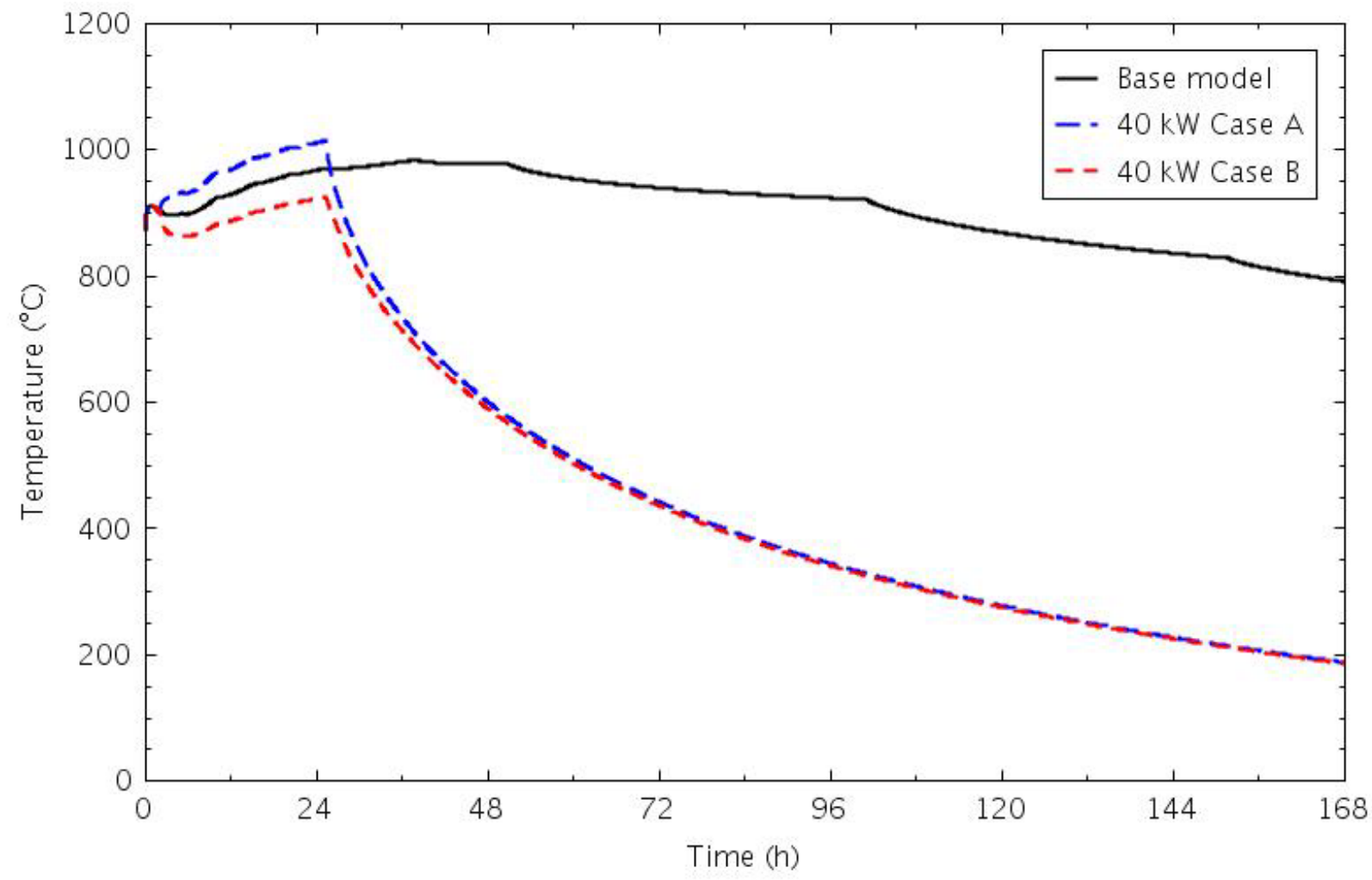

Figure 53. Peak middle core ring ceramic temperatures for the Test PG-26 pre-test calculation base case and 40-kW Cases A and B. 


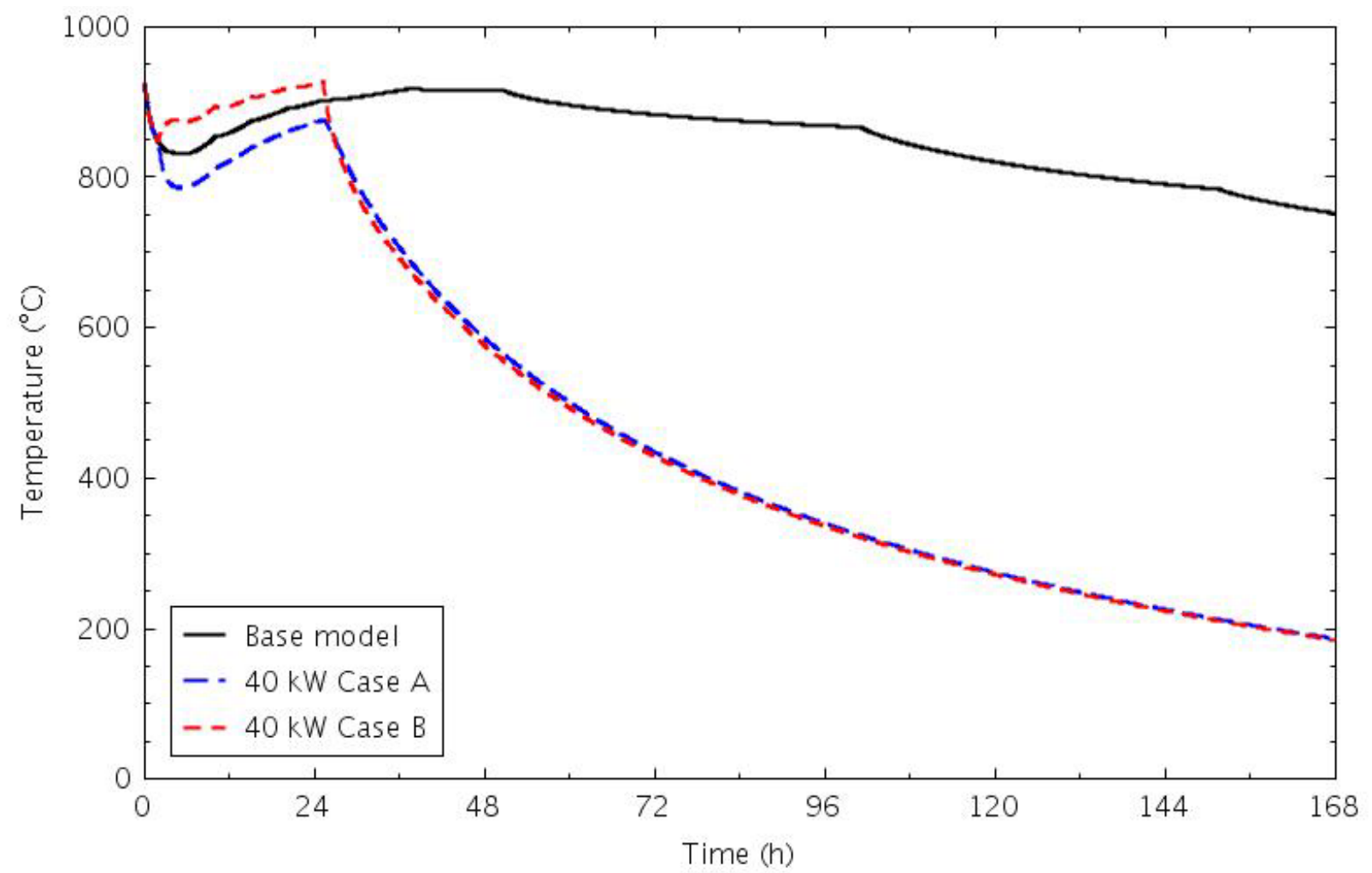

Figure 54. Peak outer core ring ceramic temperatures for the Test PG-26 pre-test calculation base case and 40-kW Cases A and B.

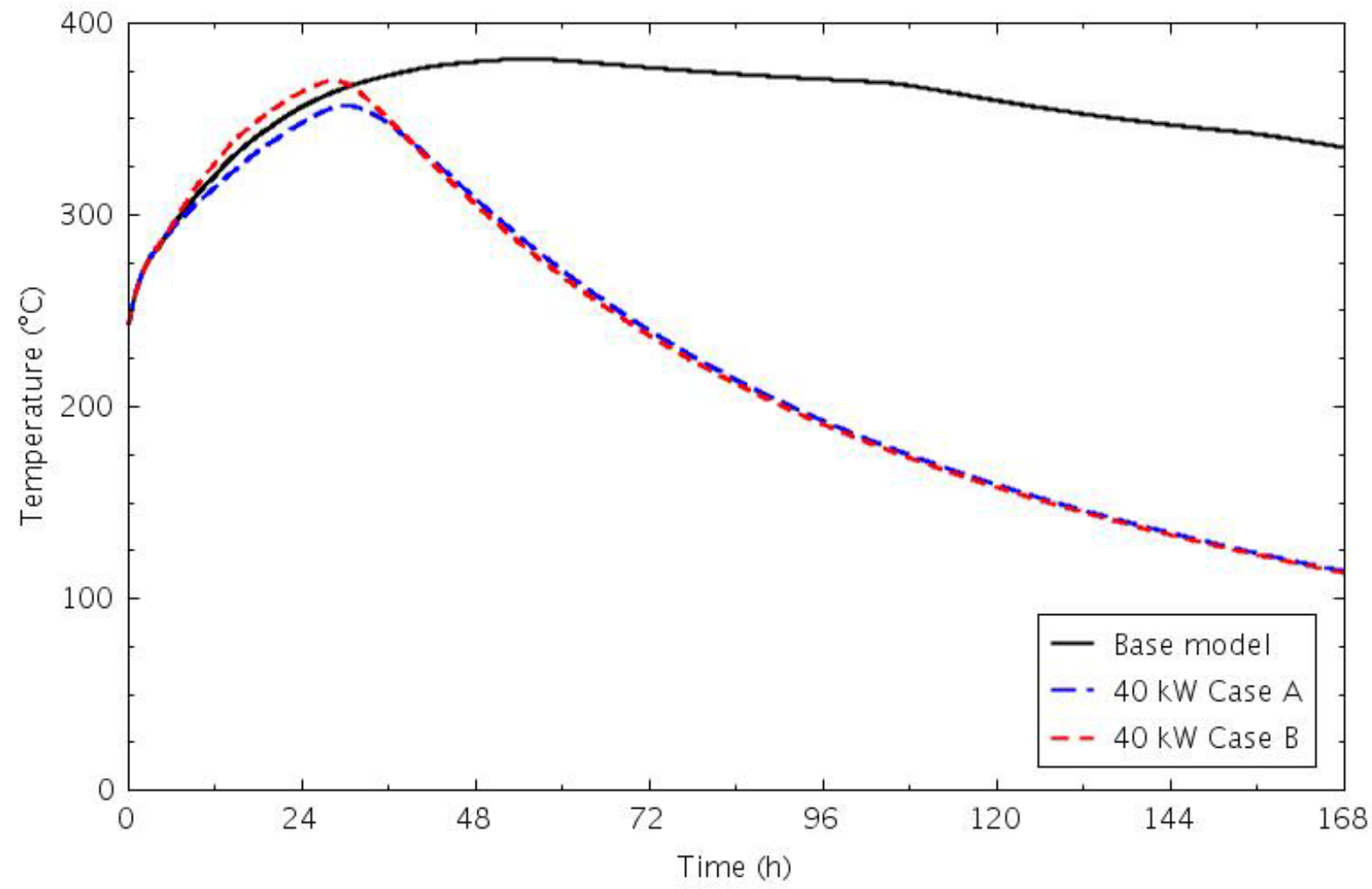

Figure 55. Peak primary pressure vessel wall temperatures for the Test PG-26 pre-test calculation base case and $40-\mathrm{kW}$ Cases A and B. 
Heat removal through the RCCS is compared to the core power in Figure 56. The peak heat removal in both sensitivity calculations occurred a few hours after the power was turned off, with the Case B peak about $1 \mathrm{~kW}$ higher than the Case A peak.

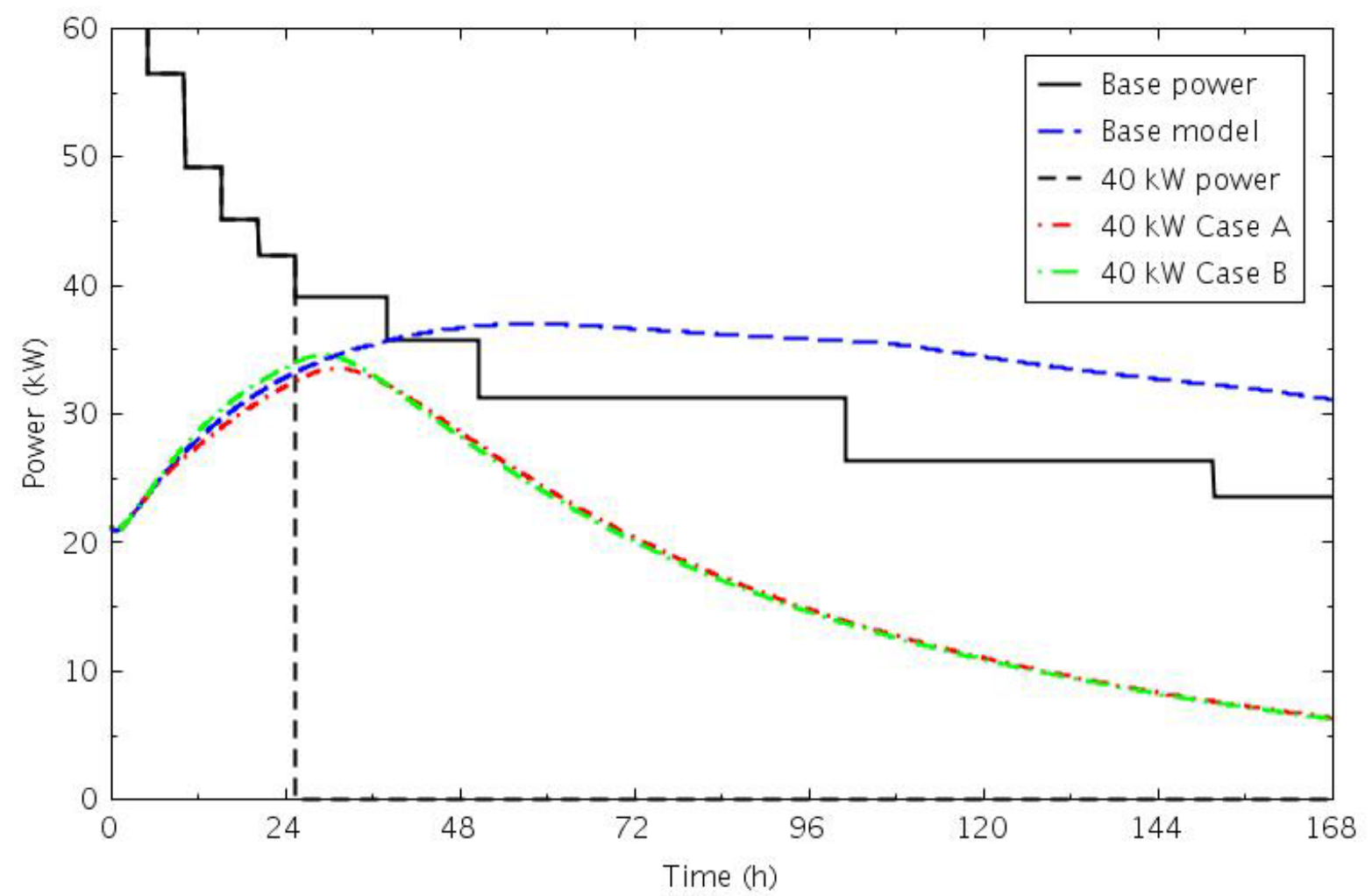

Figure 56. Core power and RCCS heat removal for the Test PG-26 pre-test calculation base case and 40-kW Cases A and B.

Coolant velocities at the top of the five core channels are presented in Figure 57 for Case A and Figure 58 for Case B. For Case A, with the power more concentrated toward the center of the core, the flow in the outer core ring reverted back to downward flow a little sooner than in the base case calculation (see Figure 9). When the core power was reduced to zero after 25 hours, the velocity in the central reflector increased for a few hours, while the velocities in the other four channels all decreased. In Case B, with most of the power in the outer core ring, only the side reflector was in downflow before the power was turned off, although the central reflector took longer to reverse than in the base case. Once the power was turned off, the outer core ring flow reversed, and the flow increased in the two innermost channels.

Another option for addressing the low heater power issue would be to turn off two of the heaters when the total decay power dropped below $80 \mathrm{~kW}$, but rather than transfer the residual power to the two remaining heaters, keep them running at the same power until the integrated decay power in the two cases would be the same. This would allow some power to be maintained longer into the transient, and would use the same approach that was used in developing the original decay power profile (Figure 3 ). For Case C, heaters 107 and 110 are left on, and for Case D, heaters 108 and 109 are left on; in both cases, the remaining heaters are turned off at 69.1 hours $(248,700 \mathrm{~s})$. This approach underpredicts the decay power from 2.02 to 25.25 hours, then overpredicts it until the heaters are turned off. 


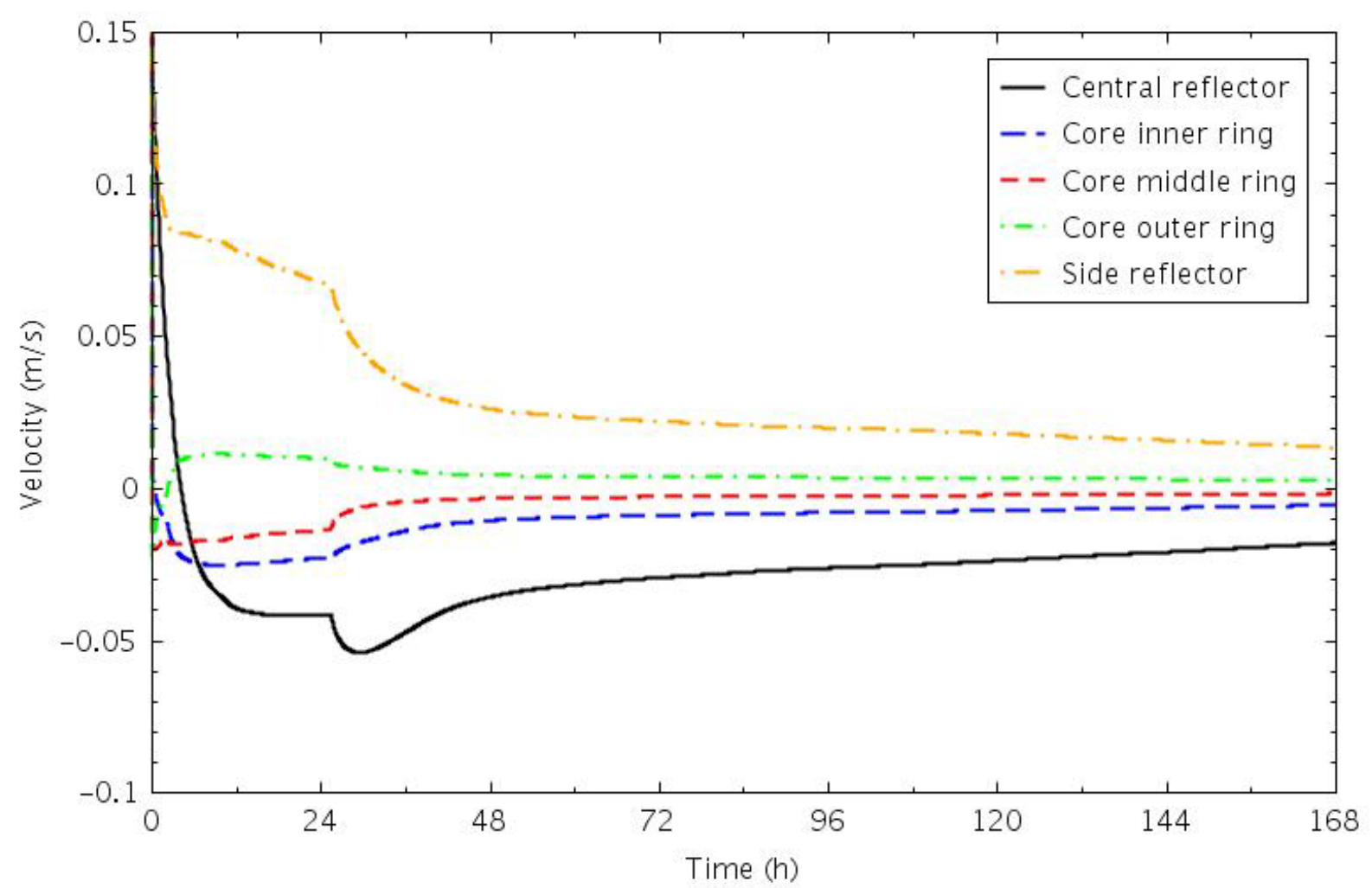

Figure 57. Coolant velocities at the top of the upper reflector for the Test PG-26 pre-test calculation base case and $40-\mathrm{kW}$ Case A.

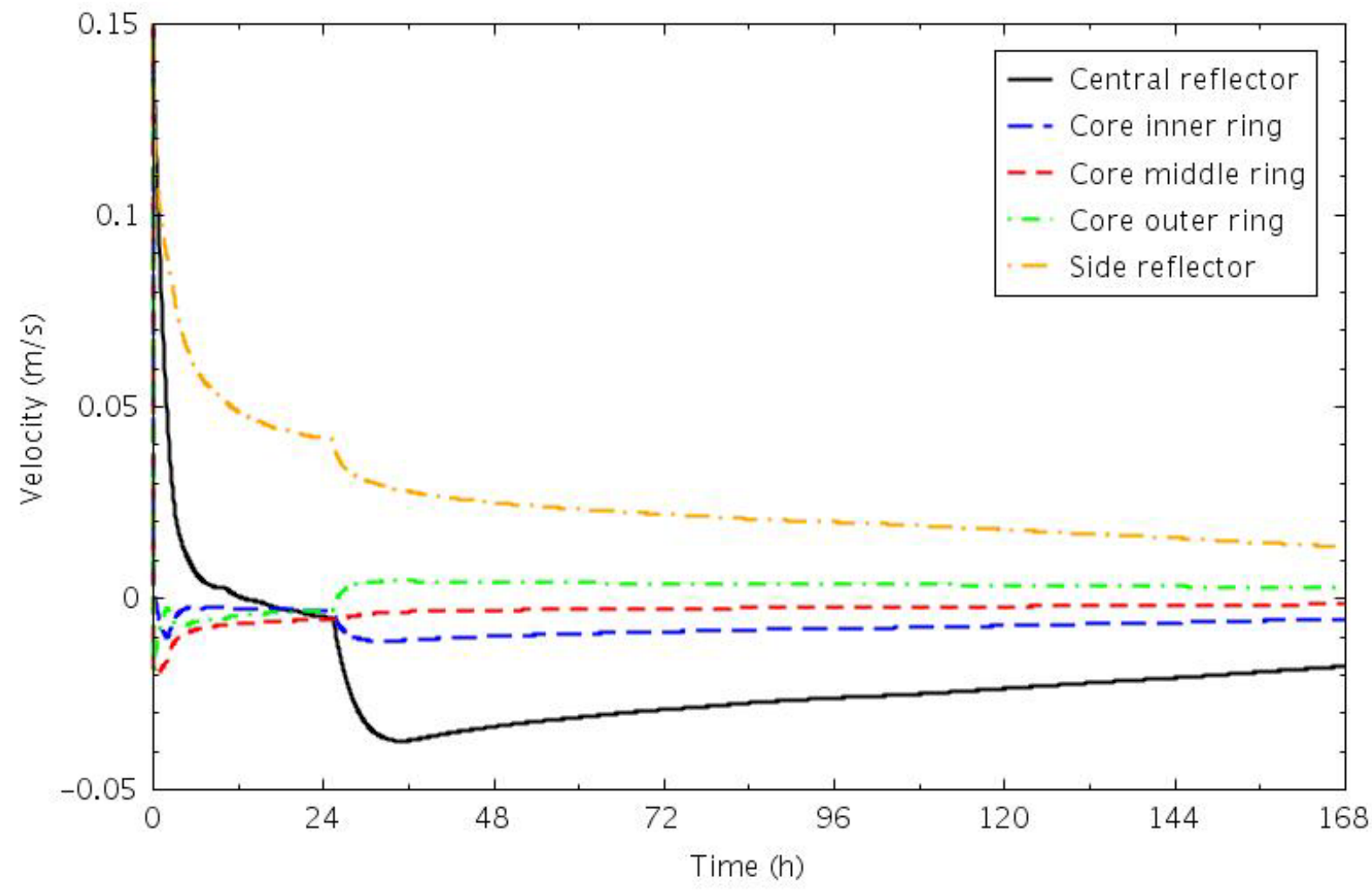

Figure 58. Coolant velocities at the top of the upper reflector for the Test PG-26 pre-test calculation base case and $40-\mathrm{kW}$ Case B. 
Figure 59 presents the peak heater rod temperatures for these two calculations and the base case. Both sensitivity calculations saw a drop in the peak temperature when the first two heaters were turned off, with Case $\mathrm{C}$ recovering more quickly because the power was more concentrated toward the inner part of the core, where the peak heater rod temperature was located before 2 hours; in Case D, the peak temperature dropped further as the location of the peak temperature shifted outward from the inner core ring. The peak temperatures at 69.1 hours were $1151^{\circ} \mathrm{C}$ in Case $\mathrm{C}$ and $982^{\circ} \mathrm{C}$ in Case $\mathrm{D}$, compared with the base case transient value of $1019^{\circ} \mathrm{C}$ and the steady-state value of $1065^{\circ} \mathrm{C}$. After the power was turned off at 69.1 hours, the temperatures decreased quickly.

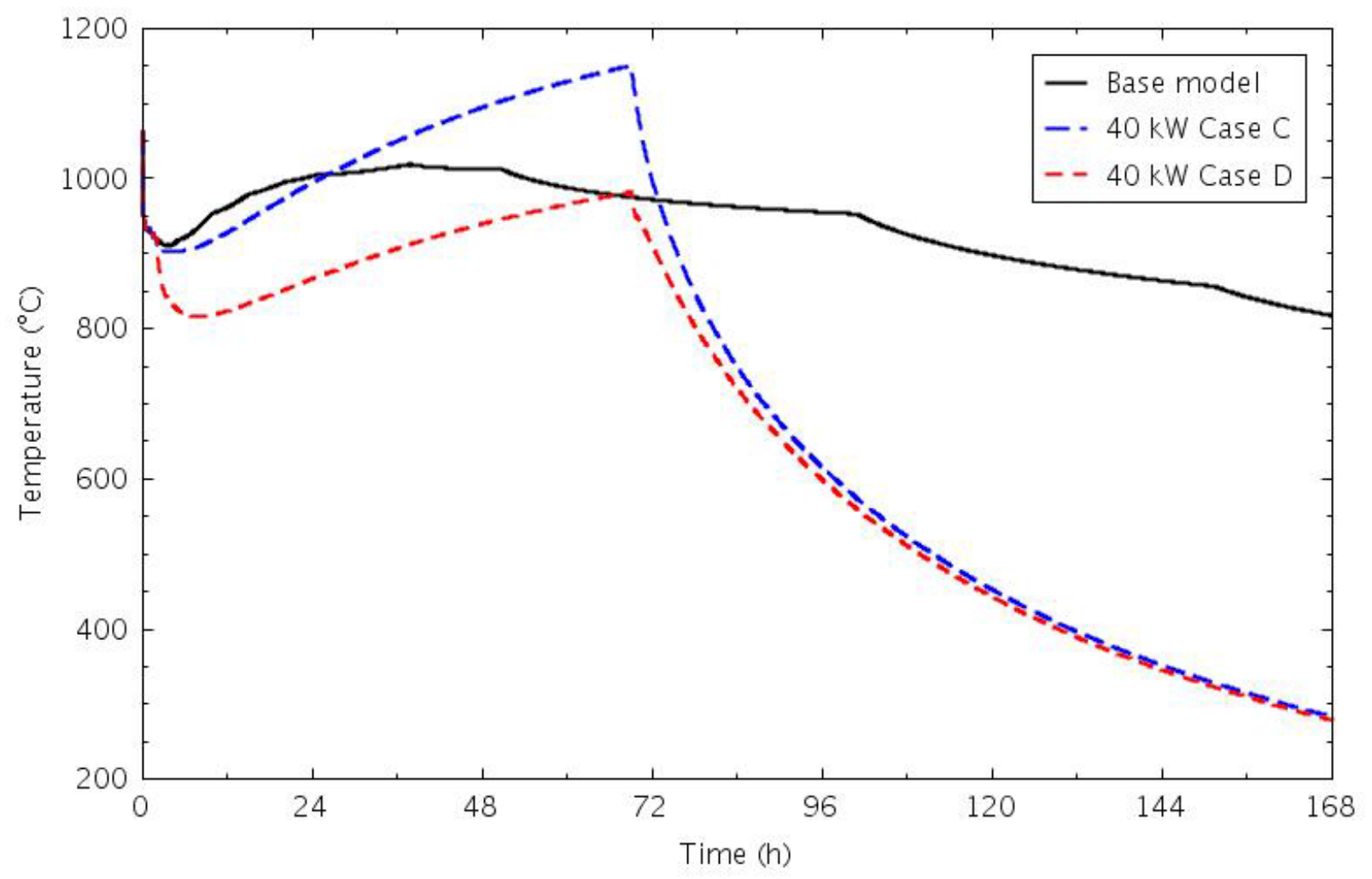

Figure 59. Peak heater rod temperatures for the Test PG-26 pre-test calculation base case and 40-kW Cases $\mathrm{C}$ and $\mathrm{D}$.

Peak ceramic temperatures in the inner core ring are shown in Figure 60. The Case D response was similar to that of the peak heater rod temperature, dropping significantly after 2 hours then reaching a peak value below that of the base case. In Case C, the heatup was only slowed for a few hours, eventually reaching a peak temperature of $1142^{\circ} \mathrm{C}, 128^{\circ} \mathrm{C}$ higher than that in the base case.

Figure 61 shows the peak ceramic temperatures in the middle core ring, where the temperature dropped in both cases at 2 hours before increasing again. Case $\mathrm{C}$ again had the higher peak temperature, $1065^{\circ} \mathrm{C}$, compared to $966^{\circ} \mathrm{C}$ in Case D and $984^{\circ} \mathrm{C}$ in the base case. Similar behavior is observed in the outer core ring, shown in Figure 62, except that Case D has the higher temperatures because most of the core power is being deposited in the outer ring. The Case $\mathrm{D}$ peak temperature was $966^{\circ} \mathrm{C}$, compared to $928^{\circ} \mathrm{C}$ in Case $\mathrm{C}$ and $918^{\circ} \mathrm{C}$ in the base case.

The peak pressure vessel wall temperatures are presented in Figure 63. With more power located in the core outer rings, Case $\mathrm{D}$ yielded a higher peak temperature, $391^{\circ} \mathrm{C}$ versus $382^{\circ} \mathrm{C}$ in Case $\mathrm{C}$; the peak value in the base case calculation was $381^{\circ} \mathrm{C}$. 


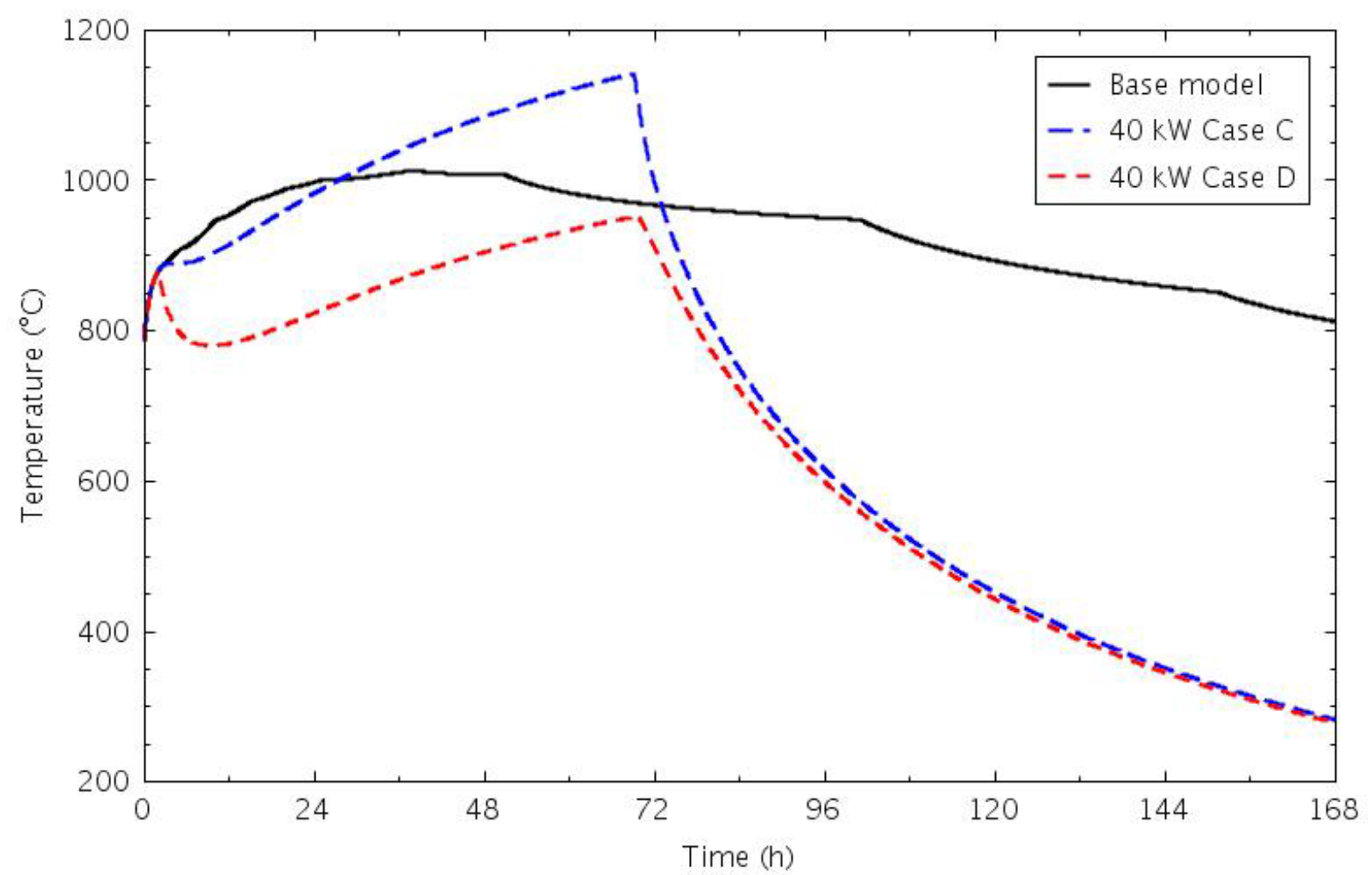

Figure 60. Peak inner core ring ceramic temperatures for the Test PG-26 pre-test calculation base case and 40-kW Cases C and D.

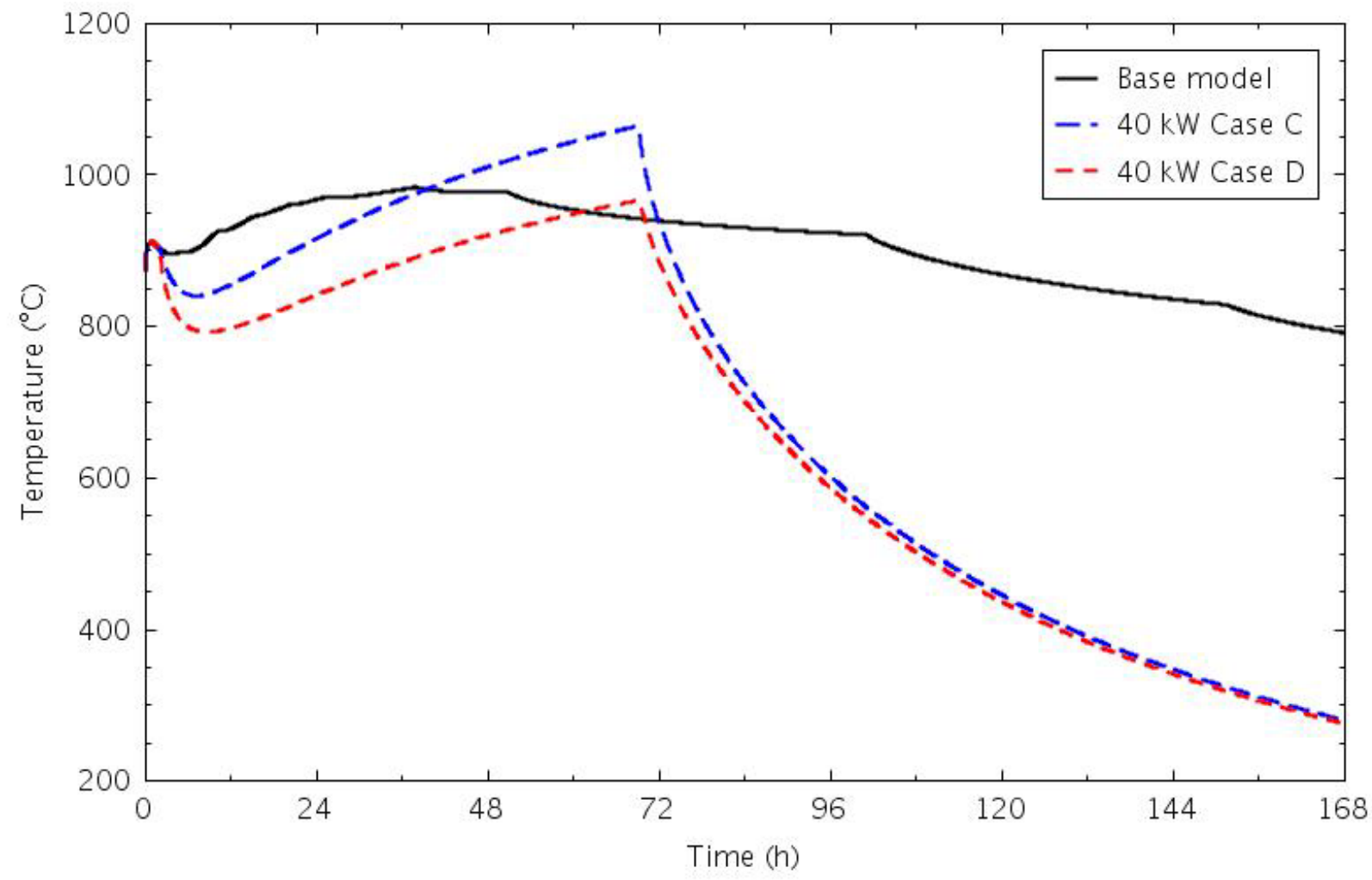

Figure 61. Peak middle core ring ceramic temperatures for the Test PG-26 pre-test calculation base case and 40-kW Cases C and D. 


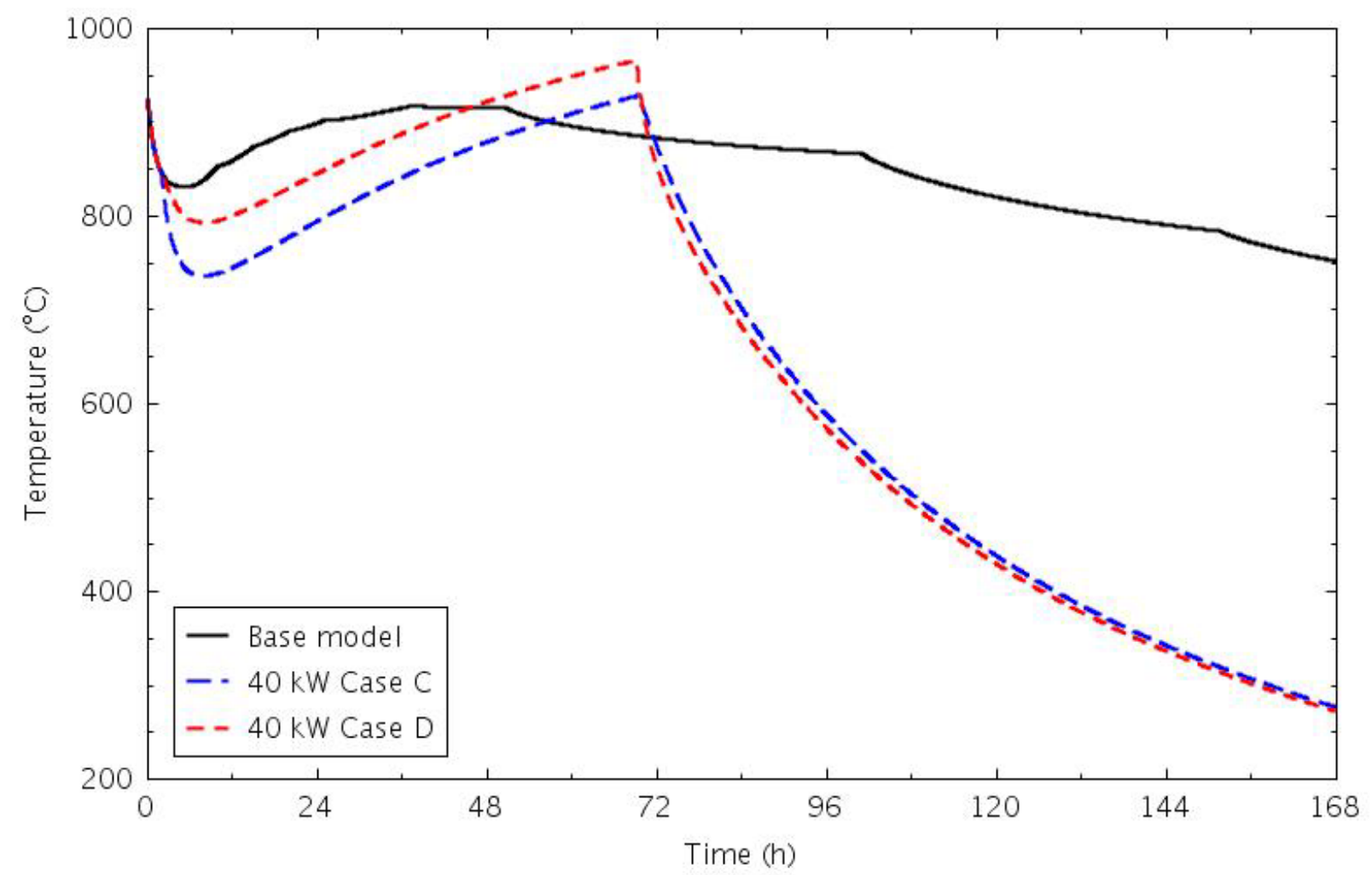

Figure 62. Peak outer core ring ceramic temperatures for the Test PG-26 pre-test calculation base case and 40-kW Cases C and D.

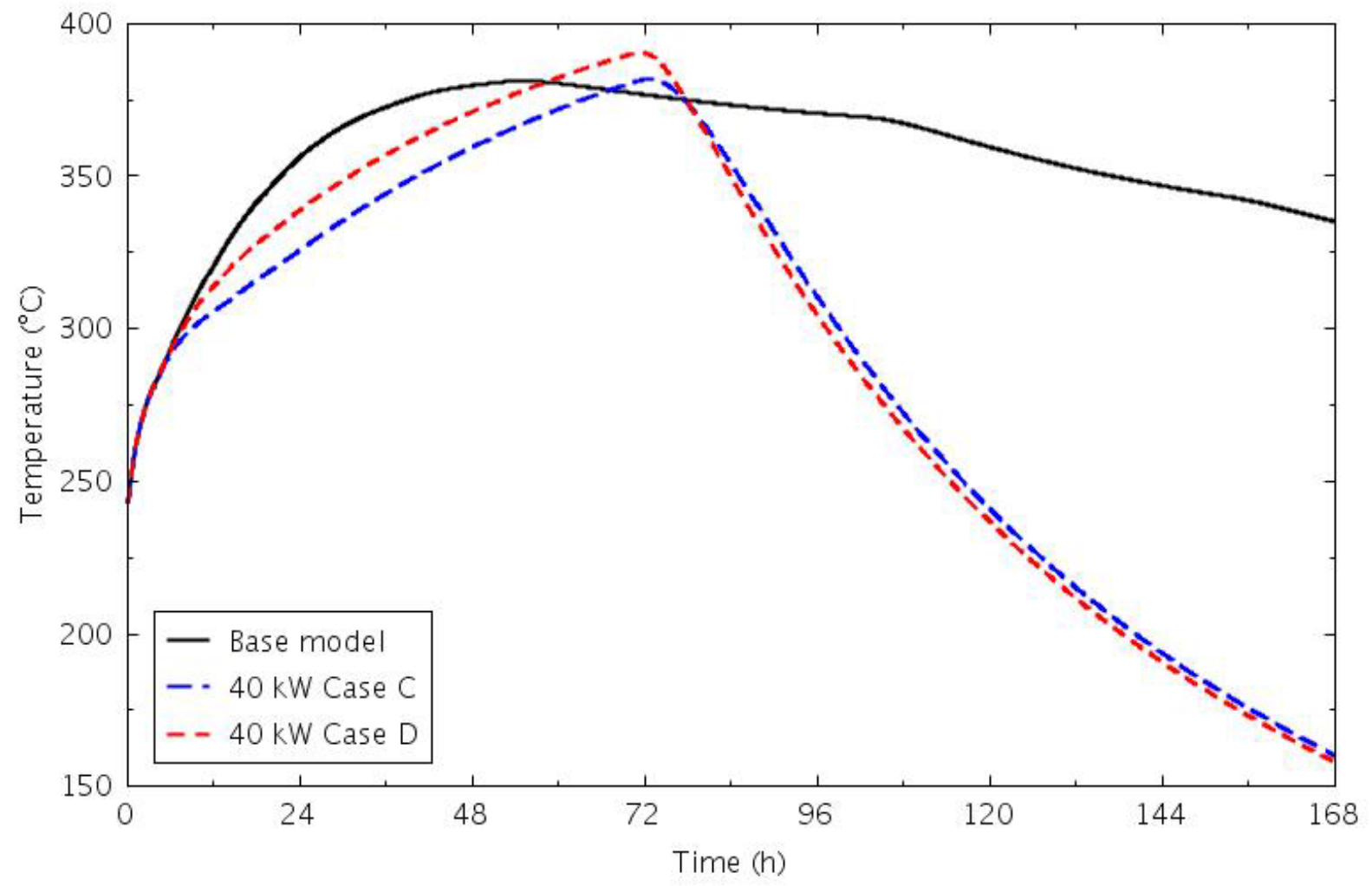

Figure 63. Peak primary pressure vessel wall temperatures for the Test PG-26 pre-test calculation base case and 40-kW Cases C and D. 
Heat removal by the RCCS is compared to the core power in Figure 64. The heat removal peaked about 3 hours after the power was turned off. The peak value in Case D was a little higher than that in Case A, reflecting the higher pressure vessel wall temperature.

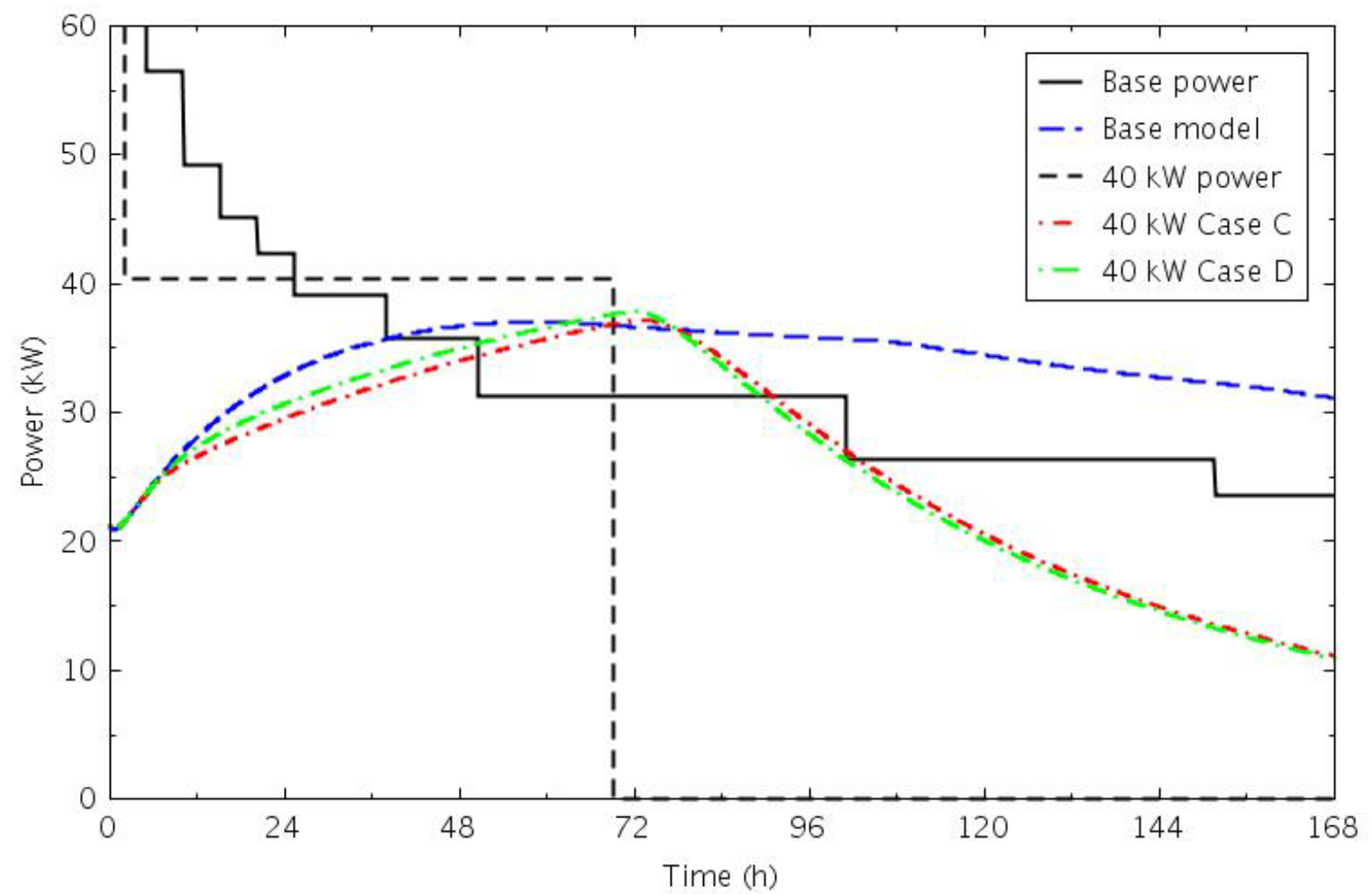

Figure 64. Core power and RCCS heat removal for the Test PG-26 pre-test calculation base case and 40-kW Cases C and D.

Coolant velocities at the top of the five flow channels in the core are shown in Figure 65 for Case C. A stable flow pattern was established in the first few hours of the transient, with flow up in the inner three channels and down in the outer two. Velocities were highest on the edges, and decreased moving away from the edges. When the power to the heater rods was turned off after 69 hours, the flows decreased in the four outer channels and increased in the central reflector, while maintaining the same flow directions. The spike in flows near 31 hours occurred when the check valve at the entrance to the steam generator briefly opened. Continued cooling by the water on the secondary side reduced the temperature and pressure of the helium in the tubes sufficiently that the check valve opened, inducing flow through the pressure vessel into the steam generator tubes.

Figure 66 shows the coolant velocities at the top of the five core flow channels for Case D. A stable flow pattern was again established in the first few hours, but only the outer reflector was flowing downward. The velocities in the other four channels were all about the same value. This continued until the heater power was turned off, after which the flow in the outer core ring reversed to downward, flow in the outer reflector and middle core ring decreased, and flow in the inner core ring and central reflector increased. There was also a noticeable separation in the channel velocities after 69 hours. 


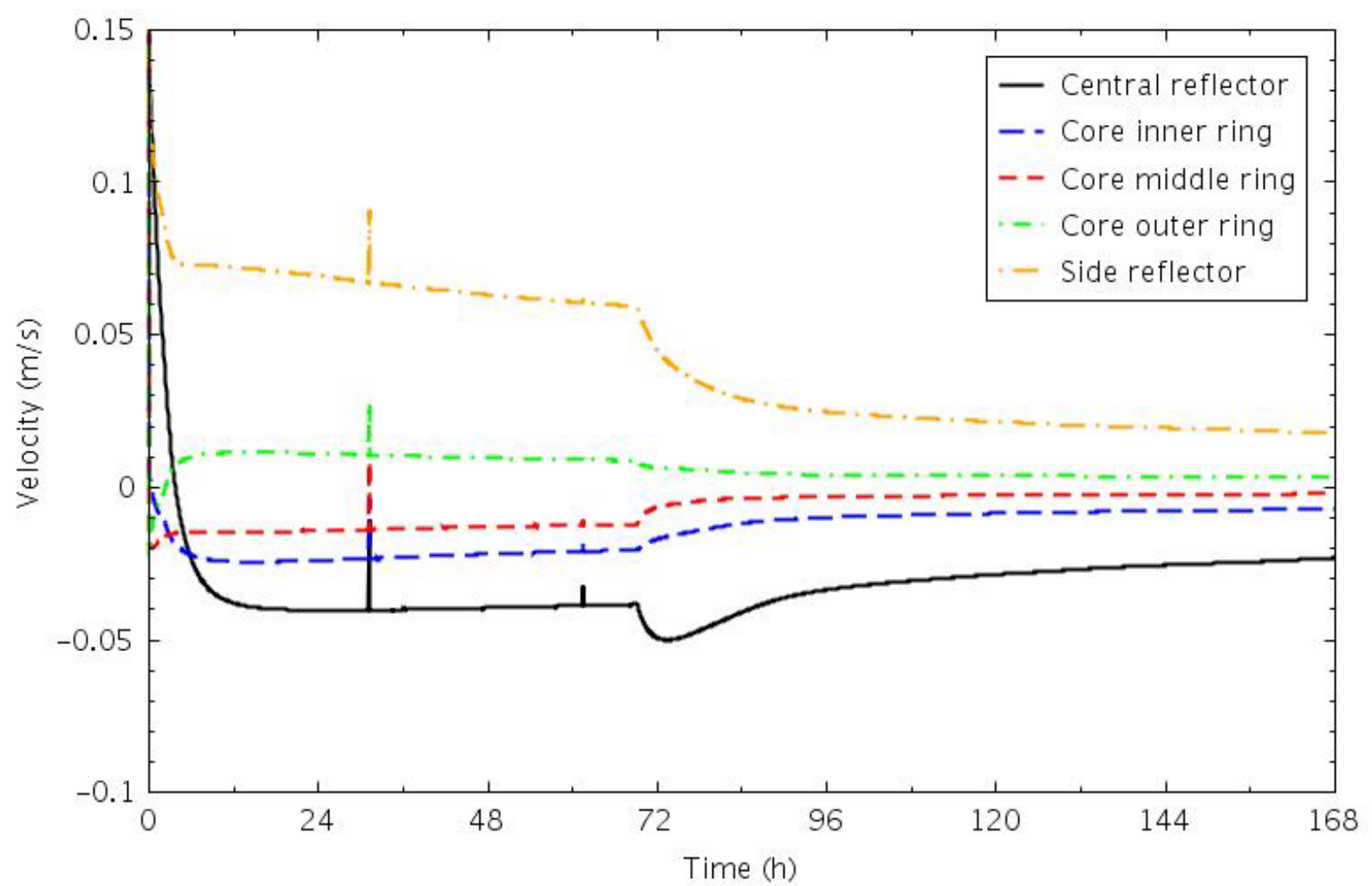

Figure 65. Coolant velocities at the top of the reflector for the Test PG-26 pre-test calculation 40-kW Case C.

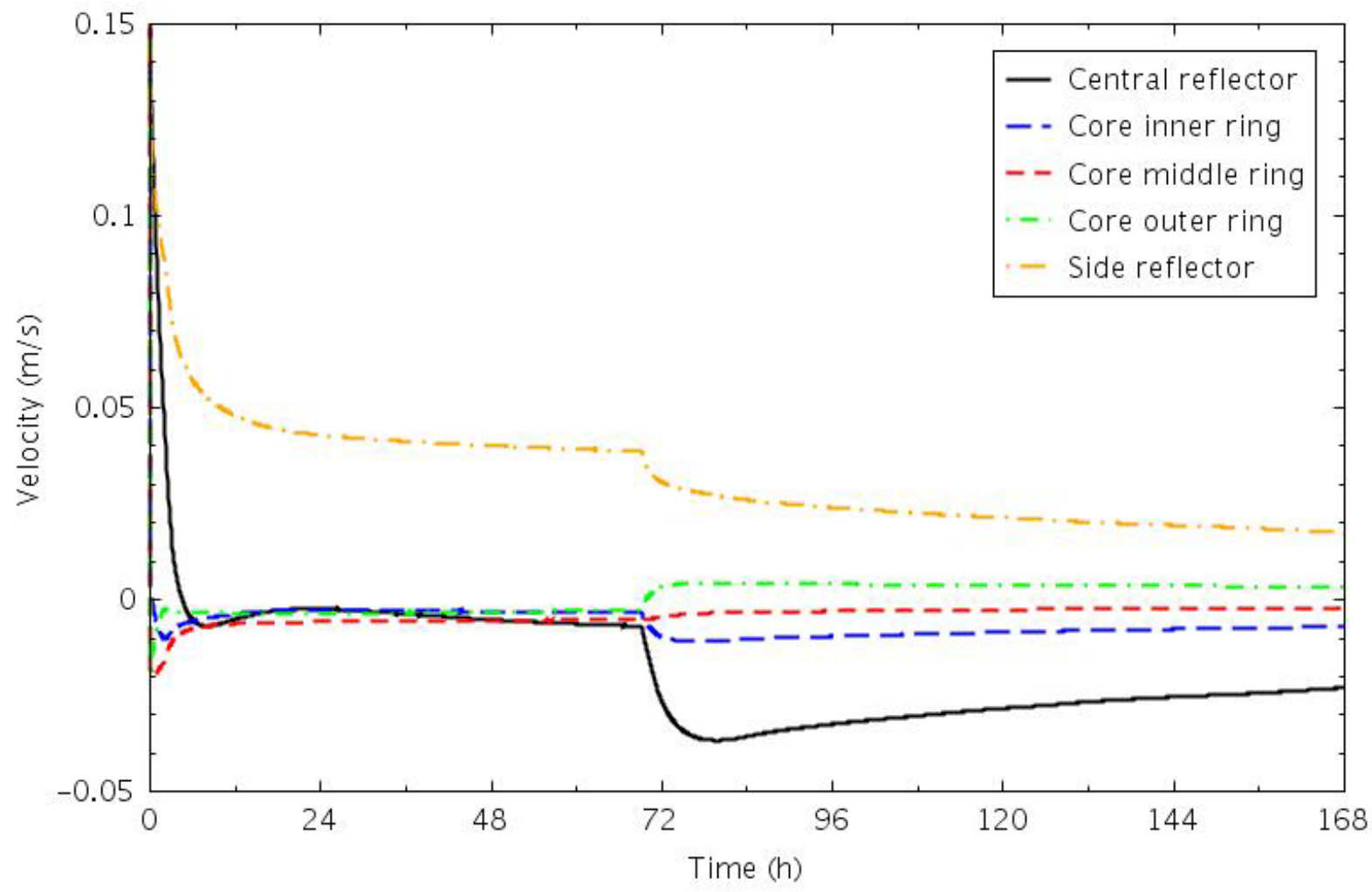

Figure 66. Coolant velocities at the top of the reflector for the Test PG-26 pre-test calculation 40-kW Case D. 


\section{Summary and Discussion}

RELAP5-3D simulations of Test PG-26 were performed. Test PG-26 is expected to be a PCC transient using four banks of heater rods $(107,108,109$, and 110). The steady-state power is $700 \mathrm{~kW}$ with nominal pressure vessel inlet and outlet coolant temperatures of 258.6 and $687.0^{\circ} \mathrm{C}$, respectively.

The transient was initiated by imposing a 60 -s forced flow coastdown in the PCS. Feedwater flow to the steam generator was maintained for $750 \mathrm{~s}$ to mostly cover the tubes and prevent code calculation failures in the boiler or downcomer region later in the transient. The steam generator was effectively isolated from the rest of the PCS by the closed check valve upstream, leaving the RCCS as the principal means of removing the stored energy and decay power from the core. The transient was simulated for 168 hours.

In the transient calculation using the base input model, there was effectively no flow in the PCS piping, and only a small recirculating flow within the core. The temperature profile in the core changed from bottom-peaked during steady state to middle-peaked. With effectively no convective heat transfer, heat from the core was removed radially via conduction and radiation. The highest temperatures occurred in the core inner ring. The peak heater rod temperature of $1019^{\circ} \mathrm{C}$ occurred at 37.8 hours in the inner core ring, and the peak ceramic temperature of $1014^{\circ} \mathrm{C}$ occurred at 37.9 hours, also in the inner core ring. These peaks occurred at the same time the RCCS heat removal exceeded the core decay power. The peak pressure vessel wall temperature of $381{ }^{\circ} \mathrm{C}$ occurred at 54.9 hours.

A sensitivity calculation was performed in which the length of the flow coastdown at the onset of the transient was reduced from $60 \mathrm{~s}$ to $10 \mathrm{~s}$. This had a minimal impact on the facility response, increasing the peak core temperatures by only $1^{\circ} \mathrm{C}$.

Reducing the RCCS flow by $80 \%$ had no effect on the peak core temperatures, but did increase the peak pressure vessel temperature by about $20^{\circ} \mathrm{C}$. Increasing the RCCS inlet temperature from $30^{\circ} \mathrm{C}$ to $60^{\circ} \mathrm{C}$ had a small effect on the peak core temperatures, raising them 10 to $20^{\circ} \mathrm{C}$, with the larger changes in the core outer ring; the peak pressure vessel temperature increased $12^{\circ} \mathrm{C}$ and occurred an hour later, compared to the base case calculation.

Turning off all of the heaters when the decay power dropped below $80 \mathrm{~kW}$ (at 2 hours) resulted in a continuous cooling of the facility, with no transient heatup of the core. This does not appear to be a viable alternative to addressing the issue of being able to maintain the heater powers in a range that is accurately controlled.

Two options for extending the power input down to $40 \mathrm{~kW}$ were modeled. In the first option, two heaters were shut off at 2 hours, and the power in the remaining pair of heaters was doubled, thus modeling the full decay power. When the decay power dropped below $40 \mathrm{~kW}$ shortly after 25 hours, these heaters were turned off. In the second option, when the first pair of heaters was turned off, the second pair was kept at the same power level, not being turned off until the integrated decay power was the same as in the first option; this extended the heater operation to 69 hours. For both options, cases were run turning off different pairs of heaters.

In the 40-kW cases, peak temperatures occurred just before the power was turned off. Keeping heaters 108 and 109 on resulted in higher temperatures from the outer core ring out to the pressure vessel wall, because most of the power was being deposited in the outer core ring, although they were not significantly higher than in the base case calculation; the peak pressure vessel wall temperature was $10^{\circ} \mathrm{C}$ higher. Keeping heaters 107 and 110 on resulted in higher peak temperatures in most of the core, because the power is concentrated in the middle of the core, with most of them above the base case values. The longer 69-hour case had the highest temperatures. The peak heater rod temperature was $1142^{\circ} \mathrm{C}, 128^{\circ} \mathrm{C}$ above the base case value, and the peak ceramic temperature was $1065^{\circ} \mathrm{C}, 81^{\circ} \mathrm{C}$ above the base case value. 
In all five decay power sensitivity calculations, the core temperatures decreased relatively quickly after the power was shut off.

Keeping all of the operating heaters on is preferable to turning one pair off because the heat is more evenly distributed in the core. However, turning one pair off may be the only option for providing a more representative transient response; it depends on how low the power to each heater can be reliably controlled.

These simulations were performed without the benefit of characterization data for the core temperature distribution. The input model needs these data to determine appropriate values to use for parameters such as material emissivities and the region of influence of the reflector cooling holes. The modeling approach used for the core blocks has not been used before with RELAP5-3D, so both steadystate and transient data are needed to determine its validity. Those data are also needed to determine if the model discretization adequately captures the important phenomena in the test facility, namely the peak ceramic and heater rod temperatures. One main concern is whether three rings of heater rods is sufficient, or are more needed to reasonably predict the peak temperatures. 


\section{References}

Bayless, Paul D., 2018, RELAP5-3D Input Model for the High Temperature Test Facility, INL/EXT-18-45579, Idaho National Laboratory, June 2018.

DOE, 1986, Preliminary Safety Information Document for the Standard MHTGR, Stone \& Webster Engineering Corp., report HTGR-86-024.

Gutowska, Izabela (izabela.gutowska@,oregonstate.edu), 2018, “HTTF figures,” Paul Bayless (paul.bayless@inl.gov), May 24, 2018.

INL, 2018, RELAP5-3D Code Manual, Volumes I-V, INL/MIS-15-36723, Idaho National Laboratory, Rev. 4.4, June 2018.

Woods, Brian, 2017, OSU High Temperature Test Facility Technical Design Report, OSU-HTTF-TECH-003-R1, Oregon State University, Rev. 1, February 2017.

Woods, Brian, 2018a, Instrumentation Plan for the OSU High Temperature Test Facility, OSU-HTTF-TECH-002-R3, Oregon State University, Rev. 3, March 2018.

Woods, Brian, 2018b, Scaled HTTF Decay Power, OSU-HTTF-CALC-001-R0, Oregon State University, June 2018. 